\title{
Synthesis, processing and material properties of conjugated polymers
}

\author{
W. J. Feast ${ }^{*}$ \\ Interdisciplinary Research Centre in Polymer Science and Technology, University of \\ Durham, Science Laboratories, South Road, Durham DH1 3LE, UK \\ and $\mathrm{J}$. Tsibouklis \\ Division of Chemistry, University of Portsmouth, St. Michael's Building, White Swan Road, \\ Portsmouth PO1 2DT, UK
}

and K. L. Pouwer, L. Groenendaal and E. W. Meijer*

Laboratory of Organic Chemistry, Eindhoven University of Technology, PO Box 513, $5600 \mathrm{MB}$ Eindhoven, The Netherlands

(Received 24 January 1996; revised 21 March 1996)

\begin{abstract}
Recent progress in the synthesis and characterization of well-defined conjugated polymers and oligomers is presented. The different synthetic schemes for most of the important conjugated polymers will be discussed using a subdivision into three main sections, covering hydrocarbon polymers, heterocyclic polymers and the oligomers, respectively. Although the materials properties will be referred to, the main emphasis of the review is directed to the different strategies that are now available to produce conjugated polymers and welldefined oligomers in a reproducible way and with full control over most of the important macromolecular properties. Copyright (C) 1996 Elsevier Science Ltd.
\end{abstract}

(Keywords: conjugated polymers; synthesis; processing; properties)

\section{INTRODUCTION}

The current interest in conjugated polymers is due to the substantial $\pi$-electron delocalization along their backbones which gives rise to interesting optical ${ }^{1}$ and nonlinear optical properties ${ }^{2-4}$ and allows them to become good electrical conductors typically when oxidized or reduced ${ }^{5,6}$. These properties may lead to a variety of practical applications such as information storage and optical signal processing, substitutes for batteries $^{7}$ and materials for solar energy conversion ${ }^{8}$. Furthermore, electroluminescence from conjugated polymers is a rapidly expanding field of interest since the reports of poly ( $p$-phenylene vinylene) based devices ${ }^{9,10}$. These possible applications are to some degree limited by the low stability towards atmospheric oxidation and the lack of processability often characterizing these materials. As a result, considerable research effort has been directed towards the preparation of well-defined conjugated polymers with improved processability and stability characteristics. The aim of this review is to discuss the recent progress in the synthesis and materials properties of polyconjugated polymers. The fundamental physics and applications of these materials in devices will be referred to, but for the detailed discussions of these matters the reader is referred to specialized reviews.

For the purpose of this review the field of conjugated polymer synthesis is divided into three main headings;

\footnotetext{
* To whom correspondence should be addressed
}

namely, hydrocarbon conjugated polymers, conjugated polymers with heteroatoms in the main chain and welldefined oligomers. Each main class is subdivided into different subheadings, referring to the major classes of conjugated polymers. Within the subheadings recent progress for a particular polymer is discussed from a synthetic point of view.

\section{HYDROCARBON POLYMERS}

\section{Polyacetylenes}

Polyacetylene (1, Figure 1$)$ is the simplest polyconjugated organic polymer The first reports on acetylene polymers date back to the last century. Cuprene, a highly crosslinked and extremely irregular product ${ }^{11}$ of acetylene polymerization in the presence of coppercontaining catalysts, being a typical example.

Polyacetylene was first prepared as a linear, high molecular weight, polyconjugated polymer of high crystallinity and regular structure in 1958 when Natta et al $^{12}$ polymerized acetylene in hexane using $\mathrm{Al}(\mathrm{Et})_{3} /$ $\mathrm{Ti}(\mathrm{OPr})_{4}$ as the initiator system. However, for a long time polyacetylene was considered of little interest because, irrespective of the method of preparation, it was obtained as an air sensitive, infusible and insoluble black powder.

A new phase in the study of polyacetylene began in the 1970 s when Shirakawa and co-workers ${ }^{13,14}$ developed a simple method for preparing film samples which on 


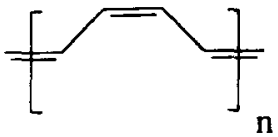

1

Figure 1 The structure of cis-polyacetylene

treatment with oxidizing agents, such as halogens or $\mathrm{AsF}_{5}$, exhibited significant electrical conductivity ${ }^{15,16}$. Today, Shirakawa's method represents the most widely employed procedure for the polymerization of acetylene although a synthetic route first described by Luttinger $^{17,18}$ in 1960 was rediscovered in the $1980 \mathrm{~s}$ and appears to be becoming increasingly popular. In 1980, Edwards and Feast ${ }^{19}$ employed an entirely different approach to the synthesis of polyacetylene by preparing a soluble, relatively stable and well characterized precursor polymer which could be converted to polyacetylene where and when required. These methods will be discussed in detail in the sections below.

Shirakawa route. Shirakawa's route to polyacetylene is an extension of the work first described by Natta et al. ${ }^{12}$. The polymerization reaction is carried out at the surface of a solution of the initiator system in an inert solvent. The initiator concentration used is significantly higher than that used in Natta's solution phase work (Scheme 1).

The standard procedure employed for the preparation of good quality polyacetylene films is as follows ${ }^{14,20,21}$ : a small amount of toluene is placed in a glass reactor and under an inert atmosphere, first titanium tetra- $n$ butoxide and then triethylaluminium are added. The concentration of titanium is approximately $0.4 \mathrm{moll}^{-1}$ and the ratio $\mathrm{Al} / \mathrm{Ti}$ is maintained within the range 3.5-4. The solution is allowed to stand at $20^{\circ} \mathrm{C}$ for $45 \mathrm{~min}$, then cooled to $-78^{\circ} \mathrm{C}$ and placed under vacuum. The internal surface of the reactor is then wetted with the initiator solution so that the walls are covered with a thin layer of the liquid and pure gaseous acetylene (pressure $<610$ $\mathrm{mmHg}$ ) is introduced. A film of polyacetylene immediately starts to form on the surface wetted by the initiator solution. The process can be interrupted by applying a vacuum. The polymer is purified by repeated washing with toluene or hexane, is dried in a stream of inert gas and kept under vacuum or in an inert atmosphere. Films ranging in thickness from $10^{-5} \mathrm{~cm}$ to $0.5 \mathrm{~cm}$ can be prepared by adjusting the time during which the surface is exposed to acetylene and the gas pressure.

The conditions under which the polymerization reaction is carried out have a profound effect on the properties and morphology of the film produced. Thus Abadie et $a l^{22}$ have shown that the conductivity of iodine doped films is substantially increased if the catalyst solution is allowed to stand for $120 \mathrm{~min}$ at temperatures higher than $20^{\circ} \mathrm{C}$ prior to the introduction of the gaseous acetylene. Similarly the morphology of the product can be controlled to give a powder, a gel-like spongy mass or a film by appropriately increasing the concentration of the initiator solution or the ratio of $\mathrm{Al}$ to $\mathrm{Ti}$ in the system ${ }^{20,23-25}$.

The synthetic procedure described above yields polyacetylene which is mainly cis. Baker et al. ${ }^{26}$ prepared almost pure trans polymer by reducing the $\mathrm{Al} / \mathrm{Ti}$ ratio to unity and omitting the catalyst aging step. In another modification of the Shirakawa method, Naarmann and co-workers $^{27}$ used silicone oil instead of toluene and prepared a polyacetylene sample which contained an approximately equal proportion of cis and trans vinylenes and a much lower concentration of $s p^{3}$-hybridized carbon atoms than is normally present in these films. A year earlier, the same group developed the, so called, adding reducing agent method ${ }^{28}$. This method involves the introduction of a reducing agent (such as $n$-butyl lithium) to the catalyst solution prior to the polymerization reaction. The polyacetylene samples thus produced are stretchable and on iodine doping conductivities of the order of $10^{5} \mathrm{~S} \mathrm{~cm}^{-1}$ have been claimed. $\mathrm{A}$ further improvement in the observed conductivity was achieved by Tsukamoto ${ }^{29,30}$. In this procedure, a solvent with high boiling point, such as decalin, is used and the catalyst is heat treated at around $200^{\circ} \mathrm{C}$. The polyacetylene obtained by this procedure can be stretched by a factor of eight and yields a reported conductivity value of more than $10^{5} \mathrm{~S} \mathrm{~cm}^{-1}$ after iodine doping.

Luttinger route. In 1980 Enkelmann et al ${ }^{31}$ noted that powdered polyacetylene specimens prepared by traditional methods possessed properties which were essentially the same as those of the material produced by Shirakawa's method. Such powders could be suspended in an inert solvent and application of the suspension to a suitable substrate followed by evaporation of the solvent gave thin films of polyacetylene. They also showed that solid specimens of almost any desired size could be prepared by moulding polyacetylene powders. Later, Enkelmann et al ${ }^{32}$ discovered that the best results are obtained using $\mathrm{Co}\left(\mathrm{NO}_{3}\right)_{2} / \mathrm{NaBH}_{4}$ as the initiator system, systems of this type containing salts and complexes of group VIII metals together with a hydride reductant were first used by Luttinger ${ }^{17}$ twenty years earlier. In a typical experimental procedure ethanol is saturated with gaseous acetylene, and sodium borohydride followed by cobalt nitrate are added. After several hours at room temperature black flakes of polyacetylene precipitate. By lowering the reaction temperature to $-30^{\circ} \mathrm{C}$ the formation of a predominantly cis structure is favoured (Scheme 2) ${ }^{32}$.

The main advantage of Luttinger's catalyst over that developed by Shirakawa is that it allows the polymerization reaction to be carried out even in the presence of water and oxygen. Frohner and Wuckel ${ }^{33}$ studied the kinetics of the reaction and found that the initial polymerization rate is high and that the polyacetylene yield is proportional to the concentration of the cobalt species. Furthermore, the same workers observed that

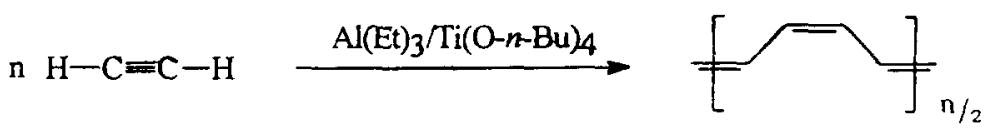

Scheme 1 Shirakawa's route to polyacetylene ${ }^{1.3}$ 


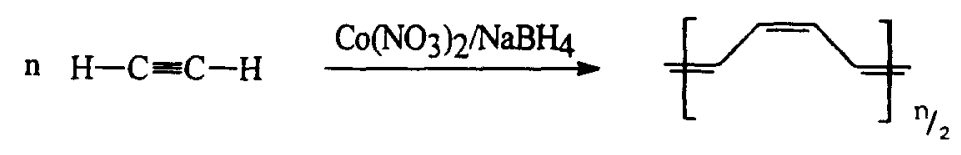

Scheme 2 Luttinger's route to polyacetylene as developed by Enkelmann et al. ${ }^{31}$

decreasing the reaction temperature results in an increase in polymer yield and crystallinity.

Precursor-polymer route. The inherent insolubility and infusibility of polyacetylene coupled with its sensitivity to air imposes a barrier to the processability of the polymer. As a result considerable research efforts have been directed towards obtaining polyacetylene from workable, easily processable polymers by means of polymer analogous transformations. In particular, the synthesis of polyacetylene from the dehydrohalogenation of poly(vinyl chloride) ${ }^{34}$ has attracted a lot of attention but the polymers prepared by this route generally possess relatively short conjugated segments and contain structural defects and cross-links. Nevertheless, materials produced in this way may be of practical use for EMR screening purposes ${ }^{35}$.

Another approach involves the use of prepolymers which can be thermally converted to polyacetylene. This approach was first described by Edwards and Feast ${ }^{19}$ (Scheme 3) and has been further refined by Feast and co-workers ${ }^{36-40}$.

The initial monomer, 7,8-bis(trifluoromethyl)tricyclo$\left[4.2 \cdot 2 \cdot 0^{2.5}\right]$ deca-3,7,9-triene is readily prepared by the thermal cycloaddition reaction between hexafluorobut2-yne and cyclooctatetraene. The polymerization reaction is carried out in the presence of ring opening metathesis polymerization initiators, such as $\mathrm{WCl}_{6} / \mathrm{SnMe}_{4}$, which act only on the strained four-membered ring to form a high molecular weight precursor polymer which is soluble in common organic solvents and can be purified, characterized and processed by conventional methods. On heating, the prepolymer can be easily and conveniently converted to polyacetylene with the evolution of 1,2-bis(trifluoromethyl)benzene. The conversion of the precursor polymer to polyacetylene is a complex process involving an exothermic symmetry allowed elimination with the formation of a new cis double bond and hexafluoro orthoxylene, the cis double bond isomerizes to trans and the xylene migrates through the film and evaporates giving a large loss in mass and contraction in volume. By controlling the conversion reaction protocol (temperature, time, pressure, mechanical stress and presence of solvent) the morphology of the final product can be regulated, expanded amorphous foams through to fully dense oriented films are accessible.
The prepolymer shown in Scheme 3 decomposes spontaneously to the polyacetylene if stored at room temperature (half life: $c a .20 \mathrm{~h}$ ). In order to produce a precursor polymer which was stable at room temperature a large number of prepolymers were examined but the majority of these possessed either insufficient or excessive thermal stability ${ }^{37}$. The synthesis of a precursor polymer with good room temperature stability 40 was achieved by the isomerization of the original monomer, 7,8-bis(trifluoromethyl)tricyclo[4.2.2.0 $\left.0^{2.5}\right]$ deca-3,7,9-triene, to 7,8 bis(trifluoromethyl)-pentacyclo[6.2.0.0 $\left.0^{2.4} \cdot 0^{3.6} .0^{5.7}\right] \mathrm{deca}-9$ ene by ultraviolet irradiation in dilute pentene solution. The polymerization of this quadricyclane analogue (Scheme 4) gives a room temperature stable precursor polymer; however, the exothermicity of the conversion reaction presents a hazard and the polyacetylene obtained contains residual trifluoromethyl groups.

Schrock and co-workers ${ }^{41}$ have developed a series of well defined ROMP initiators of the type $\mathrm{M}(\mathrm{CH}-t-\mathrm{Bu})$ $(\mathrm{NAr})(\mathrm{O}-t-\mathrm{Bu})_{2}$ in which $\mathrm{M}=\mathrm{W}$ or $\mathrm{Mo}$ and $\mathrm{Ar}=2,6-$ $\mathrm{C}_{6} \mathrm{H}_{3}-i-\mathrm{Pr}_{2}$ which allows better control over this polymerization reaction. Using these systems polyacetylene prepolymers of controlled molecular weight and polydispersities close to unity can be prepared. Furthermore, the use of these systems allows the controlled introduction of end-groups to the polymer chain ${ }^{42}$.

The main difference between the polyacetylene products obtained by the Shirakawa and precursor polymer routes lies in their morphology and relative order. Generally Shirakawa's polymer is obtained in a fibrillar morphology with low bulk density and variable crystallinity whereas the precursor polymer route gives access to materials of more controlled morphology. Thus, continuous solid films with densities in the range $1.05-1.1 \mathrm{~g}$ $\mathrm{cm}^{-3}$ may be routinely obtained, which can be essentially amorphous, semicrystalline or highly crystalline and may be oriented by stretching during or prior to conversion.

More recently Swager et al. ${ }^{43}$ demonstrated an alternative precursor route to polyacetylene in which the production of volatile by-products is avoided. The method involves the ring opening polymerization of benzvalene and the subsequent catalytic isomerisation to polyacetylene of low crystallinity (Scheme 5).

Soluble polyacetylenes. Irrespective of the method adopted for its synthesis polyacetylene itself is an insolu-

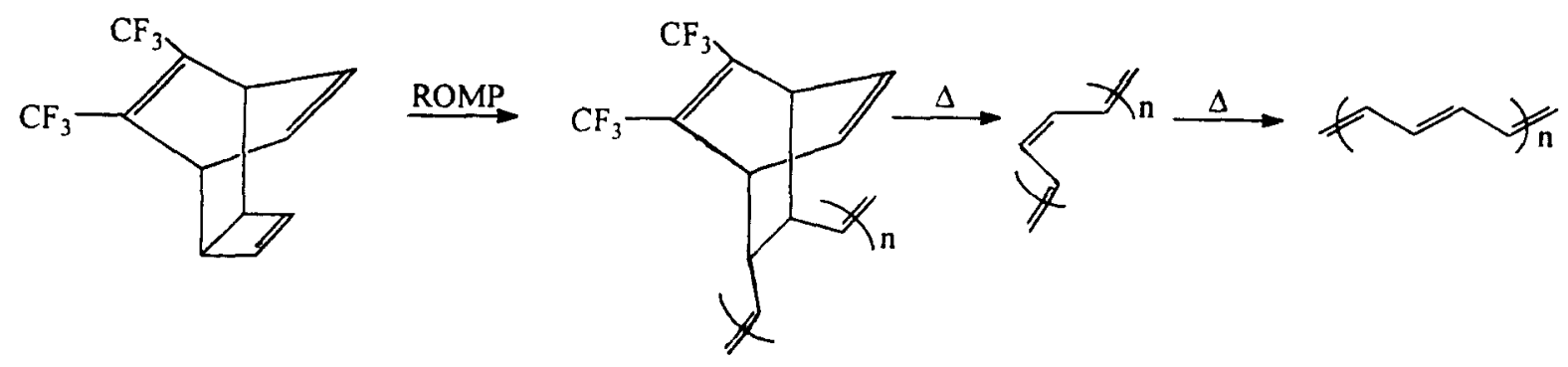

Scheme 3 The Durham precursor route to polyacetylene ${ }^{19}$ 

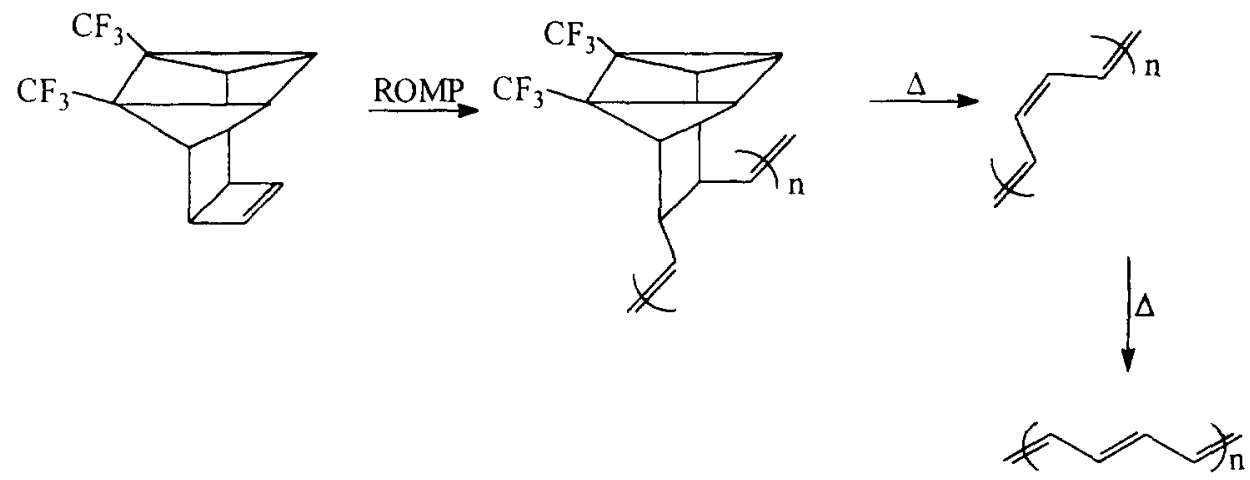

Scheme 4 Durham precursor route using a quadricyclane analogue as monomer ${ }^{40}$

n<smiles>C1=CC2CC1C1CC21</smiles>

Schrock catalyst

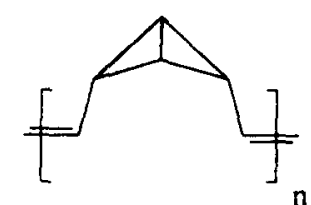

$\stackrel{\mathrm{HgCl}_{2}}{\longrightarrow}$

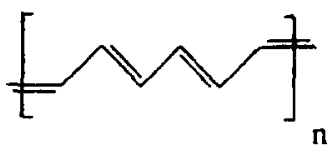

Scheme 5 Swager's polyacetylene route starting from benzvalene ${ }^{43}$

ble, infusible and generally intractable material. In order to obtain soluble polyacetylene analogues monosubstituted acetylenes ${ }^{44-46}$ have been polymerized to yield polymers with side groups attached to every second carbon atom. In most cases these materials are soluble, but the optical absorption maximum of the resulting polymer is higher in energy than that observed for polyacetylene indicating a lower effective conjugation length. The electrical conductivity of all substituted polyacetylene analogues reported to date is significantly lower than that of polyacetylene itself ${ }^{47}$. The reduction in conjugation length is attributed to steric repulsions between adjacent side groups which causes the polymer chains to twist. This loss in planarity is readily understood since the rotation barrier about the single bonds in polyacetylene has been calculated ${ }^{48}$ to be about $6 \mathrm{kcal} \mathrm{mol}^{-1}$. Recently, Grubbs and co-workers ${ }^{49}$ demonstrated that the ring opening metathesis polymerization of monosubstituted cyclooctatetraene derivatives leads to partially substituted polyacetylenes that are both soluble and highly conjugated (Scheme 6).

\section{Polydiacetylenes}

Polydiacetylenes are synthesized by the topochemical polymerization of diacetylenes ${ }^{50-73}$. Most work has focused on the polymerization of crystalline diacetylenes, while some investigations report polymerization in the liquid-crystalline state and as Langmuir-Blodgett multi- layers. Before the different processes are discussed, a short review of monomer syntheses is given.

Synthesis of diacetylenes. Symmetrically disubstituted diacetylenes are usually obtained via Glaser ${ }^{74}$ coupling of terminal acetylenes. The reaction is carried out in the presence of a cuprous salt with air as oxidant. An alternative synthesis, the reaction of the terminal acetylene with cupric acetate in pyridine, was proposed in 1956 by Eglington and Galbraith ${ }^{75}$.

In 1957 Cadiot and Chodkiewicz reported ${ }^{76}$ coupling of a haloacetylene, usually obtained by reaction of the terminal acetylene with sodium hypobromite although alternative methods are also available ${ }^{80-82}$, with a terminal acetylene in the presence of cuprous salts (Scheme 7). This method is the most satisfactory procedure for the synthesis of unsymmetrically disubstituted diacetylenes.

Alternative approaches for the synthesis of diacetylenes include the iodine and cupric salt oxidation of Grignard acetylides ${ }^{77}$, the condensation of acetylenic Grignard reagents with 1 -bromoacetylenes ${ }^{78}$ and the permanganate oxidation of sodium acetylides ${ }^{79}$. However, these methods are of limited use.

Solid state polymerization. The solid state polymerization of diacetylenes (thermally or by irradiation) can yield nearly perfect polymeric single crystals of large

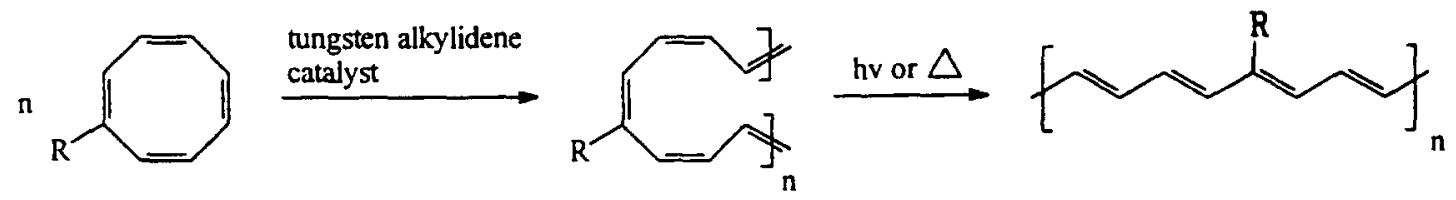

Scheme 6 Grubbs' soluble polyacetylene from monosubstituted cyclooctatetraene ${ }^{49}$

$$
\mathrm{R}^{\mathrm{l}}-\mathrm{C} \equiv \mathrm{C}-\mathrm{H}+\mathrm{X}-\mathrm{C} \equiv \mathrm{C}-\mathrm{R}^{2} \stackrel{\mathrm{CuCl}}{\longrightarrow} \mathrm{R}^{1}-\mathrm{C} \equiv \mathrm{C}-\mathrm{C} \equiv \mathrm{C}-\mathrm{R}^{2}
$$

Scheme 7 Route to unsymmetrically disubstituted diacetylenes ${ }^{76}$ 
dimension with anisotropic mechanical and optical properties. The photoreactivity of dicetylenes was first noted as early as $1882^{50}$ but it was not until 1969 that the current interest in the preparation and study of the macroscopic properties of single crystal diacetylene polymers was initiated by Wegner ${ }^{51}$. The topochemical polymerization of an array of diacetylene monomers proceeds by 1,4-addition reactions of the rigid diacetylene units to yield a conjugated extended polymer chain (Scheme 8 ).

The diacetylene polymers are believed to exist in two mesomeric forms (Scheme 8). The packing of the monomer units in the crystal is characterized by the separation $(d)$ of the monomers in the direction of the array and the angle $(\gamma)$ between the axis of the array and the diacetylenic rod. The perpendicular distance $(s)$ between the diacetylene units seems to be critical for solid state polymerization. Correlation of the lattice packing of the diacetylene monomers with solid state reactivity have indicated that the reacting $\mathrm{C}_{1}$ and $\mathrm{C}_{4}$ carbon atoms must be closer than $4 \AA$ for polymerization to occur ${ }^{52,53}$. Bloor $^{52}$ has related the effects of variation in $d$ and $\gamma$ to the reactivity of diacetylenes towards polymerization and found that, apart from the $4 \AA$ criterion, the monomers should be parallel to one another, or, if non-parallel, the monomer molecules must be related by a glide plane or screw axis. Nevertheless, an example of a reactive non-parallel diacetylene monomer has been reported ${ }^{53-55}$. The criteria for solid state reactivity are more easily satisfied by monomers with large end groups than by those with small end groups ${ }^{52}$. The role of the end groups seems to be critical since the interactions of the end groups determine the monomer crystal lattice structure. The flexibility of the side groups attached to the diacetylene unit must also be taken into consideration when designing a reactive diacetylene molecule. There are examples known where a compact molecular structure is obtained in the crystal with the side groups impeding the reaction ${ }^{52}$. Nevertheless considerable improvements in predicting expected crystal structures of diacetylenes from knowledge of molecular structures are required before the problem of obtaining a single crystal polymer from a specifically designed monomer molecule can be solved.

The nature of the propagating chain end has been the subject of much discussion but it is now generally accepted $^{56-59}$ that the photoinitiation reaction step involves the production of diradicals from the interaction of two diacetylene molecules. The most widely used technique in the study of polymerization kinetics is differential scanning calorimetry. However, although a vast volume of literature has been published concerning 2,4-hexadiyne-1,6-diol, bis( $p$-toluene sulfonate) 2 , little work on other diacetylenes appears to have been done.

Diacetylene 2 may be polymerized thermally in the solid state. The time required for polymerization varies from $2 \mathrm{~h}$ at a temperature just below the melting point to two months at ambient temperature. The polymerization process is characterized by the occurrence of an induction period, during which time the polymerization rate increases by a factor of up to $200^{60}$. Induction times during solid state reactions have been explained ${ }^{61}$ in terms of the incubation period necessary for the nucleation of a polymer crystal phase. This explanation, however, does not apply in the case of 2 where the polymer forms a solid-solution with the monomer. For polymerization of $\mathbf{2}$ the only structural change observed after polymerization is a $10 \%$ contraction of the crystal ${ }^{62}$ along the chain axis. The lattice strain generated by the mismatch of the polymer and monomer lattices is believed to be responsible for the autocatalytic effects observed during polymerization. On the basis of this model, Baughman ${ }^{63}$ developed a model which is consistent with the observed phenomena. According to this work, formation of the polymer chains is initiated during the induction period but the chain length is determined by the crystal strain field. Chain lengths of 10-20 units are estimated to be formed during the induction period. At about $10 \%$ conversion, irrespective

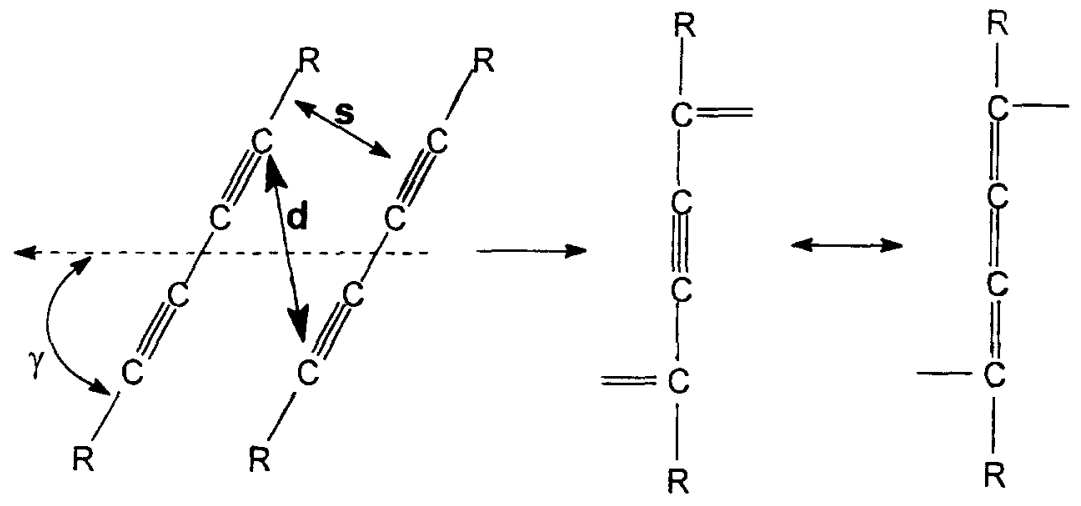

Scheme 8 Synthesis of polydiacetylene via 1,4-addition reactions<smiles>Cc1ccc(S(=O)(=O)OCC#CC#CCOS(=O)(=O)c2ccc(C)cc2)cc1</smiles>

Figure 2 2,4-Hexadiyne-1,6-diol, bis( $p$-toluene sulfonate) 
of the polymerization temperature, crystal strain is relieved as conversion to polymer takes place resulting in a strain free polymer crystal. Polymerization during the induction period and during the fast polymerization regime have been found to have the same activation energy ${ }^{60,64,65}$. As a result of these observations, it was concluded that the rate determining step for this polymerization was chain initiation.

The determination of molecular weight distributions in polydiacetylenes by conventional methods has been difficult due to the tendency of polydiacetylenes to form aggregates or microgels in solution. However, methods making use of chain length dependent solid-state properties have proved useful ${ }^{66-68}$. Wenz and Wegner ${ }^{69}$ have reported the molecular weight distributions of some $\gamma$-ray polymerized bis-toluenesulfonates. Chain lengths of about 1500 units were reported corresponding to weight average molecular weights of about $800000 \mathrm{~g}$ $\mathrm{mol}^{-1}$. Measurements were made using light scattering and confirmed by gel permeation chromatography. The variation in the molecular weight distribution with increasing degree of polymerization has also been studied $^{69}$. In general, at low polymer concentrations, short chains of approximately 60 repeat units are present. At higher conversion rates, the g.p.c. maximum rapidly shifts to higher values. A characteristic feature is that only the high molecular weight (1500 units) polymer is formed above about $20 \%$ conversion.

Polymerization in Langmuir-Blodgett film structures. The transfer of amphiphilic monolayers from the airwater interface to solid supports by the LangmuirBlodgett film technique can yield ultra-thin, homogenous and well-ordered mono- and multi-layer films. The polymerization of amphiphilic diacetylene molecules organized by the Langmuir-Blodgett film technique can lead to polymer structures of controlled thickness and orientation ${ }^{70}$. Langmuir-Blodgett films in which pentacosa-10,12-diynoic acid and henicosa-2,4-diynylamine were combined to form alternate-layer structures have been polymerized via irradiation with ultraviolet light and shown to possess pyroelectric properties ${ }^{71}$.

Polymerization in the liquid-crystalline state. Mesogenic diacetylene monomers which form thermotropic liquid crystal phases can undergo polymerization on thermal annealing. In appropriately designed molecules the polymerization proceeds in a controlled manner to yield polydiacetylenes which also exhibit liquid crystalline behaviour ${ }^{72.73}$.

\section{Polyphenylenes}

Four synthetic routes ${ }^{83-86}$ for the preparation of polyphenylenes have been employed fairly generally, namely: oxidative coupling, organometallic coupling, dehydrogenation of polycyclohexylenes and cycloaddition reactions. These, together with the other methods available for the synthesis of polyphenylenes, are discussed in the sections below.

Oxidative coupling. The most commonly employed method for the preparation of polyphenylenes involves the oxidative coupling of substituted and unsubstituted benzenes via treatment with a Lewis acid catalyst/oxidant system. In 1963 Kovacic and Kyriakis ${ }^{87}$ synthesized poly ( $p$-phenylene) by stirring benzene, anhydrous $\mathrm{AlCl}_{3}$ and anhydrous $\mathrm{CuCl}_{2}$ for $2 \mathrm{~h}$ at temperatures between $25^{\circ} \mathrm{C}$ and $35^{\circ} \mathrm{C}$. The reaction is believed to involve an initial one-electron oxidation of benzene to its radical cation, followed by reaction of the radical cation with several benzene molecules (Scheme 9) to give an oligomeric radical cation. A second one-electron oxidation, followed by loss of two protons aromatizes the terminal rings, and oxidative rearomatization of the dihydro structures by $\mathrm{CuCl}_{2}$ yields the polymer ${ }^{88}$.

A number of other catalyst/oxidant systems have been employed for the conversion of benzenes to polyphenylenes. These include $\mathrm{Cu}^{2+}$ and $\mathrm{Ru}^{3+}$ ion-exchanged montmorollonite clays ${ }^{89,90}$ and $\mathrm{AsF}_{3} / \mathrm{AsF}_{5}{ }^{91}$. The structural features and physical properties of the polymer prepared via oxidative polymerization depend to a large extent on the nature of the reagents ${ }^{86}$. Thus, it has been claimed that polyphenylenes with ortho linkages can be obtained from the oxidative polymerization of monosubstituted benzenes (e.g. toluene, chlorobenzene) under conditions analogous to those employed for the preparation of poly $(p \text {-phenylene })^{86}$. Polyphenylenes linked at the meta position are in general synthesized by treatment of $m$-terphenyl or mixtures of the $m$-terphenyl and biphenyl with anhydrous $\mathrm{AlCl}_{3} / \mathrm{CuCl}_{2}$ at elevated temperatures $\left(85^{\circ} \mathrm{C} \text { and } 180^{\circ} \mathrm{C}\right)^{92.93}$. Polymers substituted in the para position are in general more difficult to process than the ortho and meta substituted analogues. Oxidations in liquid $\mathrm{SO}_{2}$ at $-75^{\circ} \mathrm{C}$ or concentrated

n

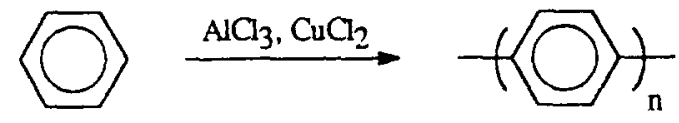

$$
\mathrm{C}_{6} \mathrm{H}_{6} \stackrel{-\mathrm{e}^{-}}{\longrightarrow} \mathrm{C}_{6} \mathrm{H}_{6}{ }^{+} \stackrel{\mathrm{n+1} \mathrm{C}_{6} \mathrm{H}_{6}}{\longrightarrow}\left[\mathrm{C}_{6} \mathrm{H}_{6} \ldots \ldots\left(\mathrm{C}_{6} \mathrm{H}_{6} \ldots \ldots . \mathrm{C}_{6} \mathrm{H}_{6}\right]^{+t}\right.
$$
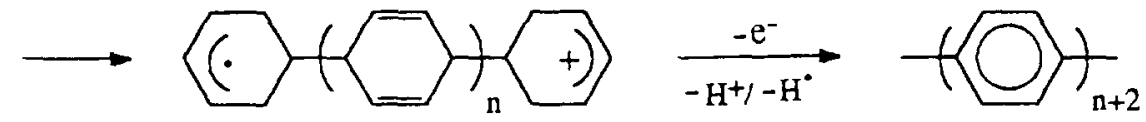

Scheme 9 Proposed oxidative coupling mechanism to polyphenylenes ${ }^{88}$ 
sulfuric acid in the presence of $\mathrm{AlCl}_{3}$ are claimed to result in the efficient formation of homogenous poly( $p$-phenylene) which is almost completely amorphous ${ }^{94}$. Highly crystalline films of this polymer can be deposited from benzene in concentrated sulfuric acid emulsion ${ }^{95}$.

An alternative means for the synthesis of polyphenylenes involves the anodic electrochemical oxidation of benzene or biphenyl in liquid sulfur dioxide on an appropriate electrode. The reaction yields passivating films if quaternary ammonium perchlorate is used as the electrolyte or conductive dendritic deposits if quaternary ammonium tetrafluoroborate is employed ${ }^{96}$. In both cases the polymer formed is reported to be linked at the para position but contains variable amounts of oxygen as phenolic groups. The electrochemical polymerization of benzene in nitromethane with aluminium chloride and water or an amine as additive results in the deposition of black polyphenylene on a platinum electrode ${ }^{97}$. Freestanding polyphenylene films containing ortho, para and meta links are obtained if the electrochemical oxidation of benzene is carried out in a two phase $\mathrm{HF}$ /benzene system $^{98}$. The anodic oxidation of benzene in nitrobenzene solution with $\mathrm{CuCl}_{2}$ and $\mathrm{LiAsF}_{6}$ results in the formation of flexible, electrically conducting films of poly ( $p$-phenylene $)^{99,100}$ as does the anodic oxidation of benzene in the presence of $\mathrm{BF}_{3} \cdot \mathrm{OEt}_{2}{ }^{101}$. The yields of the polymers prepared by this method are restricted by the area of the anode irrespective of whether the reaction is carried out in nitrobenzene or in the bulk ${ }^{102}$.

Organometallic coupling. Ullmann and Wurtz-Fittig type reactions have been utilized for the synthesis of polyphenylene oligomers but these methods cannot be applied to the synthesis of polymers since yields are low ${ }^{83}$. The preparation of polyphenylenes via the coupling of Grignard reagents has proved more suitable ${ }^{83}$. Thus the coupling of the mono-Grignard reagent of dihalobenzene in the presence of organometallic or organic promoters ${ }^{103,104}$ has been used for the synthesis of a range of para and meta substituted polyphenylenes (Scheme 10) ${ }^{105-107}$. However, the combination of lithiated anthracene and anthraquinone species is reported to be the most efficient method for the synthesis of polyanthrylenes ${ }^{108-110}$.
Dehydrogenation of polycyclohexylenes. The polymerization of 1,3-cyclohexadiene in the presence of various Ziegler type initiator systems $\mathrm{s}^{83,111}$ or $n$ butyllithium ${ }^{112}$ yields poly(1,3-cyclohexadiene). Dehydrohalogenation of this precursor polymer with chloranil or via halogenation/pyrolysis gives polyphenylene $e^{111}$. Cationic polymerization of the same monomer produces a mixture of 1,4- and 1,2-bonded structures which on halogenation/pyrolysis form a polyphenylene with ortho and para linkages 111 . Diester derivatives of 5,6-dihydroxy-1,3-cyclohexadiene have also been polymerized under radical conditions using benzoyl peroxide or AIBN after which the resulting polycyclohexylenes were converted to polyphenylenes by pyrolysis ${ }^{113}$ (Scheme 11), the favoured precursor being the methyl carbonate derivatives $\left(\mathrm{R}=\mathrm{CH}_{3} \mathrm{O}\right.$ - in Scheme 11).

The molecular weight of the thus formed polyphenylenes are greatly influenced by the relative stereochemistry and size of the diester substituted polymers. This work has been improved recently by the work of Grubbs et $a l^{114}$ in the regiospecificity of the polymerization.

Cycloaddition reactions. 1,4-Cycloadditions of biscyclopentadienones with bisacetylenes can yield high molecular weight polymers $83,115,116$ which contain approximately equal proportions of meta and para substituted phenylene units. Low molecular weight polyphenylenes containing ethynyl branches have been prepared ${ }^{117}$ by polycyclotrimerization of diacetylene in the presence of $\mathrm{Al}(i-\mathrm{Bu})_{3}$ and $\mathrm{TiCl}_{4}$ whereas polyphenylene copolymers with phenyl, vinyl and alkyl branches can be obtained by the reaction of diacetylene with an appropriately substituted acetylene $e^{118,119}$. The thermal eliminative ring closure of 1,4-diphenyl-3-(N,N-dimethylamino)-hex-5-en-1-yne has been shown ${ }^{120}$ to give terphenyl and by an analogous method the poly $(\mathrm{N}, \mathrm{N}-$ dimethylaminohex-5-en-1-yne) derivative shown in Scheme 12 affords phenyl substituted poly ( $p$-phenylene)s on pyrolysis ${ }^{121}$.

Other synthetic routes. Poly( $p$-phenylene) contaminated with small amounts of bridging diazo groups has been prepared ${ }^{122}$ by heating the bisdiazonium salt of<smiles>CC(C)(Br)c1ccc(C(Br)(Br)Br)cc1</smiles>

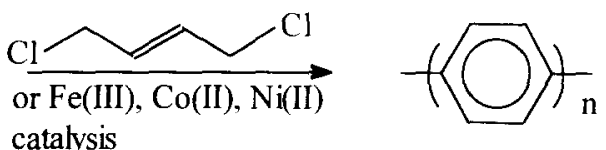

Scheme 10 Poly( $p$-phenylene) by Grignard polymerization ${ }^{83,103,104}$

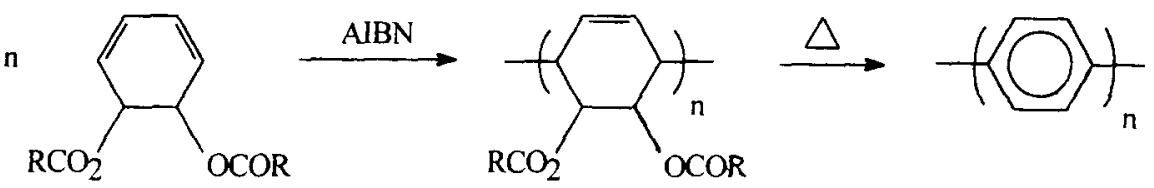

Scheme 11 Poly( $p$-phenylene)s by dehydrogenation of polycyclohexylenes ${ }^{113}$ 

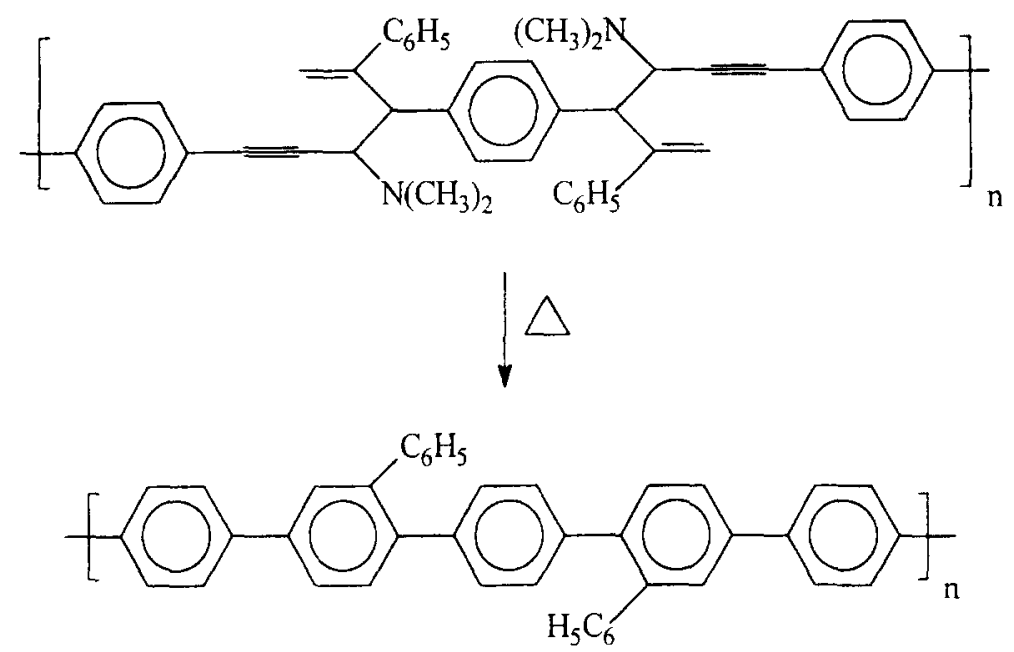

Scheme 12 Poly ( $p$-phenylene) by thermal ring closure of a poly(N,N-dimethylamino-hex-5-en-1-yne) derivative ${ }^{121}$

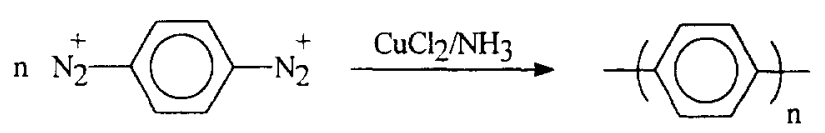

Scheme 13 Poly ( $p$-phenylene) via coupling of a bisdiazonium salt ${ }^{122}$

p-diaminobenzene in ammoniacal $\mathrm{Cu}^{+}$or $\mathrm{Fe}^{2+}$. In this case the polymerization mechanism is thought to involve homolytic cleavage of the carbon to diazonium group bonds followed by $\mathrm{C}-\mathrm{C}$ coupling (Scheme 13).

The electrochemical reduction of 1,4-dibromobenzene or $4,4^{\prime}$-dibromobiphenyl in THF/HMPA on a mercury pool electrode with $\mathrm{Ni}(0)$ complex catalysts and lithium perchlorate as the electrolyte gives good yields of insoluble poly $\left(p\right.$-phenylene) as a pale yellow powder ${ }^{123}$. By analogy, using an acetonitrile solution of $\mathrm{Ni}\left(\mathrm{PPh}_{3}\right)_{2}$, $p$-dibromobenzene has been reduced on a platinum or glassy carbon electrode with a tetrabutylammonium salt as electrolyte ${ }^{124}$. The resulting electroactive polymer coating is of the poly ( $p$-phenylene) type but it is contaminated with one nickel atom for every six or seven polymer repeat units ${ }^{124}$. Homogeneous undoped films of poly ( $p$-phenylene) can be deposited onto a solid cathode by electroreduction of $4,4^{\prime}$-dibromophenyl activated by a $\mathrm{Ni}(0)$ complex of 1,2-bis(diphenylphosphino-ethane) in an equimolar proportion. Electrodeposited thin layers of this polymer can be either oxidized or reduced in acetonitrile solution containing lithium salt as the supporting electrolyte $^{125}$. This method has been extended to the polycondensation of 2,7-dibromo-9,10-dihydrophenanthrene with isolated zero-valent nickel complexes and electrochemically generated zero-valent nickel complexes to afford poly (9,10-dihydrophenanthrene-2,7-diyl) which essentially possesses the same conjugation system as poly( $p$-phenylene) ${ }^{126,127 a}$ (Scheme 14).

Another route to substituted poly( $p$-phenylene) derivatives makes use of the Bergman cyclization of enediynes ${ }^{127 \mathrm{~b}}$ (Scheme 15). Thermal treatment $(T=50-$ $160^{\circ} \mathrm{C}$ ) of the enediyne yields poly ( $p$-phenylene) derivatives with $M_{\mathrm{n}}$ values of $1500-2500$.

Similarly poly(1,4-naphthalene)s can be prepared by thermolysis of ortho-dialkynylbenzenes.

Precursor routes to cross-linked polyphenylenes have been reported ${ }^{128}$. Soluble substituted polyphenylenes with number average molecular weights of up to 6300 are obtained by the $\mathrm{Ni}(0)$-catalysed homocoupling reaction of bis $\{[$ trifluoromethyl)sulfonyl]oxy\} derivatives of substituted hydroquinone and benzene derivatives having two bromine or chlorine leaving groups ${ }^{129}$. Other classes of soluble poly ( $p$-phenylene)s have been synthesized by the polymerization of 2,5-dibromo-1,4-di$n$-alkylbenzenes ${ }^{130}$ and 2,5-dibromobiphenyl ${ }^{131}$, via Yamamoto coupling of 4-bromo-2,5-di- $n$-hexylbenzeneboronic acid ${ }^{132,133}$ and (3,5-dibromophenyl)boronic acid $^{134}$, anionic polymerization of 2-phenyl-1,3-cyclohexadiene followed by aromatization ${ }^{131}$ and spontaneous polymerization of 1-bromo-4-lithiobenzene in hexamethylphosphoramide ${ }^{135}$.

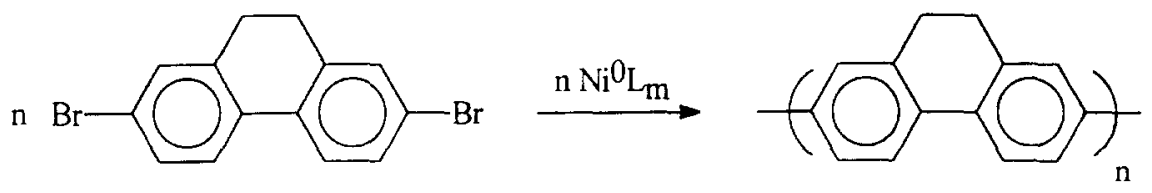

Scheme 14 Poly(dihydrophenanthrene) via a nickel catalysed polycondensation ${ }^{126,127 a}$
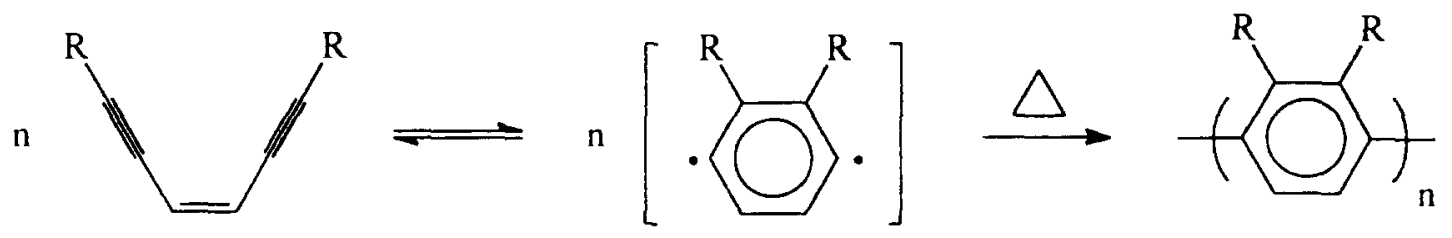

Scheme 15 Poly ( $p$-phenylene)s via thermolysis of enedyenes ${ }^{127 b}$ 


\section{Poly (phenylene vinylene)s}

Poly(phenylene vinylene)s (PPVs) possess a chemical structure which is intermediate between that of polyacetylene and polyphenylene. Oriented PPV is highly crystalline ${ }^{136,137}$, mechanically strong and environmentally stable. A number of approaches have been developed for the synthesis of this polymer and its analogues ${ }^{138-140}$. Early attemps utilized dehydrohalogenation or Wittig condensation reactions which resulted in the formation of intractable oligomeric powders, but since the development of the water-soluble precursor method dense, highly oriented free standing polymer films of high molecular weight are reproducibly prepared $^{137,141-143}$. The Wessling-Zimmermann precursor route is outlined in Scheme 16.

The precursor sulfonium polyelectrolyte is prepared in aqueous solution by the base induced polymerization of an appropriate bis-sulfonium monomer, see Scheme 16. The reaction is usually carried out at low temperatures in fairly dilute monomer solutions and in equimolar (or lower) base to monomer ratios in order to suppress the premature formation of unsaturated polymer segments by thermal or base induced elimination of solubilizing side chains. The polymerization reaction is terminated by the addition of dilute aqueous hydrochloric acid to the reaction mixture which is then dialysed against water in order to separate the high molecular weight fraction from the monomeric and oligomeric residues as well as the sodium and chloride ions. A study of the polymerization mechanism ${ }^{144}$ revealed the existence of an intermediate of quinoid structure during the early stages of polymerization. In order to shift the reaction equilibrium towards the side of the polymer the stabilization of the quinoid intermediate or the removal of the thioether byproduct is desirable. This is readily achieved by the introduction of hexane in the reaction mixture ${ }^{145}$. The hexane/water medium creates a twophase system which, with vigorous stirring, produces an inverse emulsion polymerization environment. By maintaining a fine dispersion good contact between the two phases and effective exchange of the reaction components is ensured. The yields achieved by the two-phase polymerization method are normally about twice as high as those obtained by other procedures ${ }^{145}$. In addition to the improved reaction yields, the inverse emulsion polymerization method produces precursor polymers with higher molecular weights.

Another group of interesting PPVs are the cyano substituted PPVs which are prepared by a Knoevenagel condensation reaction between a diacetonitrile and a dialdehyde (Scheme 17) ${ }^{145 \mathrm{~b}}$.

Because of the versatility of the Knoevenagel condensation reaction this route can also be used for the synthesis of hetero-aromatic cyanopolymers such as the

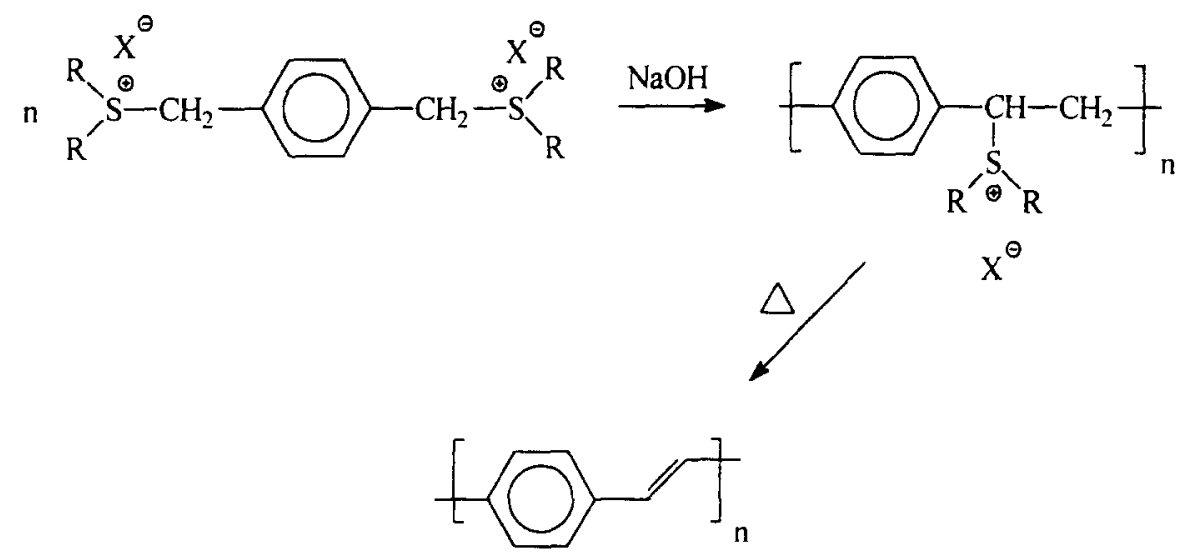

Scheme 16 Poly(phenylene vinylene) by sulfonium polyelectrolyte route ${ }^{141}$<smiles>[R]c1cc(C=O)c([R4])cc1C=O</smiles><smiles>[Z]C=C(C)c1cc([R])c(/C(C)=C/c2cc([R2])c(I)cc2[R4])cc1[R4]</smiles>

Scheme 17 Knoevenagel condensation synthesis of cyano substituted PPVs ${ }^{145 b}$ 


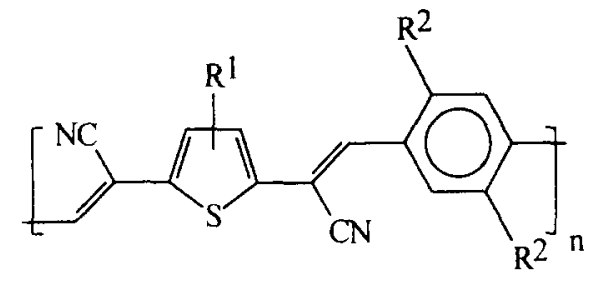

3

Figure 3 Heteroaromatic cyanopolymers ${ }^{145 b}$

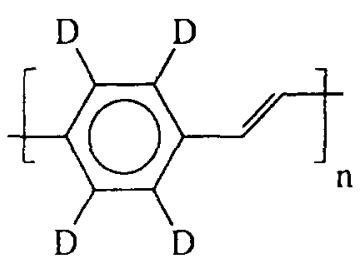

Figure 4 Deuterated PPV ${ }^{149}$

poly(thienylenephenylene vinylene) copolymer $\mathbf{3}$ and poly(thienylene vinylene) 4 (Figure 3$)^{145 \mathrm{~b}}$.

Properties of PPV films. Homogeneous dense precursor films may be readily prepared as coatings on substrates or in free-standing form by slow evaporation of the solvent. Casting the solution on a PTFE block or a glass dish treated with dichlorodimethylsilane as release agent, facilitates the preparation of free-standing films from which those thicker than approximately $1 \mu \mathrm{m}$ can easily be lifted free. The conversion to the conjugated polymer is carried out by placing the cast and oriented films under vacuum or in an inert gas atmosphere in a constant-temperature bath at a desired temperature (determined by the nature and number of substituents attached on the benzene ring) ${ }^{146}$. Control of the sample morphology is readily achieved by varying the casting and conversion protocol. The full conversion of the precursor monomer to PPV requires a temperature of at least $300^{\circ} \mathrm{C}$ but annealing at temperatures of $400^{\circ} \mathrm{C}$ or higher leads to degradation. In the absence of an inert gas atmosphere or vacuum a proportion of the vinylene carbons are oxidized to carbonyls during the elimination process ${ }^{142}$. Heat treatment at temperatures of less than $300^{\circ} \mathrm{C}$ results in the formation of a copolymer which contains both saturated and unsaturated segments ${ }^{139}$.

The molecular orientation in uniaxially drawn PPV films has been characterized by infrared dichroism and $\mathrm{X}$-ray diffraction and very high values of the Hermans orientation function have been reported ${ }^{137.147,148}$. Recently, Simpson et al. ${ }^{149}$ employed deuterium quadrupole-echo n.m.r. experiments to study the chain orientation of drawn PPV films in which the phenylene ring was deuterated (Figure 4).

The films were prepared from water-cast films of the precursor polymer poly[(2,3,5,6-tetradeuterio- $p$-xylylidene) tetrahydrothiophenium chloride] and were heated and stretched to effect simultaneous orientation and elimination. The results demonstrated that the average tilt of the phenylene ring relative to the chain axis was $7.7^{\circ}$, close but not exactly equal to the $9.2^{\circ}$ predicted for a transstilbene-like structure. The difference was attributed to chain disorder within crystallites or at domain boundaries $^{149}$.

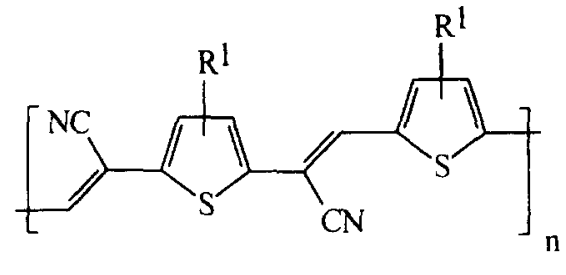

4
Highly oriented PPV shows high electrical conductivity upon vapour-phase doping with $\mathrm{AsF}_{5}{ }^{142,143}$ but iodine doped films show only modest conductivities. The crystal structures of neutral pristine and doped forms have been studied by wide-angle X-ray diffraction ${ }^{150}$. Poly( $p$-phenylene vinylene) was found to undergo a firstorder crystal-crystal phase transition when chemically doped with $\mathrm{AsF}_{5}, \mathrm{SbS}_{5}$ or sulfuric acid or when electrochemically oxidized with $\mathrm{ClO}_{4}^{-}$as the counterion. The doping process does not disrupt the original orientation of the PPV crystallites and the crystalline phases obtained with all the above dopants are similar in character indicating a closely related family of electrically conductive structures all of which possess orthorhombic symmetry. On the basis of this work an electrically conductive phase consisting of layers of polymer chains separated by a layer of the chemical dopant was proposed ${ }^{150}$. The influence of crystal defects and chain disorder on the electrical properties of PPV polymers have also been investigated. Highly drawn films of fully converted PPV exhibit a high degree of crystallinity and near-perfect orientation but, since distinctive paracrystalline diffraction patterns have been

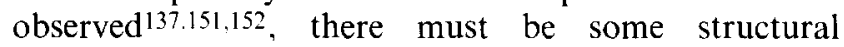
disorder.

The one-dimensional band structures of PPV have been calculated ${ }^{153-155}$. DaCosta et al. ${ }^{156}$ have extended the work by calculation of the three-dimensional band structure of PPV in order to study the effects of interchain coupling. The major effects are reported to be due to coupling of carbons in the ring to their closest neighbours (hydrogens or rings in adjacent chains). According to this study the existence of polarons in a perfect PPV crystal is not permitted but since these have been experimentally identified their existence is explained in terms of the presence of traces of residual precursor polymer within the matrix.

Arsenic pentafluoride doped PPV is not stable in air. In order to stabilize the $p$-type doped form of the polymer and decrease its ionization potential and band gap, the phenylene ring may be substituted with electrondonating substituents or replaced by heterocyclic aromatic molecules ${ }^{157}$. By adopting this approach highly conducting iodine-doped films of poly(2,5-dimethoxy-pphenylene vinylene) (Figure 5, 5) $)^{158,159}$, poly(2-methoxy-pphenylene vinylene) $(6)^{145,160}$, poly(2,3,5,6-tetramethoxy$p$-phenylene vinylene) $(7)^{161}$, poly $(2,5$-thienylene vinylene $)$ (8) ${ }^{162,163}$ and poly(2,5-furylene vinylene) (9) ${ }^{164}$ of much improved air stability 157,158 have been prepared. The synthesis of the donor acceptor substituted poly(2methoxy-5-nitro- $p$-phenylene vinylene) (10) and its copolymers with PPV has also been reported but these materials have a higher band gap than PPV itself ${ }^{165}$. The interest in these materials is as potential 


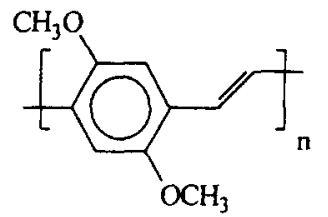

5

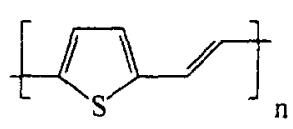

8

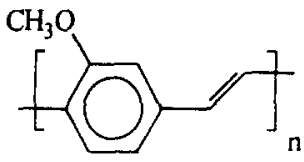

6

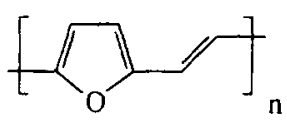

9

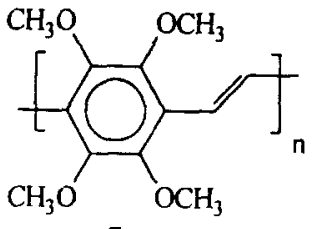

7

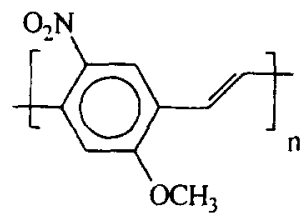

10

Figure 5 An anthology of poly(phenylene vinylene)s

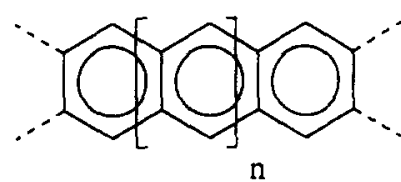

11

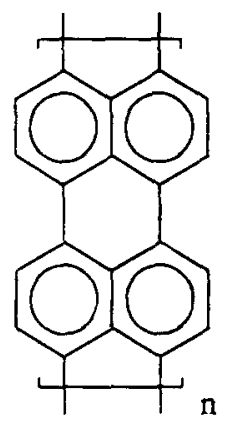

12
Figure 6 Linear polyacenes and polyarylenes

electroluminescent components of light emitting diodes and there is a great amount of activity in the area of new poly(arylene vinylene) synthesis at present.

\section{Two-dimensional ladder structures}

Two-dimensional, ribbon-type conjugated polymer structures are known to exhibit better thermal stability and higher rigidity than their one-dimensional analogues ${ }^{166,167}$. Furthermore, materials of this type are expected to exhibit low band gaps. The synthesis of defect free ladder or ribbon polymers is a demanding task which has attracted the attention of many research groups. The main synthetic strategies for the preparation of such materials is the utilization of repetitive cycloaddition reactions and, more recently, a two step approach in which a linear polymer is subjected to polymer-analogous ring-closure reactions with formation of ladder structures 168,169 .

Linear polyacenes (Figure 6, 11) and polyarylenes (12) can be considered as two-dimensional subunits of graphite. Polyacenes are not stable if more than a few repeating units long. However, polyarylenes can be prepared from oligonaphthalene precursors by an electron-transfer induced electrocyclic process (oxidation or reduction) in which neighbouring naphthyl components are fused to perylene units ${ }^{170,171}$.

The synthesis of polyacenes, high molecular weight analogues of biphenylene, has been explored ${ }^{172}$. The most commonly employed procedure for the synthesis of this class of compounds involves the $\eta^{5}-\mathrm{C}_{5} \mathrm{H}_{5} \mathrm{CoL}_{2}$ $\left(\mathrm{L}=\mathrm{CO}, \mathrm{CH}_{2} \mathrm{CH}_{2}\right.$ ) catalysed cocyclization of orthotetraethynylarenes which can result in a series of multi[N]phenylenes ${ }^{173}$ (Scheme 18).

Because the alkynylarenes are readily prepared from the corresponding haloarenes by Pd-catalysed alkynylation and since $\mathrm{Si}\left(\mathrm{CH}_{3}\right)_{3}$ can function as a masked halogen the method lends itself to the preparation of well-defined oligomers by an iterative procedure ${ }^{173-176}$.

Another method to prepare polyarenes makes use of a palladium-catalysed Suzuki coupling ${ }^{177}$ followed by a cyclization reaction (Scheme 19). After the crosscoupling reaction the resulting polyphenylene has to be

1) $\left(\mathrm{CH}_{3}\right)_{3} \mathrm{Si}-\mathrm{C}=\mathrm{C}-\mathrm{H}, \mathrm{Pd}\left(\mathrm{C}_{6} \mathrm{H}_{5} \mathrm{CN}\right)_{2} \mathrm{Cl}_{2}, \mathrm{CuI}$

2) $\mathrm{KOH}$<smiles>Ic1cc(I)c(I)cc1I</smiles>

3) $\left(\mathrm{CH}_{3}\right)_{3} \mathrm{Si}-\mathrm{C}=\mathrm{C}-\mathrm{Si}\left(\mathrm{CH}_{3}\right)_{3}, \mathrm{CpCo}(\mathrm{CO})_{2}, \mathrm{hv}, \triangle$<smiles>C[SiH2]c1cc2c(cc1[SiH](C)C)c1cc3c4cc([SiH](C)C)c([SiH](C)C)cc4c3cc21</smiles><smiles>CC#CC[C@H]1c2ccccc2C(C)(C)c2cc3c(cc21)C(C)(C)c1ccccc1-3</smiles>

Scheme 18 Vollhardt's route to multi[N]phenylenes ${ }^{172}$ 


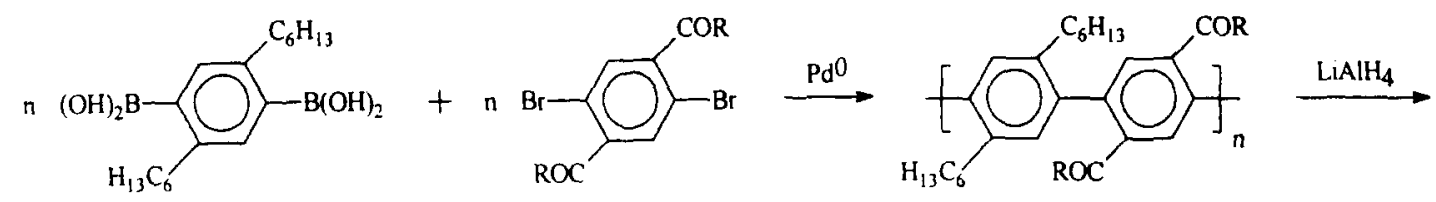

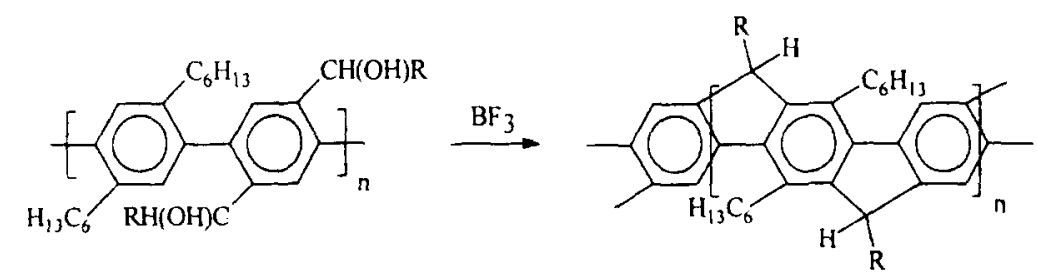

Scheme 19 Polyarenes by the Suzuki/BF -cyclization sequence $^{178,179}$

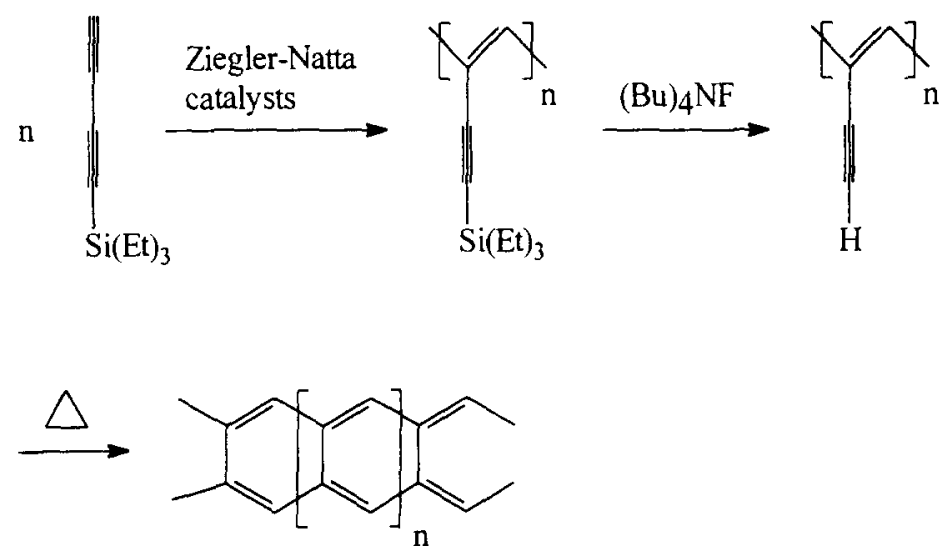

Scheme 20 Polyacenes by thermal polymerization ${ }^{188,189}$

planarized. This is performed by a $\mathrm{BF}_{3}$ catalysed cyclization reaction which results in the double-stranded, fully soluble poly(fluoreneacene) $\mathbf{s}^{178,179}$.

Other routes to polyacenes make use of DielsAlder-reaction 178,180-182, condensation-type cyclization reactions ${ }^{183,184}$, a 'zipping-up' polymerization of vinyl substituted polymers ${ }^{185-187}$, or polymerization of butadiynes as precursors ${ }^{188,189}$ (Scheme 20). Unfortunately some of these methods give insoluble products from which no reliable structural information can be obtained $^{178}$.

A well-known route to polyarylenes is the pyrolysis of perilene-3,4,9,10-tetracarboxylic acid dianhydride 13 in vacuo or under inert atmosphere giving black insoluble polymers which, from detailed structural analysis of films (X-ray, electron diffraction analysis, Raman spectroscopy), appear to be two-dimensional carbonaceous networks ${ }^{190-194}$ (Scheme 21). Under well-controlled conditions mirror like thin films can be formed on appropriate substrates.

Another route is shown in Scheme 22, the first step is the formation of poly(naphthalene) 16 via a palladium (0) catalysed Suzuki-type condensation of naphthalenes containing bromo and boronic acid functionalities ${ }^{195}$. In the next step this polymer is cyclized in a two-step procedure resulting in soluble macromolecules with ladder-type segments up to quaterarylene units 17. Unfortunately it is impossible to get complete cyclization via this approach.
Besides these hydrocarbon ladder polymers there are also a number of heteroatom containing species $^{178,196,197-200}$.

\section{HETEROCYCLIC POLYMERS}

\section{Polythiophenes}

The first polythiophene (Figure 7, 18) synthesis was described in 1883 when the purification of thiophene
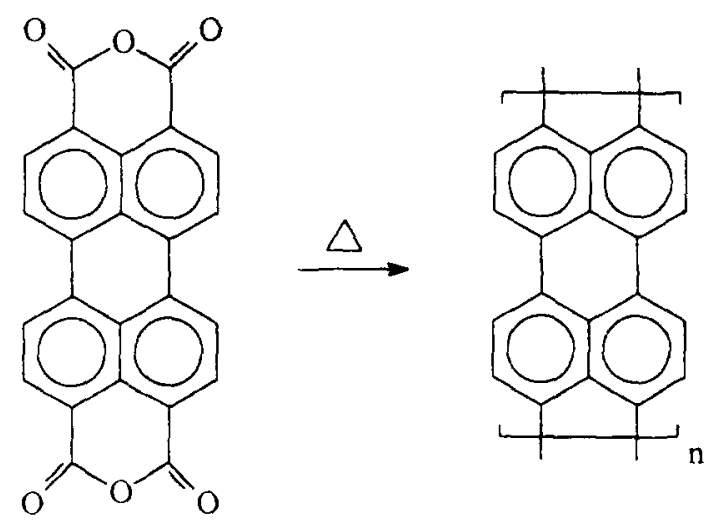

13 


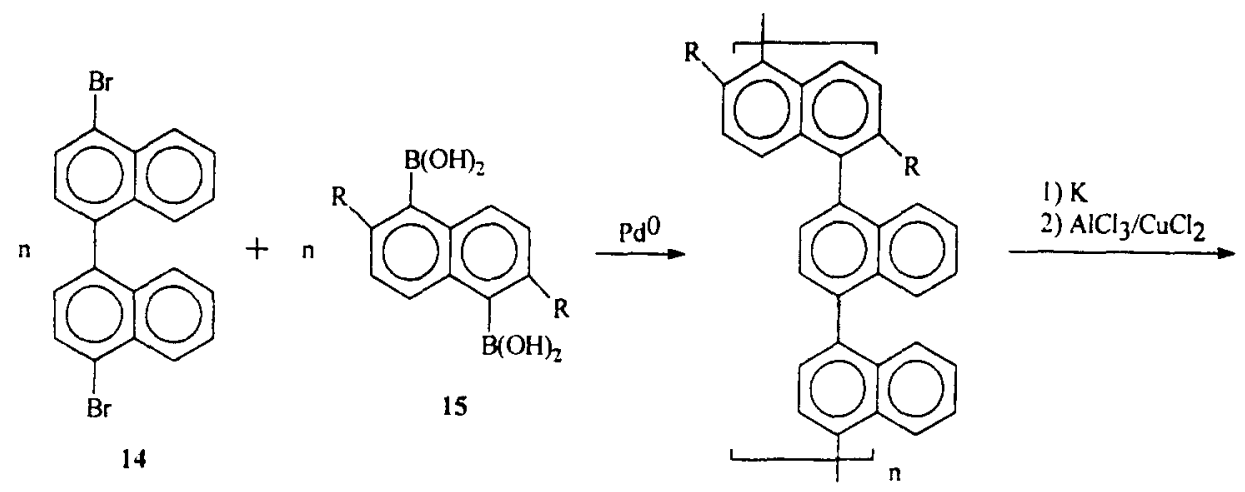

16

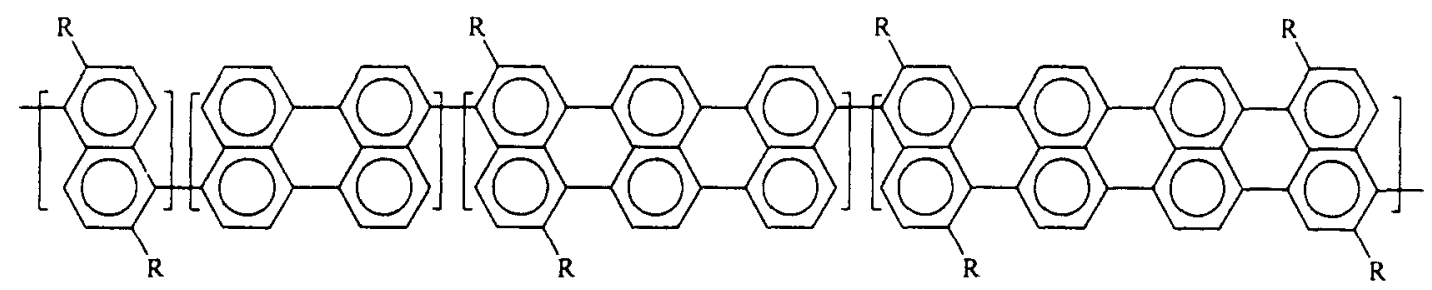

17

Scheme 22 Suzuki/cyclization route to polyarylenes ${ }^{195}$

with sulfuric acid yielded a dark insoluble material ${ }^{201}$. However, it was not until the early 1980s that any welldefined polymeric material was obtained. After the first reports of a controlled synthesis by Yamamoto ${ }^{202}$ and Lin $^{203}$, using the Grignard-type coupling of 2,5-dibromothiophene, a vast number of articles concerning the synthesis and properties of polythiophenes has been published.

Extended $\pi$-conjugation in polythiophenes is only possible in polymers with perfectly 2,5 -linked repeating units; however, 2,4- and 2,3-couplings as well as hydrogenated thiophene units can also be found in the polymers $^{204}$. These structural defects interrupt the conjugation and, as a result, will impair the development of properties related to conductivity and nonlinear optics.

Polythiophenes, like many other linear polyaromatic compounds, are insoluble in organic solvents due to their rigid backbone. This lack of solubility and processability, as well as problems related to the characterization of polythiophenes, has been overcome by the introduction of flexible side chains at the 3- and/or 4-position. Appropriate solubility in common organic solvents has been achieved with an alkyl side chain of more than four carbon atoms at every repeating unit ${ }^{205}$. Longer alkyl side chains are required in the case of copolymers with less than one side chain per repeating unit.

With the introduction of substituents at the 3-position of polythiophenes a number of different regioisomers are possible, namely head-to-tail (HT), head-to-head $(\mathrm{HH})$ and random configurations (Scheme 23) ${ }^{206,207}$.

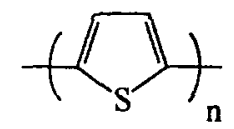

Figure 7 Polythiophene
Head-to-head coupling of alkyl groups is sterically unfavourable for coplanarity and hence causes a significant loss of conjugation; however, head-to-tail coupling does not limit conjugation. The significant difference in coplanarity between head-to-head and head-to-tail couplings shows the subtleties in the tradeoff between resonance energy and steric hindrance in substituted polyheterocycles. Studies on regioregular polythiophenes, recently accessible via a number of elegant routes, have shown that the crystallinity increases with regioregularity and that the possibility of side-chain crystallinity is essential for the development of optimal properties. In the case of regiorandom polymers the optimal chain length for properties like conductivity and optical nonlinearities has been determined to be in the range of seven to nine carbon atoms ${ }^{208}$; the conductivity of doped regioregular polythiophenes with an $n$-dodecyl side chain at the 3-position surpasses that of polymers wth an $n$-octyl side chain ${ }^{209}$. Even self-assembly in thin films of regioregular 3-substituted polythiophenes has been observed. In addition to improved solubility and crystallinity, the introduction of side chains in the 3- and/ or 4-position also decreases the probability of $\alpha-\beta$ couplings, since at least one of the $\beta$ positions is already occupied $^{210,211}$.

3,4-Dialkyl substitution in monomers results in a significant loss of coplanarity ${ }^{212}$, while in 3,4-dialkoxy and 3-alkyl-4-alkoxy polythiophenes the presence of an oxygen atom attached to the thiophene unit, is enough to decrease steric hindrance and limit the loss of conjugation $^{213}$. An unexpectedly high regioregularity was found in the polymerization of 3-methyl-4alkoxythiophenes $^{214}$.

An interesting and intriguing property of substituted polythiophenes is the temperature dependence of the $u . v$. absorption; an increase in temperature causes the $\lambda_{\max }$ to shift to shorter wavelengths. This thermochromism arises from a conformational change in the aromatic backbone as a result of an increased disorder of the alkyl 

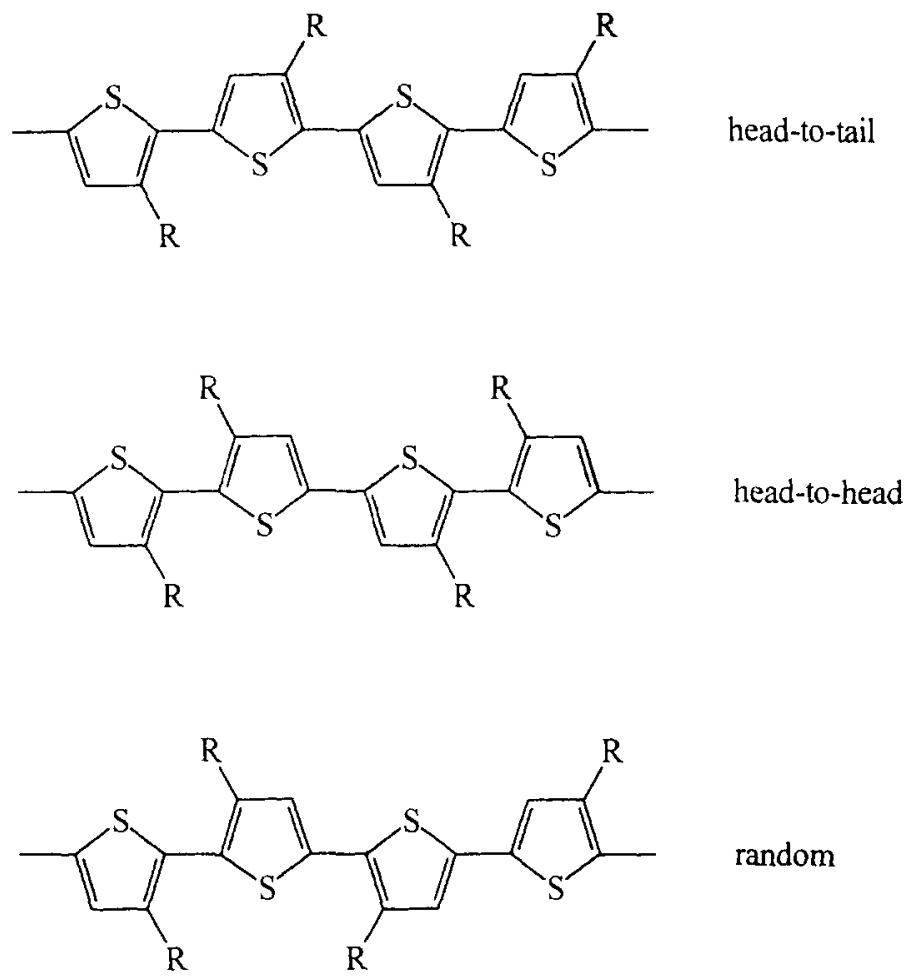

Scheme 23 Different regioisomers in polythiophene

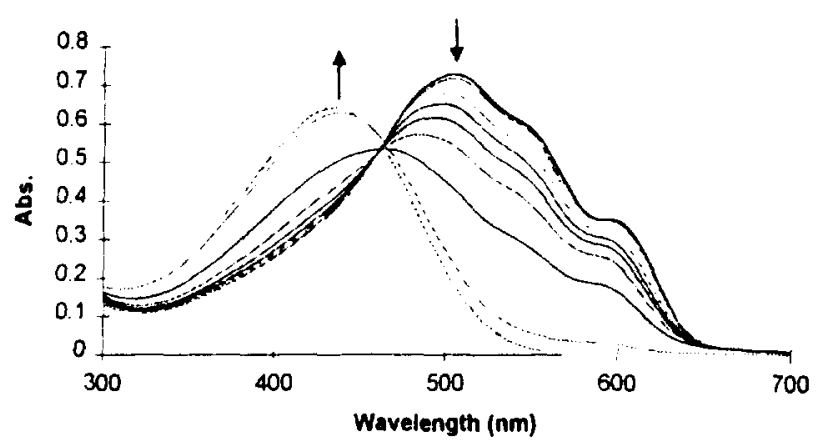

Figure 8 Thermochromism in a 3-substituted polythiophene $\mathrm{e}^{218}$

side chains ${ }^{215-217}$. It is now well-accepted that two distinct structures are possible depending on solvent and temperature; a predominantly coplanar structure in an aggregated form in a poor solvent or at low temperatures and a conformationally disordered nonplanar structure in a good solvent or at higher temperatures (Figure 8$)^{218}$.

Much controversy exists about the actual molecular weight of polythiophenes. G.p.c. determinations using polystyrene standards overestimate the molecular weight by a factor of ten compared to the determination relative to oligothiophene standards ${ }^{219}$. A similar phenomenon has been observed in the molecular weight determination of poly( $t$-butylnaphthalene) although in that case the deviation is only around $10 \%{ }^{220}$. By using multi-angle light scattering (MALLS) the calculated molecular weight values for polythiophenes are two to five times larger than those obtained by g.p.c. relative to polystyrene standards ${ }^{221}$.

For the preparation of polythiophenes three main synthetic strategies have been employed, namely: electrochemical coupling, oxidative coupling and organo- metallic coupling of 2,5-disubstituted monomers. These three routes will be discussed in the following sections.

Electrochemical synthesis of polythiophenes. Since the first reports by Diaz ${ }^{222}$, the synthesis of polythiophenes by electrochemical oxidation has been widely used. Although the mechanism is not fully understood, it is proposed that the polymerization proceeds via the coupling of two radical cations, formed by the oxidation of the monomer as outlined in Scheme $24^{223}$.

Aromatization of the bithiophene intermediate is the driving force for the transformation of the dihydro dimer. The dimer, having a lower oxidation potential than the monomer, is readily oxidized and undergoes further coupling. The polymer is deposited in its oxidized conducting form onto the electrode, allowing the polymerization to proceed. This method has the advantage that during the polymerization homogeneous, stable films are formed. These films can be characterized by optical and electrochemical methods. The electrochemical polymerization has been applied for the synthesis of unsubstituted polythiophene224,225 and 3-substituted polythiophenes including poly(3-methylthiophene $)^{226}$, poly(3-ethylthiophene) ${ }^{227}$ and number of different soluble poly(3-alkylthiophene) $\mathrm{s}^{228,229}$. However, in all cases reported so far, the polymers obtained possess a regiorandom structure.

The electrochemical polymerization of substituted thiophenes has also been used to synthesize a variety of functional polymers. Oxygen containing substituents on the 3-position of thiophenes have been used, including methoxy ${ }^{230}$ and polyether substituents ${ }^{231}$, leading to materials with conductivities as high as $1000 \mathrm{~S} \mathrm{~cm}^{-1}$. A highly transparent conducting polymer has been obtained from the electrochemical polymerization of 3,4-ethylenedioxythiophene (Figure 9, 19) ${ }^{232}$.

Similarly polyfluoroalkyl substituted polythiophenes 


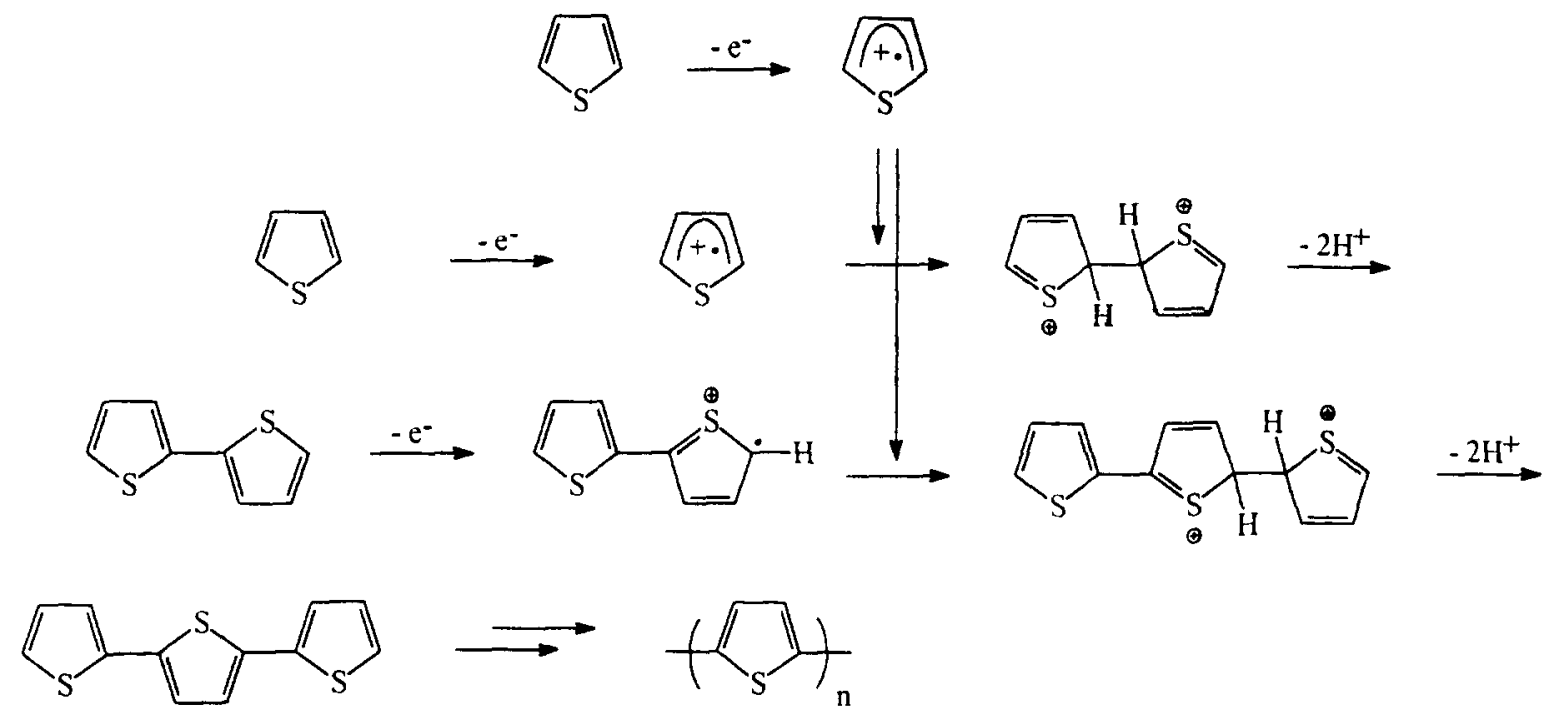

Scheme 24 Electrochemical polymerization of thiophene $e^{223}$

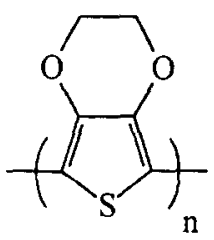

19

Figure 9 Poly(3,4-ethylenedioxythiophene) ${ }^{232}$

can be synthesized ${ }^{234}$, while water-soluble, self-doped polythiophenes have been prepared by the introduction of ionic groups in the side chain ${ }^{235-238}$.

Thiophene oligomers such as bithiophenes ${ }^{239}$ and terthiophenes possess lower oxidation potentials than the thiophene monomers $(1.05 \mathrm{~V}, 1.31 \mathrm{~V}$, and $2.07 \mathrm{~V}$ (vs. SCE) for terthiophene, bithiophene and thiophene, respectively) ${ }^{240}$ and are therefore more suitable for the electrochemical polymerization since this lower oxidation potential decreases the risk of over oxidation. Also 2,5-disilyl substituted thiophenes have been polymerized electrochemically with concomitant elimination of the silyl substituents 241 .

Oxidative coupling to polythiophenes. Conducting polythiophenes are formed in the oxidation of thiophene or 2,2' -bithiophenes with arsenic(V) pentafluoride $\left(\mathrm{AsF}_{5}\right)$. Reduction of the insoluble material with ammonia clearly demonstrated that polymerization has occurred $^{242}$. However, due to the poisonous properties of arsenic(V)pentafluoride this method has not been widely adopted. A more convenient method was developed by Yoshino et al. ${ }^{243}$ who used iron(III) trichloride $\left(\mathrm{FeCl}_{3}\right)$ as the oxidizing agent and chloroform as the solvent under anhydrous conditions. Subsequent reduction with ammonia provided the neutral polymer in good yields. This coupling reaction is simple and has now been widely employed for the synthesis of polythiophenes from thiophene with alkyl 244,245 , alkoxy212 and alkylsulfonic acid 246 substituents and bithiophenes with one ${ }^{247}$ and two ${ }^{248,249}$ alkyl substituent. These bithiophene monomers can also be polymerized using milder oxidants $\mathrm{s}^{250}$.

Recently, scientists have been able to regioselectively polymerize 3-(4-octylphenyl)-thiophene using $\mathrm{FeCl}_{3}{ }^{251}$. By adding the $\mathrm{FeCl}_{3}$ slowly and therefore maintaining a low $\mathrm{Fe}^{3+} / \mathrm{Fe}^{2+}$ ratio, this 'soft' polymerization leads to a polymer with up to $94 \%$ head-to-tail couplings (Scheme 25).

The oxidative coupling of thiophenes provides materials with higher molecular weights than the route described above. However, in a recent study ${ }^{252}$ a comparison has been made between the polymerization of 3-hexylthiophene and its deuterated analogue indicating that considerable crosslinking occurs through the alkyl side chain. The degree of crosslinking is reduced by performing the reaction at temperatures below $-20^{\circ} \mathrm{C}$, which also increases the yield of soluble 3-substituted polythiophenes.
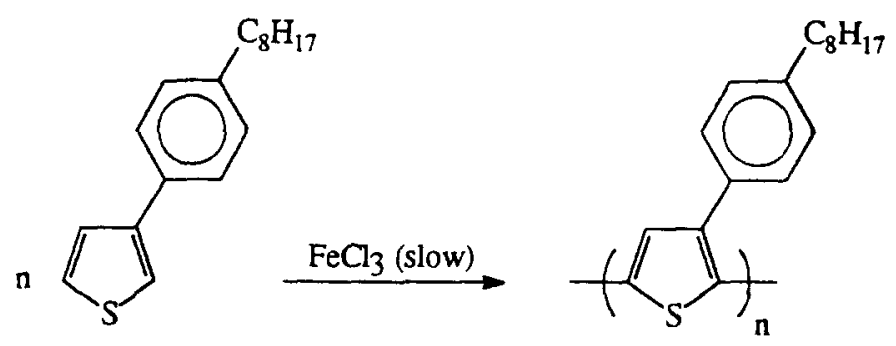

Mainly head-to-tail

Scheme 25 Chemical and regioselective polymerization of 3-(4-octylphenyl)thiophene ${ }^{251}$ 
Organometallic mediated syntheses of polythiophenes. The nickel ${ }^{253}$ and palladium ${ }^{254}$ catalysed cross-coupling of an aromatic organometallic compound with an aromatic organohalide is a well-known method for the synthesis of oligoheterocycles ${ }^{255}$. Organomagnesium derivatives are most widely employed in polythiophene chemistry, despite the availability of a variety of organometallic species ${ }^{256}$. The reaction of 2,5-dibromothiophene with magnesium and subsequent polymerization using a nickel catalyst was described in 1980 , with a reported yield of $40-60 \%$ based on 2,5dibromothiophene $\mathrm{e}^{202,203}$. The yields have been improved up to $93 \%$ by using 2,5-diiodothiophene, magnesium and $\mathrm{Ni}(\mathrm{dppp}) \mathrm{Cl}_{2}$ as catalyst ${ }^{257}$.

The synthesis of 3-alkylsubstituted polythiophenes, with molecular weights varying from 2500 to 18000 , has also been accomplished by this method, although the structures obtained are regiorandom ${ }^{258,259}$. This regiorandomness has been explained in terms of the inhomogeneity of the Grignard iodide mixture, which consists of diiodo-, bis-Grignard- and two monoiodo-monoGrignard compounds ${ }^{260,261}$. Cross-coupling has also been utilized for the synthesis of 3-substituted thiophene precursors $^{262,263}$.

Highly regioregular head-to-tail 3-alkylpolythiophenes have been prepared by McCullough et al. via the polymerization of 2-bromomagnesio-5-bromo-3alkylthiophenes (Scheme 26) 209,264-266.

By this elegant route a variety of highly regioregular (over 98\% head-to-tail) polymers has been obtained in yields ranging from 33 to $69 \%$. These polymers exhibit enhanced conductivity and optical properties when compared with the regiorandom materials. The conductivity of poly(3-dodecylthiophene) reaches values upto $1000 \mathrm{~S} \mathrm{~m}^{-1}$ whereas for the regiorandom material the conductivity is limited to $20 \mathrm{~S} \mathrm{~cm}^{-1}$. The difference in the position of the maximum absorption (450 vs. $434 \mathrm{~nm}$ in solution and 480 vs. $526 \mathrm{~nm}$ in the solid state) are indicative of enhanced coplanarity in these regioregular polythiophenes. As a result, the thermochromism of these regioregular polythiophenes is much more pronounced. X-ray analysis indicates a crystalline and self-assembled structure and a well-defined distance between the polymer chains ${ }^{267}$. Cyclic voltammetry exhibits two oxidation potentials vs. one broad oxidation potential for the regiorandom poly(3alkylthiophene)s ${ }^{268}$.

Another approach to modulate the regioregularity is by using zinc instead of magnesium in the nicke1 269,270 or palladium ${ }^{271}$ catalysed polymerizations. The use of $\mathrm{Ni}(\mathrm{dppp}) \mathrm{Cl}_{2}$ affords regioregular samples (Scheme 27) ${ }^{272}$ and Japanese workers had similar experience with zerovalent nickel ${ }^{273,274}$. In the latter case the 2,5dihalothiophene was coupled without being transformed to an organometallic intermediate, and therefore, yields a regiorandom polythiophene.

Due to the improved properties of the regioregular 3substituted polythiophenes, the polymerization based on the organometallic coupling of thiophene monomers is now by far the most valuable method of synthesis. Recently, a number of polymers with functional groups has been synthesized using the organometallic route, giving rise to polythiophenes with unique sensor properties for ionic impurities ${ }^{275-277}$.

\section{Polypyrrole}

The first synthesis of polypyrrole (Figure 10, 20), which included a description of the conducting properties of the product, was published in 1968278 . The electrochemical oxidation of pyrrole in $0.1 \mathrm{~N}$ sulfuric acid yielded a black conducting film. Improvements by using organic solvents and different electrolytes have

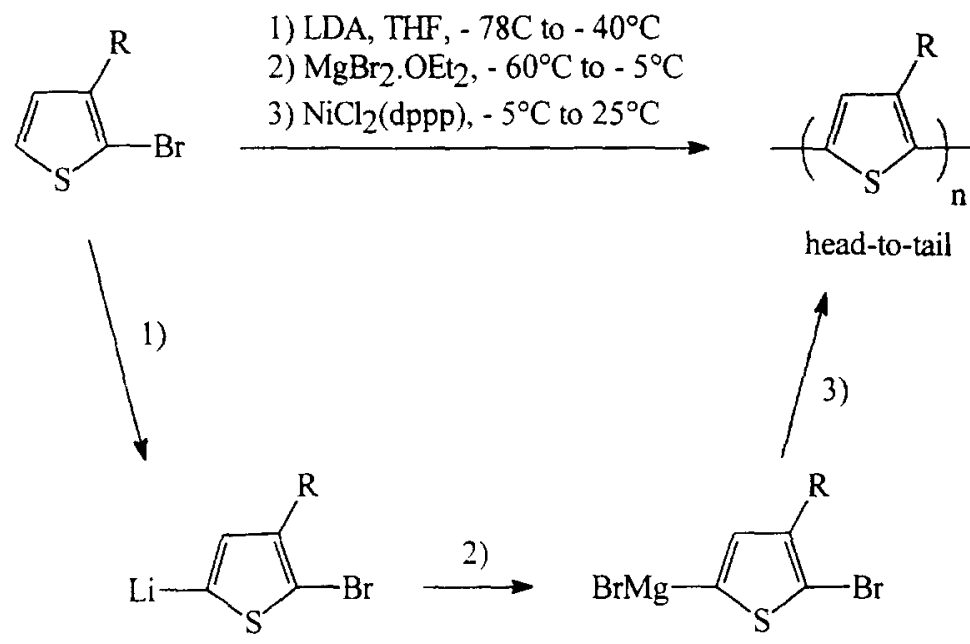

Scheme 26 McCullough's route to regioregular polythiophenes ${ }^{209,264-266}$

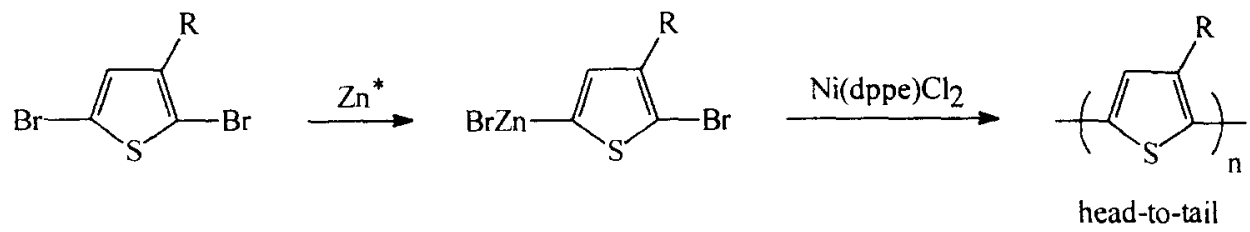

Scheme 27 Riecke's regioselective route to HT-polythiophene 272 


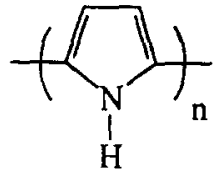

20

Figure 10 Polypyrrole

made the electrochemical method the most commonly employed polymerization technique ${ }^{279,280}$. The mechanism of the electrochemical polymerization is similar to that of thiophene as shown in Scheme 24.

Oxidized polypyrrole is stable under ambient conditions and up to temperatures exceeding $300^{\circ} \mathrm{C}$. The neutral form of polypyrrole, on the other hand, has not been isolated and characterized, due to its extreme susceptibility to oxidation $(-0.02 \mathrm{~V}$ vs. SCE).

The electrochemical route to polypyrrole provides good quality films. The counter ion has a considerable influence on the conductivity and mechanical properties $^{281}$. Changing the counter ion from oxalate to perchlorate increases the conductivity by a factor of $10^{205,274}$. Commercially available polypyrrole films with tosylate as counterion exhibit a conductivity of $15 \mathrm{~S} \mathrm{~cm}^{-1}$ and the stability of the film under ambient conditions is extremely good; a decrease in conductivity of less than $15 \%$ per year has been reported ${ }^{282}$. Alkylsulfonates and phosphates have also been used as electrolyte ${ }^{283}$, while processable polymer blends have been formed using sulfonated polystyrenes as counter ions ${ }^{284}$.

Oxidation with chemical oxidizing agents (sulfuric acid $^{285}$, bromine and iodine ${ }^{286}$, copper(II) perchlorate ${ }^{287}$, iron trichloride ${ }^{288}$ ) of a neutral polypyrrole film increases the conductivity compared to that of the electrochemical oxidized material ${ }^{289}$. 2,2'-Bipyrrole has been used as monomer in the chemical oxidative polymerization, but the properties of the product are similar to the polymer prepared directly from pyrrole $e^{290}$.

Soluble polypyrroles can be prepared by the introduction of flexible side chains ${ }^{229,291-293}$. In contrast with the progress made in the synthesis of regioregular 3substituted polythiophenes, all 3-substituted polypyrroles reported so far are synthesized in a regiorandom fashion. 3-Alkyl pyrroles, the monomers in the electrochemical polymerization, have been synthesized via
Friedel-Crafts acylation of N-protected pyrrole, followed by Clemmenson reduction (Scheme 28) 294-296.

Substitution at nitrogen also affords soluble polymers. However, the conductivity is reduced drastically due to the strong steric interactions of this substituent at nitrogen and the hydrogens at the 3- and 4-positions of the adjacent pyrrole ring. Both rings are forced out of plane resulting in a loss of conjugation and a reduced conductivity ${ }^{297}$. At first sight the difference between a 3substituted polypyrrole and a $\mathrm{N}$-substituted polypyrrole is marginal with respect to steric hindrance, but the conductivities differ significantly, again illustrating how subtle structural differences influence the structureproperty relationship. Chemical oxidative polymerization has also been applied to 3-alkyl pyrroles ${ }^{285,286}$, and 3,4-dimethoxy pyrrole ${ }^{298}$.

The introduction of sulfonic acid groups in the alkyl side chain afforded water-soluble self-doped polypyrroles $^{299}$. When the sodium salt of the 3-alkylsulfonic acid pyrrole is used as monomer it also acts as an electrolyte for the electrochemical synthesis. A second long alkyl chain on the 4-position of the pyrrole ring affords a highly ordered lammellar polymer which is also soluble in chloroform ${ }^{300}$. Langmuir-Blodgett techniques have been used to improve the ordering of polypyrrole films ${ }^{301,302}$.

Structural defects like $\alpha-\beta$ couplings are inherent to the oxidative polymerization approach and are always present in the materials synthesized according to the methods described above. This failure to produce perfectly 2,5-linked polypyrroles has been overcome by using organometallic polymerization techniques. Pyrroles with a tert-butoxycarbonyl (BOC) protecting group at nitrogen have been polymerized via a Stille ${ }^{254}$ coupling, yielding a soluble non-planar precursor polymer which was deprotected by thermal treatment (Scheme 29) ${ }^{303}$.

This polypyrrole, although of relatively low molecular weight (approximately 16 pyrrole units), exhibits a perfect $\alpha, \alpha$-structure and is fully characterized.

Recently, the reductive Ullmann ${ }^{304}$ coupling of 2,5-dibromo-N-BOC-pyrrole has been reported to yield similar polymers to those described above ${ }^{305}$. Using preparative h.p.l.c. it appeared to be possible to isolate the first 20 members of the N-BOC protected oligopyrroles, which were all characterized. Similarly, a self-doped analogue of polypyrrole has been prepared using $\mathrm{N}$ butyl-3,4-pyrroledione in the Ullmann polymerization ${ }^{306}$.

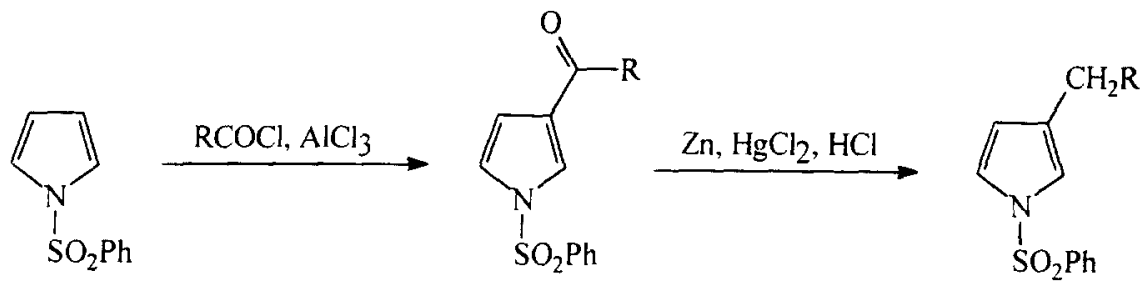

Scheme 28 Synthesis of a 3-alkyl substituted pyrrole derivative (294-296 $^{28}$

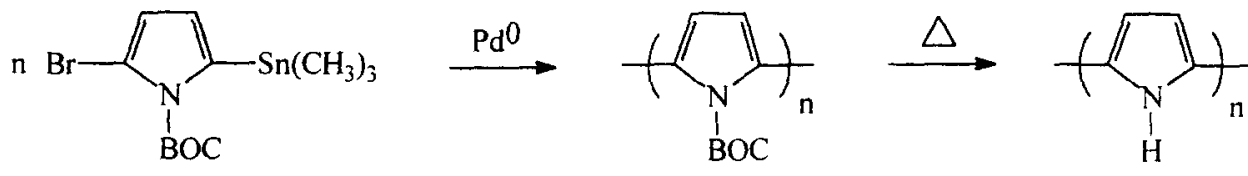

Scheme 29 Polypyrrole prepared by the Stille coupling/thermolysis sequence ${ }^{303}$ 


\section{Polyaniline}

Polyaniline (Figure 11,21 ), also known as 'aniline black', was first prepared in 1834 and has been the subject of intensive research ever since ${ }^{307}$. In the $1980 \mathrm{~s}$ the conducting properties of polyaniline were recognized and the number of papers dealing with this conducting polymer grew rapidly. The main reasons for this growth, besides the scientific interest, are the low cost of aniline, the relatively easy production process and the stability of the conducting forms.

Synthesis of polyaniline. Oxidation of aniline is the most widely employed synthetic route to polyaniline and can be performed either electrochemically or chemically. The reaction is usually carried out in acidic media. The electrochemical method was originally developed by Letheby as a test for the determination of small quantities of aniline $e^{308}$. The method has been improved ever since $^{309-311}$ and has also been applied to alkyl ${ }^{312,313}$, alkoxy $^{314}$ and dimethoxy ${ }^{315}$ substituted anilines, the latter exhibiting a conductivity comparable to that of unsubstituted polyaniline.

Chemical oxidation is usually carried out in acidic aqueous environments with an oxidizing agent such as ammonium persulfate ${ }^{316}$, but has also been performed in chloroform using tetrabutyl ammonium periodate ${ }^{317}$.

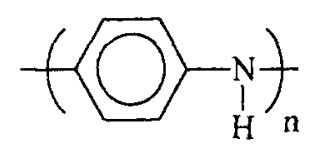

21
$\mathrm{Alkyl}^{312}$ and alkoxy ${ }^{314}$ substituted polyanilines have also been prepared utilizing this chemical method.

It has been stated that in polyaniline crosslinking occurs during the electrochemical synthesis due to the potential applied ${ }^{318}$. However, non-oxidatively synthesized polyaniline, exhibiting the same properties, has a fully linear structure ${ }^{319}$. Crosslinking in polyaniline can also be accomplished when the emeraldine base is heated up to $300^{\circ} \mathrm{C}^{320}$.

Properties of polyaniline. Polyaniline can occur in a number of well-defined different oxidation states ${ }^{320}$, each with its own name as originally attributed by Green and Woodhead (Figure 12) (21 $^{\text {. }}$.

The different states range from the fully reduced leucoemeraldine via protoemeraldine, emeraldine and nigraniline to the fully oxidized pernigraniline. Unlike in most other polyaromatics, the fully oxidized state in polyaniline is not conducting. As a matter of fact none of the above-described states are conducting. Polyaniline becomes conducting when the moderately oxidized states, in particular the emeraldine base, are protonated and charge carriers are generated. It is this process, generally called 'protonic acid doping ${ }^{312}$, which makes polyaniline so unique; no electrons have to be added to or removed from the insulating material to make it conducting. The different oxidation states of polyaniline can also be generated by doping with oxidants such as iodine, but the resulting conductivity is lower than that obtained via protonic acid doping ${ }^{314}$.

The conducting mechanism is believed to involve polaronic carriers; the protonated emeraldine consists of a delocalized poly(semiquinone radical cation) (17,322,323 $^{\text {. }}$ The conductivity is affected by the water content; completely dry samples are five times less conductive

Figure 11 Polyaniline

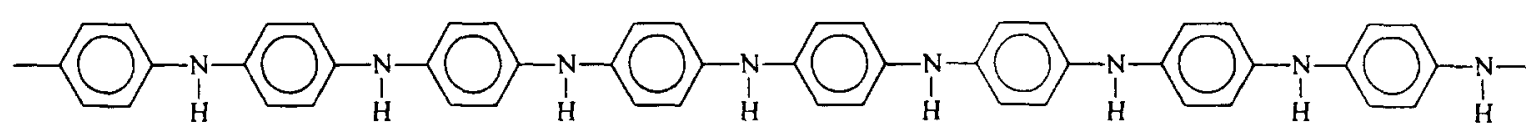

leucoemeraldine
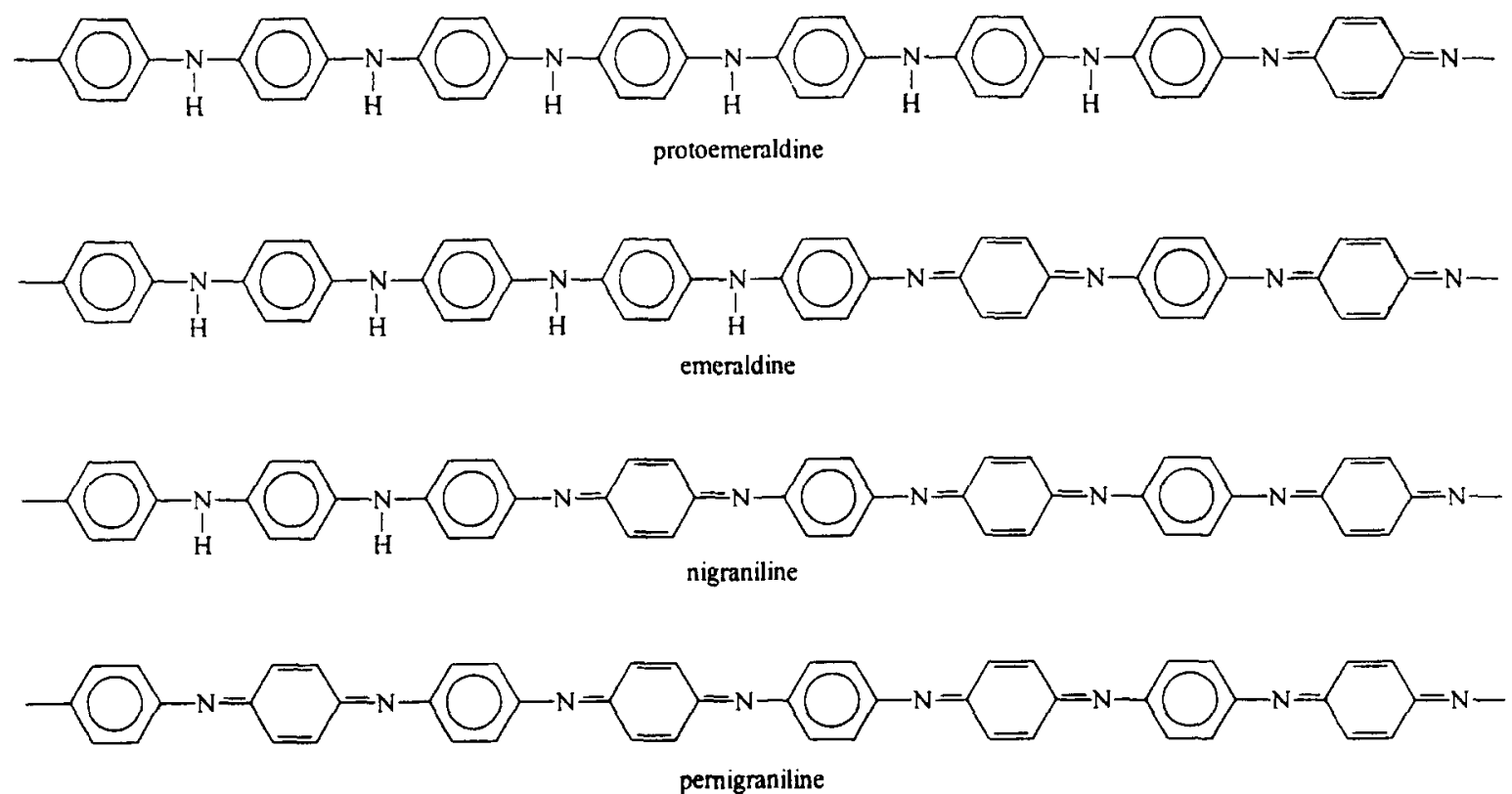

Figure 12 The different oxidation states in polyaniline ${ }^{321}$ 
than samples containing some water ${ }^{316}$. The emeraldine base is soluble in $\mathrm{N}$-methyl-pyrrolidone ${ }^{324}$, but protonated polyaniline is insoluble in organic solvents and only soluble in aqueous acids. Substitution of the aniline monomer with alkyl or alkoxy groups improves the solubility in organic solvents but has a negative influence on the conductivity ${ }^{301,325,326}$. The position of the substituent also has an influence on the polymerization. The ortho and meta isomers give the same polymer, but the reactivity of the meta isomer is considerably lower, resulting in a lower yield ${ }^{312}$. Self-doped polyaniline, containing sulfonic acid substituents, has been synthesized by sulfonation of the emeraldine base ${ }^{327}$.

A different approach to the production of soluble polyanilines is the use of $n$-alkyl sulfonic acids as proton donor. Polyaniline doped with $n$-4-dodecylphenylsulfonic acid does indeed give soluble and highly conducting materials ${ }^{328,329}$. Stable thin films of polyaniline, that can be processed out of solution, are prepared from the emeraldine base with camphorsulfonic acid as dopant. $m$-Cresol as cosolvent is essential to obtain a chiral crystalline structure ${ }^{330}$.

Although no data are available concerning the health risks of polyaniline, the possible presence of benzidine moieties, which are well-known carcinogens, suggests careful manipulation of both aniline and its polymers is advisable.

\section{Other polymers}

In the field of conducting and $\pi$-conjugated polymers most attention has been paid to the polymeric systems described above. However, a variety of other polymers containing heterocyclic rings has been synthesized and studied. In the following sections some of the most promising classes, with respect to improved materials properties, will be discussed.

Small band gap polymers. The search for small band gap polymers is a special field of research within the general area of synthetic metals. Although many participants recognize the interest and importance of this class of polymers, the number of dedicated papers is limited. In addition to their high conductivity, these systems are expected to be transparent in their conducting form, and when the band gap approaches zero, these materials are predicted to exhibit metallic properties.

In 1984 Wudl et al. ${ }^{331}$ published the synthesis of poly(isothianaphthene) (PITN) (Figure 13, 22) with a band gap of $1 \mathrm{eV}$ (for comparison: polythiophene has a band gap of $2 \mathrm{eV}$ ). Limited synthetic work has been performed on these kinds of system ever since, but recently the syntheses of a substituted PITN and of poly(2,3dihexylthieno[3,4-b]pyrazine (23) were published ${ }^{332}$.

The small band gap is believed to arise from the relatively large contribution of the quinoid structure in the polymers ${ }^{333}$. Calculations predict that a copolymer of thiophene and isonaphthothiophene will exhibit a band gap of $0.5 \mathrm{eV}^{334}$.

Polycyclopenta[2,1- $\left.b ; 3,4-b^{\prime}\right]$ dithiophen-4-one (24) has a band gap of $1.2 \mathrm{eV}$ due to its reduced aromatic character ${ }^{335}$. The introduction of one fused thiadiazole unit in a terthiophene molecule resulted in a polymer with a band gap of $0.9 \mathrm{eV}$, arising to some extent from the nitrogen-sulfur interactions improving the intrachain charge mobility ${ }^{336}$. The synthesis of a polymer with a band gap as low as $0.5 \mathrm{eV}$ based on the idea of bringing together positive and negative charges was published by Havinga et al..$^{337}$, using polysquarenes (25) and polycroconanes $(\mathbf{2 6})$ which were synthesized by using a condensation polymerization. Furthermore, Jenekhe ${ }^{338-341}$ has suggested that the introduction of methine groups between thiophene moieties would provide polymers with band gaps as low as $0.75 \mathrm{eV}$; however, the validity of this approach has been questioned ${ }^{342}$.

None of the small band gap materials reported so far has conductivities surpassing the conventional polymers like doped polythiophene, polypyrrole and polyaniline, an observation which puts the supposed importance of the band gap in perspective ${ }^{343}$.

Fused monomers. Fused heterocyclic compounds like thieno[3,2-b]pyrrole ${ }^{344}$ (Figure 14, 27), thieno[3,2-b] thio-

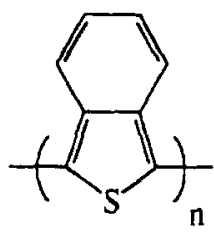

22<smiles>CC1(C)C(=O)C(=Nc2ccc(N3CC3)cc2)C1[O]</smiles>

25

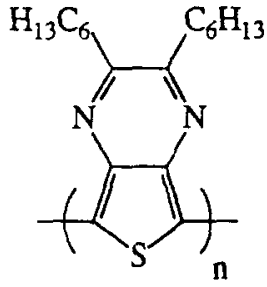

23

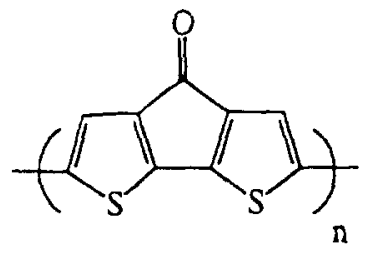

24<smiles>[R]N1C(=CC2=C(O)C(=CC)C(=O)C2=O)C(C)(C)c2cc3c(cc21)C(C)(C)C(C)N3[R]</smiles>

Figure 13 Some examples of small band gap polymers 
phene ${ }^{345}$ (28) and dithieno $\left[3,2-b ; 2^{\prime}, 3^{\prime}-d\right]$ thiophene ${ }^{346}(29)$ have been polymerized electrochemically. Other nitrogen containing polymers such as poly(quinoxaline-5,8-diyl) ${ }^{347}$ (30), poly(quinoline-5,8-diyl) (31) and poly(isoquinoline$1,4$-diyl) $)^{348}$ (32) have been synthesized by the condensation polymerization of the dibromo compounds under the influence of a zerovalent nickel catalyst.

A completely fused ladder polymer with a quinoline moiety was synthesized by cyclization of the amine and ketone functionalities of a polyphenylene backbone ${ }^{349}$, yielding a polymer with a high degree of coplanarity.

A special kind of fused polyaromatic is polyphenylene sulfide. The polymer has been synthesized by a number of methods including electrochemically from thiophenol ${ }^{350}$, oxidatively from phenylene disulfide ${ }^{351}$ and chemically from 4,4'-dibromo-phenylene disulfide with copper ${ }^{352}$. The aromatic rings of polyphenylene sulfide are coupled upon oxidation with arsenic(V) pentafluoride in arsenic(III) trifluoride leading to fused benzothiophene moeities ${ }^{353}$. Conductivities upto $200 \mathrm{~S} \mathrm{~m}^{-1}$ have been reported.

Finally, some results from studies on fused conjugated polymers based on dyes have been published ${ }^{354,355}$; these materials are claimed to be intrinsically conducting.

Other homopolymers. Polypyridine has been synthesized through the homocoupling of 2,5-dibromopyridine ${ }^{356}$ or $5,5^{\prime}$-dibromo-2,2' $2^{\prime}$-bipyridine ${ }^{357}$ with zerovalent nickel catalysts (Scheme 30 ).
The polymers are only soluble in formic acid as is also the case in methyl substituted polypyridine ${ }^{358}$. However, the introduction of hexyl groups induces solubility in other organic solvents ${ }^{359}$. Recently, the peculiar properties of these polypyridines have been attributed to selfassembly $^{360}$. Poly(pyrimidine-2,5-diyl) ${ }^{361}$ has been prepared utilizing the same method. Other examples of heterocyclic homopolymers are polypyridazine ${ }^{362}$ and polythiazole ${ }^{363}$.

\section{Copolymers}

The synthesis of alternating benzenoid-heteroaryl copolymers enables, in principle, the combination of the properties of different homopolymers into one material, increasing the scope of synthesis and applications. The synthesis of these copolymers has, however, received relatively little attention. This will probably change with the increasing interest in small band gap polymers. The idea of using copolymers to introduce alternating structures of electron-rich and electron-poor moieties has emerged. Three synthetic routes have been developed to make copolymers: (a) the direct polymerization of the different aromatics by either oxidative or chemical coupling methods; (b) ring closure of precursor polymers; and (c) polymerization of oligomers which already contain the desired array of units. The different strategies are outlined in the sections below.

Direct polymerization. Oxidative copolymerization<smiles>c1cc2sccc2[nH]1</smiles>

27<smiles>CC(C)(C)c1ccc(C(F)(F)F)c2nccnc12</smiles>

30<smiles>c1cc2sccc2s1</smiles>

28<smiles>c1cc2sc3ccsc3c2s1</smiles>

29<smiles>CC(C)(C)c1cnc(C(C)(C)C)c2ccccc12</smiles>

31

Figure 14 Fused monomers and fused polymers

n<smiles>Fc1ccc(Br)cn1</smiles><smiles>CCO[N+]#N</smiles><smiles>CC1C=CC(C)(C)CN1C(C)(C)C</smiles><smiles>Brc1ccc(-c2ccc(Br)cn2)nc1</smiles><smiles>CC(C)(C)c1ccc(-c2ccc(C(C)(C)C)cn2)nc1</smiles>

Scheme 30 Nickel catalysed polymerization of pyridine derivatives 356,357 
requires monomers having similar oxidation potentials, otherwise the material obtained is more likely to have a block rather than the required alternating structure. This places limits on the oxidative approach but it has, nevertheless, been used for a pyrrolethiophene copolymer, prepared by the electrochemical polymerization of pyrrole and $\alpha$-terthiophene ${ }^{364}$, monomers having oxidation potentials of $1.2 \mathrm{~V}$ and $1.05 \mathrm{~V}$, respectively.

The chemical route to alternating polymers is much more general; the reaction of bis-metallated and dihaloaromatic species of which either one can contain the heterocyclic ring, yields a completely alternating copolymer when palladium or nickel catalysts are used. Thus, heterocycles such as thiophene, selenophene and pyridine have been coupled with benzene and biphenyl using magnesium and a nickel catalyst ${ }^{365,366}$. Thiophene and furan have been coupled with benzene and substituted benzenes utilizing zinc and palladium catalysts $\mathrm{s}^{367,368}$ while alkoxy-substituted benzenes and thiophenes have been transformed into an alternating copolymer via the Stille coupling ${ }^{369}$. The Suzuki coupling ${ }^{370}$ (arylhalide and boronic acid derivative) has been used in the coupling of alkyl-substituted benzenes with N-BOC protected pyrroles $^{371}$ (Scheme 31).

When zerovalent nickel is used as a catalyst in the copolymerization of thiophene with benzene or pyridine $^{372}$, materials with a random structure are formed due to the absence of organometallic monomers in this type of polymerization 373,374 . Reaction of dibromothiophenes and $p$-phenylene diamines under 'Ullmann conditions' yields copolymers of aniline and thiophene $e^{375}$.

A final example of copolymers prepared by the direct polymerization route are the random head-to-tail poly (3- alkylthiophene) copolymers prepared by McCullough et al. using two different monomers (Scheme 32$)^{376}$.

Precursor route. Thiophenes and pyrroles can be synthesized by the ring closure of diacetylenes with hydrogen sulfide $\mathrm{e}^{377}$ and primary amines ${ }^{378}$, respectively, or from 1,4-diketones with Lawesson's reagent ${ }^{379}$, primary amines 380 and ammonium acetate ${ }^{381,382}$, respectively (Scheme 33).

An alternating copolymer of phenylene and diacetylene or 1,4-diketone moieties offers the possibility of the synthesis of an alternating copolymer consisting of phenylene and thiophene or pyrrole rings. Thus 1,4diethynylbenzene was oxidatively coupled to give the phenylene diacetylene copolymer, containing approximately $10 \%$ of the undesired meta isomer. Upon ring closure with hydrogen sulfide and aniline the phenylene thiophene and the phenylene $\mathrm{N}$-phenyl pyrrole polymers were obtained ${ }^{383}$.

The reaction of terephthaldehyde and the bis-Mannich base of 1,4-diacetyl benzene with sodium cyanide as catalyst (Stetter reaction ${ }^{384}$ ) yielded polyphenylene-1,4butanedione; the alternating phenylene 1,4-diketone polymer. Ring closure with Lawesson's reagent (LR) or ammonia yielded the phenylene thiophene and phenylene pyrrole copolymers in good yield (Scheme 34$)^{385}$.

Oligomer polymerization. In order to avoid the formation of block copolymers by the oxidative polymerization of different monomers, it is possible to use oligomers containing the desired sequence of units which can then be oxidatively polymerized. In this way a copolymer of thiophene and pyrrole has been prepared by the electrochemical polymerization of $2,2^{\prime}$-thienylpyrrole ${ }^{386}$. Similarly, a number of trimers containing thiophene,<smiles>CCc1cc(Br)c([18OH])cc1[18OH]</smiles><smiles>Cn1c(Br)ccc1Br</smiles>

$\mathrm{m}=1,3$
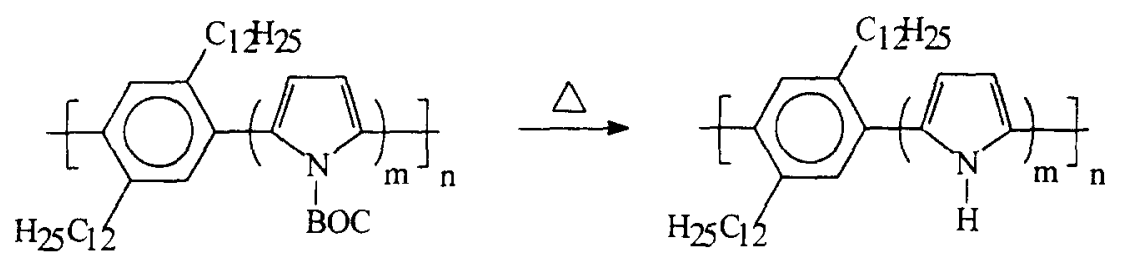

Scheme 31 Synthesis of a soluble pyrrole-benzene copolymer by Suzuki coupling/thermolysis ${ }^{371}$

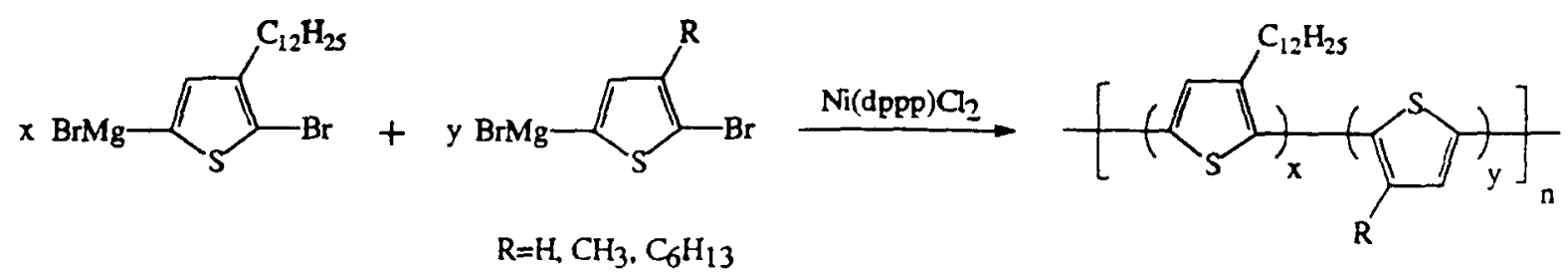

Scheme 32 Synthesis of a random head-to-tail poly(3-alkylthiophene) copolymer ${ }^{376}$ 
a)<smiles>C(C#Cc1cccs1)#Cc1cccs1</smiles>

b)

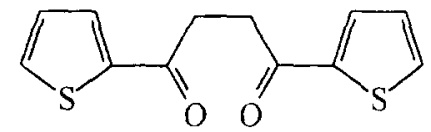

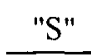<smiles>c1csc(-c2ccc(-c3cccs3)s2)c1</smiles><smiles>CC(C)(C)C1CC1</smiles><smiles>C1C2CC1C2</smiles><smiles>[R]n1c(-c2cccs2)ccc1-c1cccs1</smiles>

Scheme 33 Ring closure reaction to thiophene and pyrrole derivatives<smiles>O=Cc1ccc(C=O)cc1</smiles><smiles>CN(C)CCC(=O)c1ccc(C(=O)CCN(C)C)cc1</smiles><smiles>[W]#[W]</smiles>
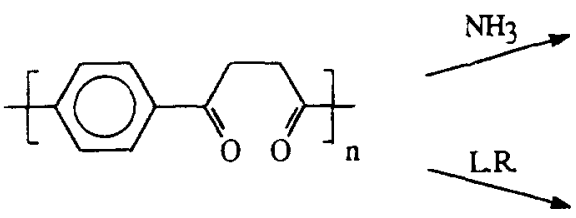<smiles></smiles>

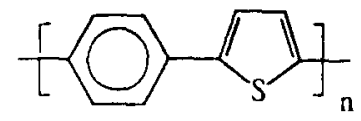

Scheme 34 Copolymers via Stetter/ring closure route ${ }^{385}$

n<smiles>Brc1cccc(-c2ccc(Br)s2)n1</smiles>

Scheme 35 Organometallic coupling of a thienylpyridine monomer ${ }^{394}$

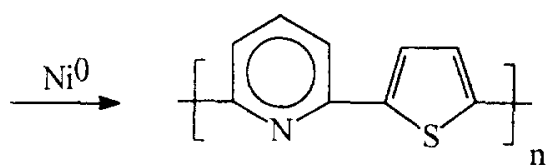

furan and $\mathrm{N}$-alkyl-pyrrole moieties have been oxidatively polymerized with $\mathrm{NOPF}_{6}$ yielding the expected copolymers $^{387-389}$

An alternating copolymer of benzene and bithiophene units has been synthesized by the polymerization of 1,4 dithienyl benzenes either electrochemically ${ }^{390}$ or oxidatively with iron(III) trichloride ${ }^{391}$. Introduction of two alkyl or alkoxy substituents on the phenyl ring afforded regular and soluble polymers ${ }^{392}$.

Two final examples are a polymer prepared by chemically oxidation of 1,4-dipyrrolylbenzene ${ }^{393}$, and one containing thiophene and pyridine units which was prepared from the dibromide using zerovalent nickel (Scheme 35) ${ }^{394}$

\section{OLIGOMERS}

During the last few years there has been a growing interest in the synthesis and characteristics of welldefined oligomeric conjugated structures. There are a number of reasons for this interest, including the ability of such oligomers to serve as model compounds for the different polymers with respect to the synthesis, spectroscopic analysis and physical properties as well as their potential applications ${ }^{395,396}$. Recently Garnier et al. reported on the first all-organic transistor using the unique properties of a self-assembled layer of a substituted sexithiophene ${ }^{397}$. The high electron mobility observed in this oligomer, almost comparable to amorphous silicon, is of critical importance to the construction of this prototype device. Although the class of oligothiophenes has received by far the most attention of all $\pi$-conjugated oligomers, other classes of oligomers, as oligopyrroles and oligoanilines, will also be discussed in the next sections.

\section{Oligothiophenes}

Well-defined oligomers of thiophene have been isolated from Marigolds ${ }^{398}$ and have been synthesized by different routes including the cross-coupling reaction of a dihalocompound with organometallics of magnesium, 
zinc or tin with a palladium or nickel catalyst (including the Kumada coupling ${ }^{399}$ to regioregular oligothiophenes, Scheme 36$)^{400-406}$, the copper(II) chloride oxidation of a lithiated thiophene $407-409$ and the ring closure reaction of a 1,4-diketone with Lawesson's reagent ${ }^{410-412}$.

The conformational analysis of oligothiophenes has been studied in detail. The structures of oligothiophenes containing two ${ }^{413}$, three ${ }^{414}$ and four 415,416 thiophene rings have been resolved by $\mathrm{X}$-ray analysis; all the compounds exhibit an all-trans conformation and are nearly coplanar. However, u.v. and n.m.r. analysis, together with calculations, have shown that in solution unsubstituted tetrathiophene exhibits a planar cistrans-cis conformation. The introduction of methyl substituents induces an equilibrium between planar cis and twisted trans-conformations and when the substituents are head-to-head the twisted trans-conformation is favoured, resulting in a considerable loss of conjugation 406,417 .

The use of oligomers containing more than six thiophene rings is restricted to substituted compounds due to the insolubility of the unsubstituted oligomers. Most of the oligomers differ from the substituted polythiophenes in their substitution pattern; they do not contain one substituent on every ring as is the case in most soluble polythiophenes.
Upon oxidation some of the shorter oligomers, containing up to six thiophene rings, were found to polymerize 418 , so the reported high conductivities of these oligomers are probably due to polymeric material 419 . Oligomers containing more than six thiophene rings do not polymerize, while it has been found that oligomers containing 11 or 12 thiophene rings exhibit conductivities of $5-20 \mathrm{~S} \mathrm{~cm}^{-1}$, being in the same range as that of polythiophene ${ }^{397,408}$.

Optical measurements show absorption maxima exceeding that of polythiophene ${ }^{394,408,420}$, but this is mainly due to a decrease of steric hindrance in the oligomers having less substituents. Extrapolation of these values results in a $\lambda_{\max }$ for polythiophene of about $540 \mathrm{~nm}^{397,410}$, implying that the perfect polythiophene has not yet been synthesized.

A number of oligothiophenes has been employed to investigate the nature of the different oxidation states in polythiophene. Oxidation of oligothiophenes proceeds in two steps. First a radical cation is obtained (the analogue of the polaron state in conjugated polymers), which exhibits a strong e.s.r. signal. Some authors have reported the dimerization of these radical cations to diamagnetic $\pi$-dimers ${ }^{421-425}$. In the second step of the oxidation the radical cation is converted into the dication (the bipolaron analogue). It has been reported that the oligomers must consist of at least six thiophene rings to

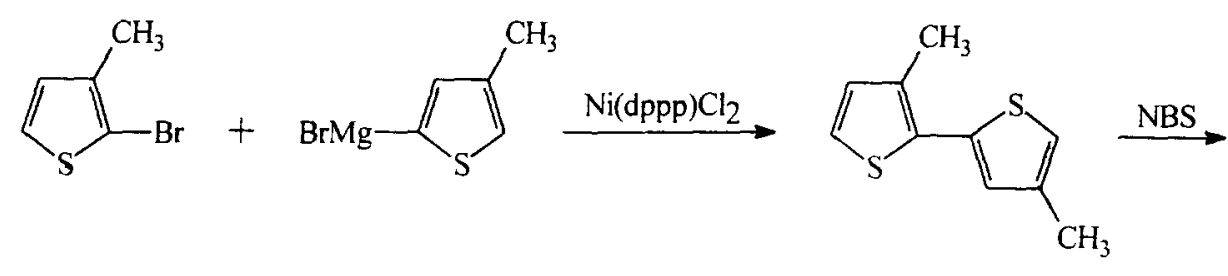<smiles>Cc1cc(-c2sccc2C)sc1Br</smiles>

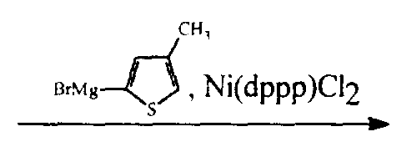<smiles>Cc1csc(-c2sc(-c3sccc3C)cc2C)c1</smiles>

Scheme 36 Kumada coupling to regioregular oligothiophenes ${ }^{406}$

a)

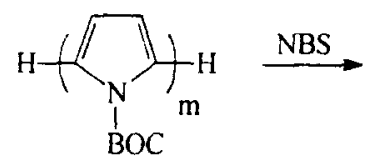

$m=1,3,5,7$<smiles>CC(=O)OC(=O)c1ccc(Br)n1C</smiles>

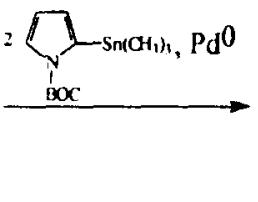

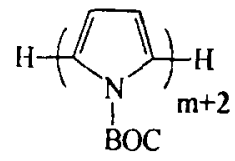

$\mathrm{BOC}$

b)<smiles>CCSc1ccc(-c2ccccc2)n1C(=O)OCc1ccccc1</smiles>

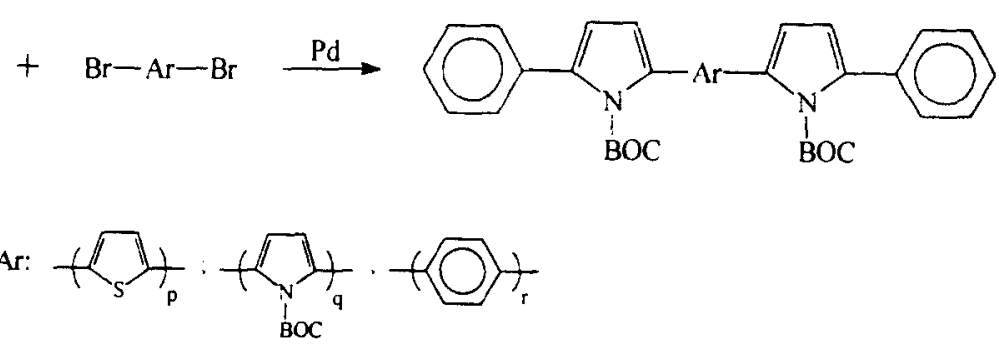

Scheme 37 Oligopyrroles by the Stille coupling reaction: (a) oligo(pyrrole-2,5-diyl)s; (b) phenyl blocked mixed oligomers based on pyrrole ${ }^{433-437}$ 
$\mathrm{n}$<smiles>CC(=O)OC(=O)n1c(Br)ccc1Br</smiles>

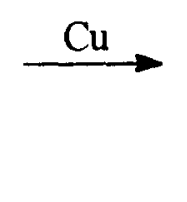

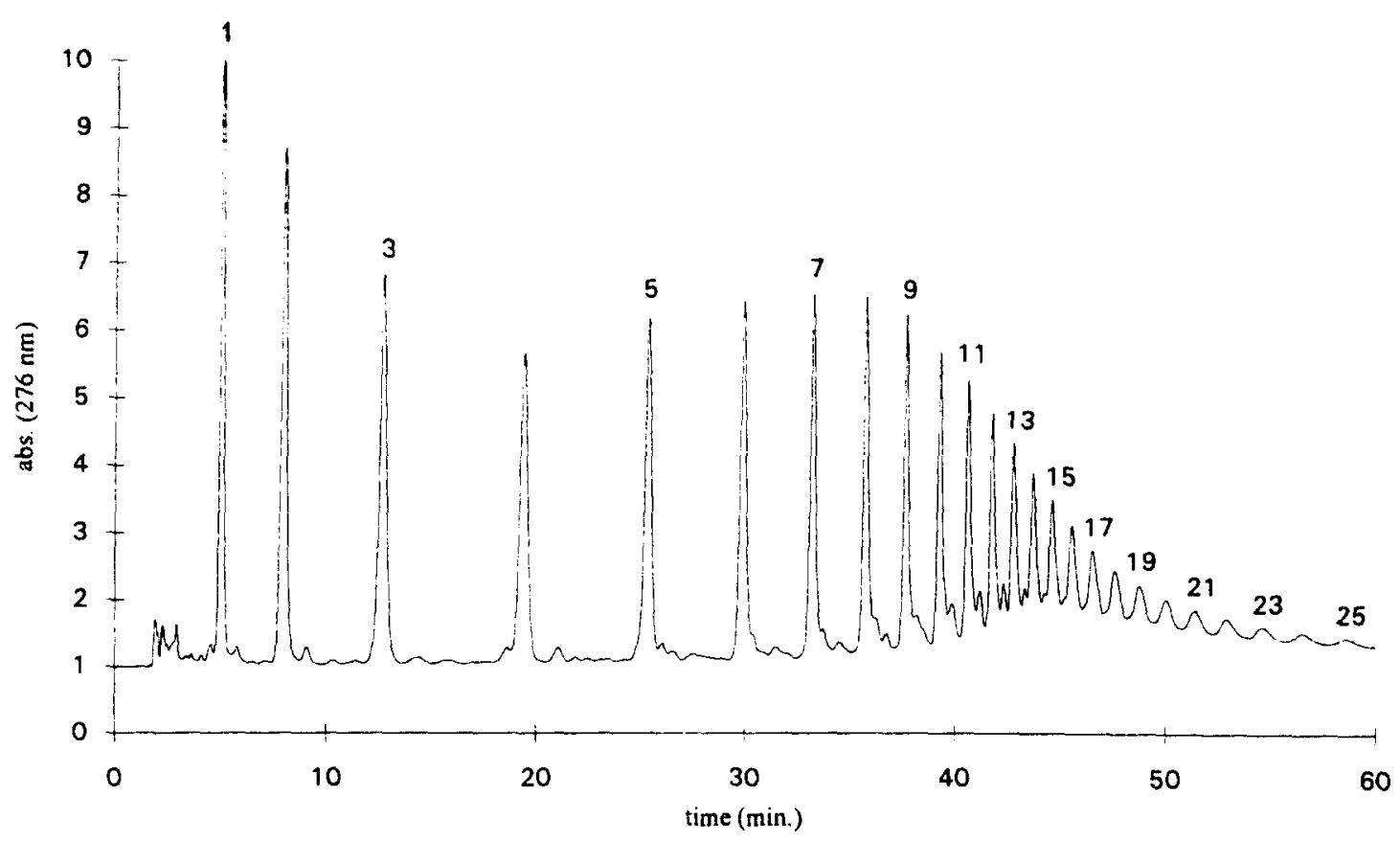

Scheme 38 H.p.l.c. analysis of the Ullmann polymerization of a dibrominated pyrrole monomer ${ }^{305}$

undergo the second oxidation $\operatorname{step}^{426}$, but this claim is at variance with other results ${ }^{427}$.

Langmuir-Blodgett films of oligothiophenes and in particular $2,2^{\prime}, 5^{\prime}, 2^{\prime \prime}$-terthiophenes derivatives exhibit large dielectric constants and high conductivities with or even without additional dopants ${ }^{428}$. Oligothiophenes also display other characteristics that have been found in polythiophenes, such as thermochromism and hyperpolarizability ${ }^{429-431}$.

\section{Oligopyrroles}

In sharp contrast to the oligothiophene series, relatively little work has been performed on the synthesis and characterization of oligopyrroles. This is mainly due to the complexity of these compounds. There are three main routes which result in oligomeric pyrrole systems. The first one consists of the oxidative coupling of $\alpha$-lithiated $\mathrm{N}$-methyl substituted oligopyrroles using $\mathrm{NiCl}_{2}$ resulting in $\mathrm{N}$-methyl substituted oligomers up to 16 pyrrole units ${ }^{432}$. The second route makes use of the previously described Stille coupling ${ }^{254}$. By performing a $\mathrm{Pd}^{0}$ catalysed cross-coupling reaction between an arylhalide and an arylstannyl derivative, both homo and co-oligomers based on pyrrole can be prepared ${ }^{303,433-437}$ (Scheme 37).

The crystal structures of the dimer $(m=0)$, trimer $(m=1)$ and pentamer $(m=3)$ of this oligopyrrole series have been resolved and clearly display coplanar structures for the unprotected oligomers and a 70 degree twist angle for the N-BOC-protected analogues ${ }^{438,439}$. The unprotected oligomers have also been investigated by $F T$-i.r. and Raman spectroscopy, cyclic voltammetry and u.v.-vis-n.i.r. spectroscopy $437,440-442$.

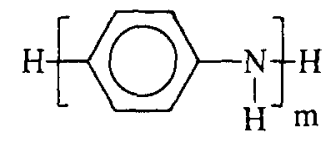

$$
\mathrm{m}=3,4
$$

Figure 15 Yoffe's trimer and tetramer as prepared by the oxidative coupling/reduction sequence ${ }^{443}$

The Ullmann polymerization of 2,5-dibromo-N-BOCpyrrole has been used to produce a mixture of oligomers up to 25 repeating pyrrole units ${ }^{305}$ (Scheme 38). Subsequent preparative h.p.l.c. separation yielded oligomers up to 20 repeating units which were all characterized by u.v. and n.m.r. spectroscopy. Upon doping $\left(I_{2}\right)$ of the deprotected pentamer, a black material with a conductivity of $100 \mathrm{~S} \mathrm{~cm}^{-1}$ was obtained.

\section{Oligoanilines}

Just like on oligopyrroles, little research has been performed on oligoanilines. However, some contributions are worth mentioning. The first members of the oligoaniline series were prepared by Yoffe et al. who, starting from $p$-aminodiphenylamine, were able to isolate tri-(Figure 15, $m=3)$ and tetraaniline $(m=4)$ by an oxidative coupling/reduction sequence ${ }^{443}$.

About twenty years later Honzl et al. synthesized a series of phenyl-blocked oligoanilines ${ }^{444}$. The dimer and trimer were prepared by a Sandmeyer type of elimination of the amino groups of Yoffe's tri-and tetraaniline while 

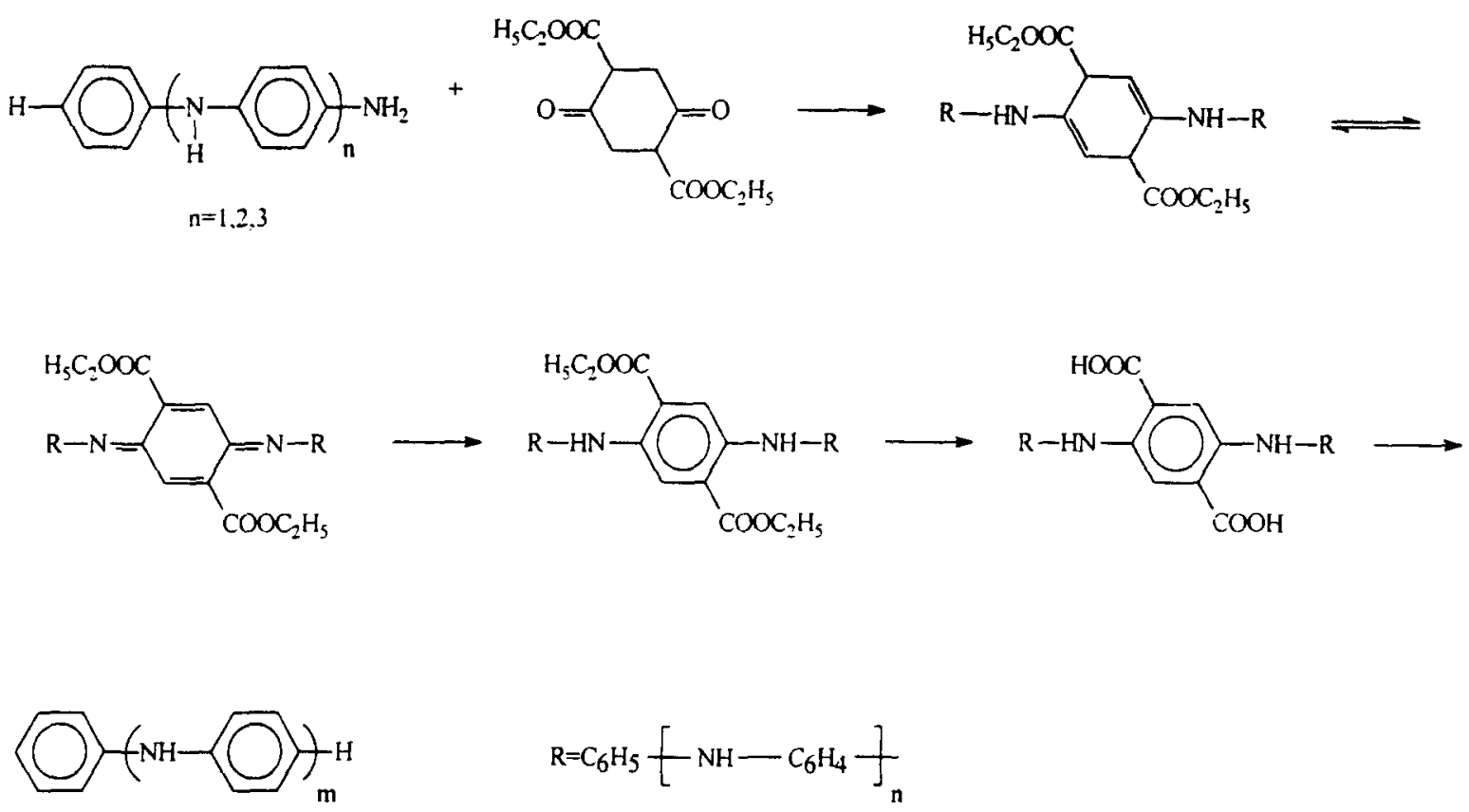

$\mathrm{R}=\mathrm{C}_{6} \mathrm{H}_{5}\left[\mathrm{NH}-\mathrm{C}_{6} \mathrm{H}_{4}\right]_{\mathrm{n}}$

$\mathrm{m}=4,6$

Scheme 39 Honzl's route to phenyl-blocked oligoanilines ${ }^{444}$

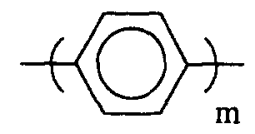

32

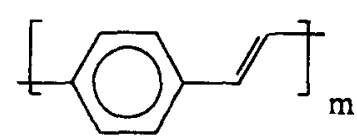

33
Figure 16 Oligophenylenes and oligo(phenylene vinylene)s

the tetramer and hexamer were prepared by modifying Liebermann's ${ }^{45}$ method of preparing derivatives of 2,5diaminoterephthalic acid (Scheme 39).

Although this method appeared not to be successful for the preparation of the octamer $(m=8)$, Wudl et al. were able to isolate this oligomer by coupling two equivalent of Yoffe's tetramer with one equivalent of dihydroxydihydroterephthalic acid and subsequent reduction with phenylhydrazine ${ }^{446}$. From physical characterization it appeared that the different oxidation states of this octamer fully represent those of polyaniline.

The last series of oligoanilines worth mentioning were prepared by Strohriegl et al. ${ }^{447}$. Starting from diphenylamine and $N, N^{\prime}$-diphenyl-1,4-phenylenediamine, they managed to prepare the $\mathrm{N}$-phenyl substituted and phenyl blocked dimer, trimer and tetramer using $n-\mathrm{BuLi}$, iodobenzene and 1,4-diiodobenzene in combination with $\mathrm{CuI}$ as catalyst.

\section{Other oligomers}

Unsubstituted phenylene oligomers (Figure 16, 32) have been prepared and their conducting behaviour has been studied as a function of chain length and structural order after oxidation with potassium ${ }^{448}$. From some of these oligomers the crystal structures have also been resolved $^{449}$. Substituted phenylene oligomers have been doped and the formation of radical anions and dianions have been studied by optical measurements; this work highlights the influence of substituents on the aromatic backbone ${ }^{450}$.
All-trans $\beta$-carotene has been studied as a model polyene $^{451}$. Oligomers containing two to four double bonds have been reduced and the different states were studied with e.s.r. (radical anions) and n.m.r. (dianions) $^{452}$.

Substituted phenylene vinylene oligomers (33) have been synthesized by a sequence of Wittig reactions ${ }^{453}$ and their radical anions and dianions studied by optical methods ${ }^{454}$. Recently, these oligomers have attracted considerable interest due to the electroluminescent properties of the parent polymer.

\section{CONCLUSIONS}

In the different sections above, we have presented a review on the wide range of conjugated polymers and oligomers. We have attempted to highlight the considerable advances in chemistry and materials science which have taken place in recent years, but within the framework of a historical perspective. The synthetic routes now available for most of the important polymers are well-established and yield materials with full control over molecular weight, polydispersity and regioselectivity. This high degree of perfection at the molecular level allows material scientists to study the ultimate properties of conjugated polymers using advanced physical characterization techniques and prototype devices. Furthermore, self-assembly of polymers, oriented samples and well-defined oligomers are present to investigate the structure-property relationship in detail. It should be stressed that many of the earlier studies have been performed with materials that, by the standards of today, are ill-defined and the results are not indicative for the ultimate properties of the materials under investigation. There are still some polymeric materials, e.g. polypyrrole, and functionalized PPVs, that need further systematic studies before they can be reliably and reproducibly prepared. Hopefully, we have managed to demonstrate that if the synthetic developments progress at the same 
rate, it will not be long before the vast array of potential practical applications associated with these materials begin to materialize. It is expected that in the next few years we will have full control over most of the important molecular parameters and that chemists are able to study the mesoscopic ordering of the well-defined conjugated polymers; the next hierarchy in the development of advanced materials.

\section{REFERENCES}

1 Patil, A. O., Heeger, A. J. and Wudl, F. Chem. Rev. 1988, 88, 183

2 Kajzar, F., Etemad, Baker, G. L. and Massier, J. Synth. Met. 1987, 17, 563

3 Chemla, D. S. in Nonlinear Optical Properties of Organic Materials and Crystals' (Ed. J. Zyss), Academic, Orlando, FL, 1987, Vols 1 and 2

4 Marder, S. R. and Sohn, J. E. in 'Materials for Nonlinear Optics: Chemical Perspectives' (Ed. D. G. Stucky), ACS Symposium Series 455. American Chemical Society, Washington, DC, 1991

5 Skotheim, T. A. (Ed.) 'Handbook of Conducting Polymers' Marcel Dekker, New York, 1986, Vols 1 and 2

6 Gorman, C. B. and Grubbs, R. H. in 'Conjugated Polymers: The Novel Science and Technology of Conducting and Nonlinear Optically Active Materials' (Eds J. L. Bredas and R. Silbey), Kluwer Academic Publishers, Dordrecht, The Netherlands, 1992, pp. 1-48

7 Brandstetter, F. Eur. Chem News Speciality Chemical Suppl. 1988, Jan., 32

8 Sailor, M. J., Ginsburg, E. J., Gorman, C. B., Kumar, A., Grubbs, R. H. and Lewis, N. S. Science 1990, 249, 1146

9 Buroughes, J. H., Bradley, D. D. C., Brown, A. R., Marks, R. N. MacKay, K., Friend, R. H., Burn, P. L. and Holmes, A. B. Nature (London) 1990, 347, 539

10 Bradley, D. D. C. Synth. Met. 1993, 54, 401

11 Naarmann, H. Angew. Makromol. Chem. 1982, 109-110, 295

12 Natta, G., Mazzanti, G. and Corraddini, P. Atti Accad. Naz. Lincei Rend. Cl. Sci. Fis., Mat. Natur. 1958, 25, 3

13 Shirakawa, H. and Ikeda, S. Polym. J. 1971, 2, 231

14 Ito, T., Shirakawa, H. and Ikeda, S. J. Polym. Sci., Polym. Chem. Ed. 1974, 12, 11

15 Shirakawa, H., Lewis, E. J., MacDiarmid, A. G., Chiang, C. K and Heeger, A. J. J. Chem. Soc., Chem. Commun. 1977, 578

16 Chiang, C. K., Fincher, C. R., Park, Y. W., Heeger, A. J., Shirakawa, H., Lewis, E. J., Gau, S. C. and MacDiarmid, A. G. Phys. Rev. Lett. 1977, 39, 1098

17 Luttinger, L. B. Chem. Ind. (London) 1960, 1135

18 Luttinger, L. B. J. Org. Chem. 1962, 27, 1591

19 Edwards, J. H. and Feast, W. J. Polymer 1980, 21, 595

20 Shirakawa, H. and Ikeda, S. Synth. Met. 1980, 1, 175

21 Abadie, M. J. M. and Boukli-Hacene, S. M. Eur. Polym. J. 1988, 24, 319

22 Abadie, M. J. M. and Boukli-Hacene, S. M. Eur. Polym. J. 1988, 24, 251

23 Whek, G. E., Chien, J. C. W., Karasz, F. E., Druy, M. A., Park, Y. W., MacDiarmid, A. G. and Heeger, A. J. J. Polym. Sci. Polym. Lett. Ed. 1979, 17, 779

24 Aldissi, M. and Schue, F. Macromolecules 1984, 17, 1633

25 Shelburne, J. A. and Baker, G. L. Macromolecules 1987, 20, 1212

26 Baker, G. L., Shelburne, J. A. and Bates, F. S. J. Am. Chem. Soc. 1986, 108, 7377

27 Haberkorn, H., Heckman, W., Kohler, G., Naarmann, H., Schlag, J., Simak, P., Theophilou, N. and Voelkel, R. Eur. Polym. J. 1988, 24, 497

28 Naarmann, H. and Theophilou, N. Synth. Met. 1987, 22, 1

29 Tsukamoto, J., Takahashi, A. and Kawasaki, K. Japan J. Appl. Phys. 1990, 29, 125

30 Tsukamoto, J. Adv. Phys. 1992, 41, 509

31 Enkelmann, V., Muller, W. and Wegner, G. Synth. Met. 1980, 1, 185

32 Enkelmann, V., Lieser, G., Muller, W. and Wegner, G. Angew. Makromol. Chem. 1981, 94, 105

33 Frohner, J. and Wuckel, L. Acta. Polym. 1987, 38, 334

34 Boweley, H. J., Gerrard, D. L. and Maddams, W. F. Makromol. Chem. 1985, 186, 715
Bott, D. C., Chai, C. K., Edwards, J. H., Feast, W. J., Friend R. H. and Horton, M. E. J. Phys. Colloq. (Paris) 1983, 44, C3, 143

37 Edwards, J. H., Feast, W. J. and Bott, D. C. Polymer 1984, 25, 395

38 Foot, P. J. S., Calvert, P. D., Billingham, N. C. and Brown, C. S. Polymer 1986, 27, 448

39 Bott, D. C., Brown, C. S., Chai, C. K., Walker, N. S., Feast, W. J., Foot, P. J. S., Calvert, P. D., Billingham, N. C. and Friend, R. H. Synth. Met. 1986, 14, 245

40 Feast, W. J. and Winter, J. N. J. Chem. Soc., Chem. Commun. 1985,202

41 Knoll, K. and Schrock, R. R. J. Am. Chem. Soc. 1989, 111, 7989

42 Widawski, G., Feast, W. J. and Dounis, P. J. Mater. Chem. 1995, 5, 1847

43 Swager, T. M., Dougherty, D. A. and Grubbs, R. H. J. Am Chem. Soc. 1988, 110, 2973

44 Masuda, T. and Higashimura, T. Adv. Polym. Sci. 1986, 81, 121 45 Masuda, T. and Higashimura, T. Acc. Chem. Res. 1984, 17, 51

46 Gibson, H. W. in 'Handbook of Conducting Polymers' (Ed. T. Skotheim), Vol. 1, Marcel Dekker, New York, 1986, pp. 405439

47 Leclerc, M. and Prud'homme, R. E. Macromolecules 1987, 20, 2153

48 Bredas, J. L. and Heeger, A. J. Macromolecules 1990, 23, 1150

49 Gorman, C. B., Ginsburg, E. J. and Grubbs, R. H. J. Am. Chem. Soc. $1993,115,1397$

50 Baeyer, A. and Landberg, L. Ber. Deutsch. Chem. Ges. 1882, 15 , 57

51 Wegner, G. Z. Naturforsch. 1969, 24b, 824

52 Bloor, D. in 'Developments in Crystalline Polymers' (Ed. D. C. Bassett), Appl. Sci., London, 1982, p. 185

53 Enkelmann, V. Adv. Polym. Sci. 1984, 63,91

54 Patel, G. N., Duesler, E. N., Curtin, D. Y. and Paul, I. C. J. Am. Chem. Soc. 1980, 102, 461

55 Enkelmann, V., Wenz, G., Muller, M. A., Schmidt, M. and Wegner, G. Mol. Cryst. Liq. Cryst. 1984, 105, 329

56 Sixl, H. and Gross, H. Mol. Cryst. Liq. Crvst. 1983, 93, 261

57 Sixl, H. and Neumann, W. Mol. Cryst. Liq. Cryst. 1984, 105, 41

58 Sixl, H. Adv. Polym. Sci. 1984, 63, 49

59 Kuzmany, H., Mehring, M. and Roth, S. 'Electronic Properties of Polymers and Related Compounds', Springer Verlag, New York, 1985, p. 240

60 McGhie, A. R., Kalyanaraman, P. S. and Garito, A. F. J. Polym. Sci. Polym. Lett. Ed. 1978, 16, 335

61 Wunderlich, B. 'Makromolecular Physics', Academic Press, New York, Vol, 2, 1971

62 Bloor, D., Korski, L., Stevens, G. C., Preston, F. H. and Ando, J. D. J. Mater. Sci. $1975,10,1678$

63 Baughman, R. E. J. Chem. Phys. 1978, 68, 3110

64 Chance, R. R. and Patel, G. N. J. Polym. Sci., Polym. Phys. Ed. 1978, 16, 859

65 Chance, R. R. and Sowa, G. M. J. Am. Chem. Soc. 1977, 99, 6703

66 Enkelmann, V., Leyrer, R. J. and Wegner, G. Makromol. Chem. $1979,180,1787$

67 Mondong, R. and Bassler, H. Chem. Phys. Lett. 1951, 78, 371

68 Young, R. J., Bloor, D., Batchelder, D. N. and Huble, C. L. J. Mater. Sci. 1978, 15, 62

69 Wenz, G. and Wegner, G. Makromol. Chem., Rapid Commun. 1982, 3, 231

70 Tieke, B. Adv. Polym. Sci. 1985, 71, 79

71 Tsibouklis, J., Pearson, C., Song, Y.-P., Warren, J., Petty, M. Yarwood, J., Petty, M. C. and Feast, W. J. J. Mater. Chem. 1993, 3, 97

72 Tsibouklis, J., Werninck, A. R., Shand, A. J. and Milburn, G. H. W. Liquid Crystals 1988, 3, 1393

73 Tsibouklis, J., Campbell, C., Werninck, A. R., Shand, A. J. and Milburn, G. H. W. Polym. Bull. 1992, 29, 661

74 Glaser, C. Ber. $1869,2,422$

75 Eglinton, G. and Galbraith, A. R. Chem. Ind. (London) 1956, 737

76 Chodkiewicz, W. Ann. Chim. 1957, 2, 819

77 Shluback, H. H. and Frantzen, V. Ann. 1951, 572, 116

78 Viehe, H. G. Ber. 1959, 92, 3064

79 Zinkevich, E. P., Sarycheva, I. K. and Preobrazhenskii, N. A. Zh. Obshch. Khim. 1966, 2, 2021

80 McCusker, H. W. and Vogt, R. J. Am. Chem. Soc. 1937, 59, 1307 
81 Jacobsen, C. L. and Carothers, D. M. J. Am. Chem. Soc. 1933, 55,4667

82 Hofmeister, H., Annen, K., Laurent, H. and Weichert, R. Angew. Chem. Int. Ed. Engl. 1984, 23, 727

83 Speight, J. G. Kovacic, P. and Koch, F. W. J. Macromol. Sci., Rev. Macromol. Chem. 1971, 5, 275

84 Jones, M. B. and Kovacic, P. in 'Encyclopaedia of Polymer Science and Engineering' (Ed. J. I. Kroschwitz), Vol. 10, Wiley, New York, 1987, p. 670

85 Naarmann, H., Beaujean, M., Merenyi, R. and Viehe, H. G. Polym. Bull. 1980, 2, 683

86 Kovacic, P. and Jones, M. B. Chem. Rev. 1987, 87, 357

87 Kovacic, P. and Kyriakis, A. J. Am. Chem. Soc. 1963, 85, 454

88 Milosevich, S., Saichek, K., Hinchey, L., England, W. B. and Kovacic, P. J. Am. Chem. Soc. 1983, 105, 1088

89 Stoessel, F., Guth, J. L. and Wey, R. Clay Miner. 1977, 12, 255

90 Soma, Y., Soma, M. and Harada, I. Chem. Phys. Lett. 1983, 99, 153

91 Aldissi, M. and Lepins, R. J. Chem. Soc. Chem. Commun. 1984, 255 92 Bilow, N. and Rust, J. B. U.S. Pat. 35824981971

93 Bilow, N. and Miller, L. J. J. Macromol. Sci., Chem. 1967, 1, 183

94 Aeiyach, S., Soubiran, S., Lacaze, P. C., Froyer, J. and Pelous, Y. Synth. Met. 1989, 32, 103

95 Levi, M. D., Pisarevskaya, E. Yu., Molodkina, E. B. and Danilov, A. I. Synth. Met. 1993, 54, 195

96 Delamare, M., Lacaze, P.-C., Dumousseau, J.-Y. and Dubois, J.-E. Electrochim. Acta 1982, 27, 61

97 Kacriyama, K., Sato, K., Someto, K. and Tanaka, S. J. Chem. Soc., Chem. Commun. 1984, 1199

98 Rubinstein, I., J. Polym. Sci., Polym. Chem. Ed. 1983, 21, 3015

99 Sato, M., Kaneto, K. and Yoshino, K. J. Chem. Soc., Chem. Commun. 1985, 1629

100 Sato, M., Tanaka, M., Kaneto, K. and Yoshino, K. Polym. Commun. 1985, 26, 356 .

101 Oshawa, T., Inoue, T., Takeda, S., Kaneto, K. and Yoshino, K. Polym. Commun. 1986, 27, 246

102 Bhadani, S. N., SenGupta, S. K., Gupta, M. K. and Prasad, J. J. Appl. Polym. Sci. 1993, 47, 1215

103 Toshiba Corp., Jpn. Pat. 8458029 (1984); Chem. Abstr. 1984, 101,73279

104 Taylor, S. K., Bennett, S. G., Khoury, I. and Kovacic, P. J. Polym. Sci., Polym. Lett. Ed. 1981, 19, 85

105 Ibuki, E., Ozaka, S., Fujioka, Y. and Yanagihara, Y. Chem Pharm. Bull. 1982, 30, 802

106 Ibuki, E., Ozaka, S., Fujioka, Y., Okada, M. and Yanagihara, Y. Chem. Pharm. Bull. 1982, 30, 2369

107 Toshima, N. and Asakura, T. Bull. Chem. Soc. Jpn. 1993, 66, 948

108 Baumgarten, M., Mullen, U., Bonhen, A. and Mullen, K. Angew. Chem. Int. Ed. Engl. 1992, 31, 448

109 Fahnenstich, U., Koch, K.-H. and Mullen, K. Macromol. Chem Rapid Commun. 1989, 10, 563

110 Auchter-Krummel P. and Mullen, K. Angew. Chem. Int. Ed. Engl. 1991, 30, 1003

111 Frey, D. A., Hasegawa, M. and Marvel, C. S. J. Polym. Sci. Part A, 1963, 1, 2057

112 Cassidy, P. E. and Marvel, C. S. Macromol. Synth. 1972, 4, 7

113 Ballard, D. G. H., Curtis, A., Shirley, I. M. and Taylor, S. C. Macromolecules 1988, 21, 294; McKean, D. R. and Stille, J. K. Macromolecules 1987, 20, 1787

114 Claverie, J. P., Gin, D. L., Conticello, V. P., Hampton, P. D. and Grubbs, R. H. Polym. Prepr. 1992, 33, 1020

115 Stille, J. K., Harris, F. W., Mukamal, H., Rakutis, R. O., Schilling, C. L., Noren, G. K. and Reed, J. A. Adv. Chem. Ser. $1969,91,625$

116 VanKerckhoven, V. F., Gilliams, Y. K. and Stille, J. K. Macromolecules 1972, 5, 541

117 Braham, J. N., Hodgins, T., Katto, T., Kohl, R. T. and Stille, J. K. Macromolecules 1978, 11, 343

118 Korshak, V. V., Sergeev, V. A. and Chernomordik, Yu. A. Vysokomol, Soedin, Ser. B. 1977, 19, 493

119 Korshak, V. V., Sergeev, V. A., Chernomordik, Yu. A. and Alaev, S. B. Izv. Akad. Nauk. SSSR, Ser. Khim. 1977, 1645

120 Laird, T., Ollis, W. D. and Sutherland, I. O. J. Chem Soc. Perkin Trans 1 1980, 1473

121 Unroe, M. R., Reinhardt, B. A. and Soloski, E. J. Polym. Prepr., Am. Chem. Soc., Div. Polym. Chem. 1987, 28, 183

122 Berlin, A. A. J. Polym. Sci. 1961, 55, 621

123 Fauvargue, J. F., Petit, M. A., Digua, A. and Savard, J. Makromol. Chem. 1985, 186, 2415
Schiavon, G., Zotti, G. and Bontempelli, G. J. Electroanal. Chem., Interfacial Chem. 1984, 161, 323

125 Aboulkassim, A. and Chevrot, C. Polymer 1993, 34, 401

126 Saito, N., Kanbara, T., Sato, T. and Yamamoto, T. Polym. Bull. 1993, 30, 291

127 (a) Yamamoto, T., Morita, A., Miyazaki, Y.. Maruyama, T., Wakayama, H., Zhou, Z. H., Nakamura, Y., Kanbara, T., Sasaki, S. and Kubota, K. Macromolecules 1992, 25, 1214; (b) John, J. A. and Tour, J. M. J. Am. Chem. Soc. 1994, 116, 5011

128 Korshak, V. V., Terplyakov, M. M. and Dvorikova, R. A. Vysokomol, Soedin, Ser. A, 1982, 24, 277

129 Percec, V., Okita, S. and Weiss, R. Macromolecules 1992, 25, 1816

130 Rehahn, M., Schuluter, A. D., Wegner, G. and Feast, W. J. Polymer 1989, 30, 1054

131 Noll, A., Siegfield, N. and Heitz, W. Makromol. Chem., Rapid Commun. 1990, 11, 485

132 Rehahn, M., Schluter, A. D., Wegner, G. and Feast, W. J. Polymer 1989, 30, 1060

133 Rehahn, M., Schluter, A. D. and Wegner, G. Makromol. Chem. 1990, 191, 1991

134 Kim, H. Y. and Webster, O. W. J. Am. Chem. Soc. 1990, 112, 4592

135 Tour, J. M. and Stephens, E. B. J. Am. Chem. Soc. 1991, 113, 2309

136 Masse, M. A., Martin, D. C., Petermann, J. H. Thomas, E. L. and Karasz, F. E. J. Mater. Sci. 1990, 25, 311

137 Bradley, D. C. J. Phys. (D), Appl. Phys. 1987, 20, 1389

138 Drefahl, V. G., Kuhmstedt, R., Oswald, H. and Horhold, H. H. Makromol. Chem. 1970, 131, 89

139 Gourley, K. D., Lillya, C. P., Raynolds, J. R. and Chien, J. C. W. Macromolecules $1984,17,1025$

140 Kanbe, M. and Okawara, M. J. Polym. Sci. (A-1) 1968, 6, 1058

141 Wessling, R. A. and Zimmerman, R. G. U.S. Patents 3401152, 1968; 37066771972

142 Murase, I., Ohnishi, T., Noguchi, T. and Hirooka, M. Polym. Commun. 1984, 25, 327

143 Antoun, S., Gagnon, D. R., Karasz, F. E. and Lenz, R. W. J. Polym. Sci., Polym. Lett. 1986, 24, 503

144 Lahti, P. M., Modarelli, D. A., Denton, F. R., Lenz, R. W. and Karasz, F. E. J. Am. Chem. Soc. 1988, 110, 7258

145 (a) Liang, W. B., Masse, M. A. and Karasz, F. E. Polymer 1992, 33, 3101; (b) Moratti, S. C., Holmes, A. B., Baigent, D. R., Friend, R. H., Greenham, N. C., Grüner, J. and Palmer, P. J. Synth. Met. 1995, 71, 2117

146 Liang, W. B., Lenz, R. W. and Karasz, F. E. J. Polvm. Sci. (A), Polym. Chem. 1990, 28, 2867

147 Gagnon, D. R., Karasz, F. E., Thomas, E. L. and Lenz, R. W. Synth. Met. 1987, 20, 85

148 Bradley, D. D. C., Friend, R. H., Lindenberger, H. and Roth, S. Polvmer 1986, 27, 1709

149 Simpson, J., Rice, D. M. and Karasz, F. E. Macromolecules 1992, 25, 2099

150 Masse, M. A., Schlenoff, J. B., Karasz, F. E. and Thomas, E. L. J. Polym. Sci., Polym. Phys. Ed. 1989, 27, 2045

151 Granier, T., Thomas, E. L. and Karasz, F. E. J. Polym. Sci. Polym. Phys. Ed. 1989, 27, 469

152 Chen, D., Winokur, M. J., Masse, M. A. and Karasz, F. E. Polymer 1992, 33, 3116

153 Brédas, J. L., Chance, R. R., Baughman, R. H. and Silbey, R. J. Chem. Phys. 1982, 76, 3673

154 Duke, C. B. and Ford, W. K. Int. J. Quantum. Chem., Quantum. Chem. Symp. 1983, 17, 597

155 Shuai, Z., Beljonne, D. and Brédas, J. L. Solid State Commun. 1991, 78, 477

156 Dacosta, P. G., Dandrea, R. G. and Conwell, E. M. Physica Review B-Condensed Matter 1993, 47, 1800

157 Elsenbaumer, R. L., Jen, K. Y., Miller, G. G., Eckhardt, H. Shacklette, L. W. and Jow, R. in 'Electronic Properties of Conjugated Polymers' (Eds H. Kazmany and M. Mehring), Springer-Verlag, Berlin, 1987

158 Antoun, S., Karasz, F. E. and Lenz, R. W. J. Polym. Sci. $(A)$, Polym. Chem. 1988, 26, 1809

159 Jen, K. Y., Shacklette, L. W. and Elsenbaumer, R. L. Synth Met. 1987, 22, 179

160 Shim, H. K., Hwang, D. H. and Lee, K. S. Makromol. Chem. Macromol. Chem. Phys. 1993, 194, 1115

161 Jin, J. I., Park, C. K. and Shim, H. K. Macromolecules 1993, 26, 1799 
162 Jen, K. Y., Maxfield, M., Shacklette, L. W. and Elsenbaumer, R. L. J. Chem. Soc. Chem. Commun. 1987, 309

163 Murase, I., Ohnishi, T., Noguchi, T. and Hirooka. M. Polym. Commun. 1987, 28, 229

164 Jen, K. Y., Jow, T. R. and Elsenbaumer, R. L. J. Chem. Soc., Chem. Commun. 1987, 1113

165 Jin, J. I., Lee, Y. H. and Shim, H. K. Macromolecules 1993, 26, 1805

166 Mullen, K. Pure Appl. Chem. 1993, 65, 89

167 Yu, L., Chen, M. and Dalton, L. R. Chem. Mater. 1990, 2, 649

168 Wegener, S. and Mullen, K. Chem. Ber. 1991, 124, 2101

169 Schluter, A.-D. Adv. Mater. 1992, 1127

170 Koch, K.-H., Fahnenstich, U., Baumgarten, M. and Mullen, K. Synth. Met. 1991, 41-43, 1619

171 Koch, K. H. and Mullen, K. Chem. Ber. 1991, 124, 2091

172 Vollhardt, K. P. C. Pure Appl. Chem. 1993, 65, 153

173 Berris, B. C., Hovakeemian. G. H., Lai, Y.-H., Mestdagh, H and Vollhardt, K. P. C. J. Am. Chem. Soc. 1985, 107, 5670

174 Hirthammer, M. and Vollhardt, K. P. C. J. Am. Chem. Soc 1986, 108, 2481

175 Blanco, L., Helson, H. E., Hirthammer, M., Mestdagh, H., Spyroudis, S. and Vollhardt, K. P. C. Angew. Chem. Int. Ed. Eng. 1987, 26, 1246

176 Helson, H. E., Vollhardt, K. P. C. and Yang, Z.-Y. Angew. Chem. Int. Ed. Engl. 1985, 24, 114

177 Miyaura, N., Yanagi, T. and Suzuki, A. Synth. Commun. 1981 11,513

178 Scherf, U. and Müllen, K. Adv. Polym. Sci. 123, 1

179 Scherf, U. and Müllen, K. Makromol. Chem. Rapid Commun. 1991, 12, 489

180 Scherf, U. and Müllen, K. Synthesis 1992, 23

181 Schlüter, A.-D. Adv. Mater. 1991, 3, 282

182 Bailey, W. J., Fetter, E. J. and Economy, J. J. Org. Chem. 1962 , 27, 3497

183 Marvel, C. S. and Levesque, C. L. J. Am. Chem. Soc. 1938, 60, 280

184 Marvel, C. S., Cormer, J. O. and Riddle, E. H. J. Am. Chem. Soc. 1942, 64, 92

185 Overberger, C. G. and Moore, J. A. Adv. Polym. Sci. 1970, 7, 113

186 Angelo, R. J., Wallach, M. L. and Ikeda, R. M. Polym. Prepr. $1967,8,221$

187 Angelo, R. J., Wallach, M. L. and Ikeda, R. M. Polvm. Prepr. $1963,4,32$

188 Teysie, P. and Korn-Girard, A. C. J. Polym. Sci. A 1964, 2, 2849

189 Kobayashi, N., Mikitoshi, M., Ohno, H., Tsuchida, E., Matsuda, H.. Nakanishi, H. and Kato, M. New Polym. Mater. 1987, 1, 3

190 Kaplan, M. L., Schmidt, P. H., Chen, C. H. and Walsh Jr, W. M. Appl. Phys. Lett. 1980, 26, 867

191 Forrest, S. R., Kaplan, M. L., Schmidt, P. H., Vekatesan, T. and Lovinger, A. J. Appl. Phys. Lett. 1982, 41, 708

192 Murakami, M. and Yoshimura, S. J. Chem. Soc, Chem Commun. 1984, 1649

193 Murakami, M. and Yoshimura, S. Mol. Cryst. Liq. Cryst. 1985 , 118, 95

194 Iqbal, Z., Ivory, D. M., Marti, J., Brédas, J. L. and Baughman, R. H. Mol. Cryst. Liq. Cryst. 1985, 118, 103

195 Anton, U. and Müllen, K. Macromolecules 1993, 26, 1248

196 Tour, J. M. and Lamba, J. J. S. J. Am. Chem. Soc. 1993, 115, 4935

197 Scherf, U. and Müllen, K. Synth. Met. 1993, 55-57, 739

198 Scherf, U. and Müllen, K. in 'Advances in Polymer Science'. Vol. 123, Springer, 1995, pp. 1-40

199 Yamamoto, T. Prog. Polym. Sci. 1992, 17, 1153

200 Yamamoto, T., Inoue, T. and Kanbara, T. Jpn J. Appl. Phys. 1994, 33, L250

201 Meyer, V. Chem. Ber. 1883, 16, 1465

202 Yamamoto, T., Sanechika, K. and Yamamoto, A. J. Polym. Sci., Polvm. Lett. Ed. 1980, 18, 9

203 Lin, J. and Dudek, L. P. J. Polym. Sci, Polym. Chem. Ed. 1980, 18,2869

204 Roncali, J., Lemaire, M., Garreau, R. and Garnier, F. Synth. Met $1987, \mathbf{1 8}, 139$

205 Jen, K.-W., Miller, G. G. and Elsenbaumer, R. L. J. Chem. Soc. Chem. Commun. 1986, 1346

206 Leclerc, M., Diaz, F. M. and Wegner, G. Makromol. Chem. $1989,190,3105$

207 Sato, M. and Morii, H. Macromolecules 1991, 24, 1196

208 Roncali, J., Garreau, R., Yasser, A., Marque, P., Garnier, F. and Lemaire, M. J. Phys. Chem. 1987, 91, 6706
209 McCullough, R. D., Tristram-Magle, S., Williams, S. P., Lowe, R. D. and Jayaraman, M. J. Am. Chem. Soc. 1993, 115, 4910

210 Waltman, R. J., Bargon, J. and Diaz, A. F. Phys. Chem. 1983, 87, 1458

211 Tourillon, G. and Garnier, F. J. Phys. Chem. 1983, 87, 2289

212 Leclerc, M. and Daoust, G. J. Chem. Soc., Chem. Commun. 1990,273

213 Langeveld-Voss, B. M. W., Janssen, R. A. J., Christiaans, M. P. T., Meshers, S. C. J., Dekkers, M. P. J. M. and Meijer, E. W. J. Am. Chem. Soc. 1996, 118, 4908

214 (a) Daoust, G. and Leclerc, M. Macromolecules 191, 24, 455; (b) Leclerc, M. and Daoust, G. Synth. Met. 1991, 41-43, 529

215 Salaneck, W. R., Inganäs, O., Thémans, B., Nilsson, J. O., Sjögren, B., Österholm, J.-E., Brédas, J.-L. and Svensson, S. J. Chem. Phys. 1988, 89, 4613

216 Tashiro, K., Ono, K., Minagawa, Y., Kobayashi, M., Kawai, T. and Yoshino, K. J. Polym. Sci., Part B: Polym. Phys. 1991, 29, 1223

217 Ekeblad, P. O. and Inganäs, O. Polym. Commun. 1991, 32, 436

218 Bouman, M. M. and Meijer, E. W. Adv. Mater, 1995, 7, 385

219 Havinga, E. E. and van Horssen, L. W. Makromol. Chem., Macromol. Symp. 1989, 24, 67

220 Fahnenstich, U., Koch, K.-H. and Müllen, K. Makromol. Chem., Rapid Commun. 1989, 10, 563

221 Pomerantz, M., Tseng, J. J., Zhu, H., Sproull, S. J., Reynolds, J. R., Uitz, R. and Arnott, H. J. Synth. Met. 1991, 41-43, 825

222 Diaz, A. Chem. Scripta 1981, 17, 145

223 For a detailed discussion see: Roncali, J. Chem. Rev. 1992, 92, 711

224 Tourillon, G. and Garnier, F. J. Electroanal. Chem. 1982, 135, 173

225 Kaneto, K., Kohno, Y., Yoshino, K. and Inuishi, Y. J. Chem. Soc., Chem. Commun. 1983, 382

226 Yasser, A.. Roncali, J. and Garnier, F. Macromolecules 1989. 22, 804

227 Sato, M., Tanaka, S. and Kaeriyama, K. J. Chem. Soc., Chem. Commun. 1985, 713

228 Hotta, S., Rughooputh, S. D. D. V., Heeger, A. J. and Wudl, F. Macromolecules 1987, 20, 212

229 Sato, M., Tanaka, S. and Kaeriyama, K. Makromol. Chem. 1987, 188, 1763

230 Blankespoor, R. L. and Miller, L. L. J. Chem. Soc., Chem. Commun. 1985, 90

231 Bryce, M. R., Chissel, A., Kathirgamanathan, P., Parker, D. and Smith, N. R. M. J. Chem. Soc., Chem. Commun. 1987, 466 Heywang, G. and Jonas, F. Adv. Mater. 1992, 4, 116

233 Havinga, E. E., Meijer, E. W., ten Hoeve, W. and Wynberg, H. Chem. Mater. 1989, 1, 650

234 Ritter, S. K., Noftle, R. E. and Ward, A. E. Chem. Mater. 1993. 5,752

235 Havinga, E. E., van Horssen, L. W., ten Hoeve, W., Wynberg, H. and Meijer, E. W. Polym. Bull. 1987, 18, 277

236 Patil. A. O., Ikenoue, Y., Wudl, F. and Heeger, A. J. J. Am. Chem. Soc. $1987,109,1858$

237 Patil, A. O., Ikenoue, Y., Basescu, N., Colaneri, N., Chen, J., Wudl, F. and Heeger, A. J. Synth. Met. 1987, 20, 151

238 Bäuerle, P., Gaudl, K.-U., Würthner, F., Sariciftci, N. S. Neugebauer, H., Mehring, M., Zhong, C. and Doblhofer, K. Adv. Mater. 1990, 2, 490

239 Arbizzani, C., Barbarella. G., Bongini, A., Mastragostino, M. and Zambianchi, M. Synth. Met. 1992, 52, 329

240 Diaz, A. F., Crowley, J., Bargon, J., Gardini, G. P. and Torrance, J. B. J. Electroanal. Chem. 1981, 121, 355

241 Masuda, H., Taniki, Y. and Kaeriyama, K. J. Polym. Sci. Part A: Polym. Chem. 1992, 30, 1667

242 Koßmehl. G. and Chatzitheodorou, G. Makromol. Chem. Rapid Commun. 1981, 2, 551

243 Sugimoto, R., Takeda, S., Gu, H. B. and Yoshino, K. Chem. Express 1986, 1, 635

244 Leclerc, M., Diaz, F. M. and Wegner, G. Makromol. Chem. $1989,190,3105$

245 Österholm, J.-E., Laakso, J., Nyholm, P., Isotalo, H., Stubb, H., Inganäs, O. and Salaneck, W. R. Synth. Met. 1989, 28, C435

246 Ikenoue, Y., Saida, Y., Kira, M., Tomozawa, H., Yashima, H. and Kobayashi, M. J. Chem. Soc., Chem. Commun. 1990, 1694

247 Andersson, M. R., Pej, Q., Hjertberg, T., Inganäs, O., Wennerström, O. and Österholm, J.-E. Synth. Met. 1993, 55/ 57,1227

248 Souto Maior, R. M., Hinkelmann, K., Eckert, H. and Wudl, F. Macromolecules $1990,23,1268$

249 Zagórska, M. and Krische, B. Polymer 1990, 31, 1379 
250 Kaeriyama, K., Masuda, H., Shirakawa, H., Akagi, K., Suezawa, H. and Hirota, M. Polym. Mater. Sci. Eng. 1991, 64, 212

251 Andersson, M. R., Selse, D., Berggren, M., Jarvinen, H., Hjertberg, T., Inganäs, $\mathrm{O}$., Wennerström, $\mathrm{O}$. and Österholm, J.-E. Macromolecules 1994, 27, 6503

252 Gautun, O. R., Carlsen, P. H. J., Samuelsen, E. J. and Mårdalen, J. Synth. Met. 1993, 58, 115

253 Jolly, P. W. and Wilke, G. 'The Organic Chemistry of Nickel', Academic Press, New York, 1975, Chapter 5

254 Stille, J. K. Angew. Chem. Int. Ed. Engl. 1986, 25, 508

255 Tamao, K., Kodama, S., Nakajima, I., Kumada, M., Minato, A and Suzuki, K. Tetrahedron 1982, 39, 3347

256 Kalinin, V. N. Synthesis 1992,413

257 Kobayashi, M., Chen, J., Chung, T.-C., Moraes, F., Heeger, A. J. and Wudl, F. Synth. Met. 1984, 9, 77

258 Elsenbaumer, R. L., Yen, K. Y. and Oboodi, R. Synth. Met $1986,15,169$

259 Inganäs, O., Salaneck, W. R., Österholm, J.-E. and Laakso, J Synth. Met. 1988, 22, 395

260 Mao, H. and Holdcroft, S. Macromolecules 1992, 25, 554

261 Mao, H., Xu, B. and Holdcroft, S. Macromolecules 1993, 26, 1163

262 Tamao, K., Sumitani, K. and Kumada, M. J. Am. Chem. Soc $1972,94,4374$

263 Kumada, M., Tamao, K. and Sumitani, K. Org. Synth. 1978, 58, 127

264 McCullough, R. D. and Lowe, R. D. J. Chem. Soc., Chem. Commun. 1992, 70

265 McCullough, R. D., Lowe, R. D., Jayaraman, M. and Anderson, D. L. J. Org. Chem. 1993, 58, 904

266 McCullough, R. D., Williams, S. P., Jayaraman, M., Reddinger, J., Miller, L. and Tristram-Nagle, S. Mater. Res. Soc. Symp. Proc. 1994, 328, 215

267 McCullough, R. D., Tristram-Nagle, S., Williams, S. P., Lowe, R. D. and Jayaraman, M. J. Am. Chem. Soc. 1993, 115, 4910

268 McCullough, R. D., Williams, S. P., Jayaraman, M., Reddinger, J., Miller, L. and Tristram-Nagle, S. Mater, Res. Symp. Proc. 1994, 328, 215

269 Yamamoto, T., Osakada, K., Wakabayashi, T. and Yamamoto, A. Makromol. Chem., Rapid Commun. 1985, 6, 671

270 Ueda, M., Miyaji, Y., Ito, T., Oba, Y. and Sone, T. Macromolecules 1991, 24, 2697

271 Chen, T.-A., O'Brien, R. A. and Riecke, R. D. Macromolecules $1993,26,3462$

272 (a) Chen, T.-A. and Riecke, R. D. J. Am. Chem. Soc. 1992, 114, 10087; (b) Chen, T.-A., Wu, X. and Riecke, R. D. J. Am. Chem. Soc. $1995,117,233$

273 Yamamoto, T., Maruyama, T., Zhou, Z.-H., Miyazaki, Y., Kanbara, T. and Sanechika, K. Synth. Met. 1991, 41-43, 345

274 Yamamoto, T., Morita, A., Miyazaki, Y., Maruyama, T., Wakayama, H., Zhou, Z.-H., Nakamura, Y., Kanbara, T., Sasaki, S. and Kubota, K. Macromolecules 1992, 25, 1214

275 Swager, T. M. Adv. Mater. 1994, 6, 595

276 Marsella, M. J., Carroll, P. J. and Swager, T. M. J. Am. Chem. Soc. 1995, 117, 9832

277 Marsella, M. J., Newland, R. J., Carroll, P. J., Swager, T. M. J. Am. Chem. Soc. 1995, 117, 9842

278 Dall'Olio, A., Dascola, G., Varacca, V. and Bocchi, V. C. R. Acad. Sci. 1968, C267, 433

279 Diaz, A. F., Kanazwa, K. K. and Gardini, G. P. J. Chem. Soc. Chem. Commun. 1979, 635

280 Kanazawa, K. K., Diaz, A. F., Gill, W. D., Grant, P. M., Street, G. B., Gardini, G. P. and Kwak, J. F. Synth. Met. 1979/80, 1, 329

281 Qian, R., Qiu, J. and Shen, D. Synth. Met. 1987, 18, 13

282 Naegele, D. and Bittihn, R. Solid State Ionics 1988, 28-30, 983

283 Wernet, W., Monkenbusch, M. and Wegner, G. Mol. Cryst. Liq. Cryst. 1985, 118, 193

284 Cross, M. G. and Lines, R. Eur. Patent 8.3304428.2, 1983

285 Salmon, M., Kanazawa, K. K., Diaz, A. F. and Krounbi, M. J. Polym. Sci. Polym. Lett. 1982, 20, 187

286 Chan, H. S. O., Munro, H. S., Davies, C. and Kang, E. T. Synth. Met. 1988, 22, 365

287 Castillo-Ortega, N. M., Inoue, M. B. and Inoue, M. Synth. Met. 1989,28, C65

288 Lei, J., Cai, Z. and Martin, C. R. Synth. Met. 1992, 46, 53

289 Street, G. B., Clarke, T. C., Krounbi, M., Kanazawa, K., Lee, V. Pfluger, P., Scott, J. C. and Weiser, G. Mol. Cryst. Liq. Cryst. $1982,83,253$
290 Lindenberger, H., Schäfer-Siebert, D., Roth, S. and Hanack, M. Synth. Met. 1987, 18, 37

291 Rühe, J., Ezquerra, T. A. and Wegner, G. Synth. Met. 1989, 28, $\mathrm{C} 177$

292 Masuda, H., Tanaka, S. and Keariyama, K. J. Chem. Soc. Chem. Commun. 1989, 725

293 Zotti, G., Shiavon, G., Berlin, A. and Pagani, G. Synth. Met. $1989,28, \mathrm{C} 183$

294 Rokach, J., Hamel, P., Kakushima, M. and Smith, G. M Tetrahedron Lett. 1981, 22, 4901

295 Kakushima, M., Hamel, P., Frenette, R. and Rokach, J. J. Org. Chem. 1983, 48, 3214

296 Anderson, H. J., Loader, C. E., Xu, R. X., Le, N., Gogan, N. J., McDonald, R. and Edwards, L. G. Can. J. Chem. 1985, 63, 896

297 Kanazawa, K. K., Diaz, A. F., Geiss, R. H., Gill, W. D., Kwak, J. F., Logan, J. A., Rabolt, J. F. and Street, G. B. J. Chem. Soc. Chem. Commun. 1979, 854

298 Merz, A., Schwarz, R. and Schropp, R. Adv. Mater. 1992, 4, 409

299 Havinga, E. E., van Horssen, L. W., ten Hoeve, W., Wynberg, H. and Meijer, E. W. Polym. Bull. 1987, 18, 277

300 Collard, M. and Fox, M. A. J. Am. Chem. Soc. 1991, 113, 9414

301 Rahman, A. K. M., Samuelson, L., Minehan, D., Clough, S. Tripathy, S., Inagaki, T., Yang, X. Q., Skotheim, T. A. and Okamoto, Y. Synth. Met. 1989, 28, C237

302 Yang, X. Q.. Chen, J., Hale, P. D., Inagaki, T., Skotheim, T. A. Okamoto, Y., Samuelson, L., Tripathy, S., Hong, K., Rubner, M. F. and den Boer, M. L. Synth. Met. 1989, 28, C251

303 Martina, S., Enkelmann, V., Wegner, G. and Schlüter, A.-D. Synth. Met. 1992, 51, 299

304 For a review see: Fanta, P. E. Synthesis 1974, 9

305 Groenendaal, L., Peerlings, H. W. I., van Dongen, J. L. J. Havinga, E. E., Vekemans, J. A. J. M. and Meijer, E. W Macromolecules 1995, 28, 116

306 Brockmann, T. W. and Tour, J. M. J. Am. Chem. Soc. 1994, 116, 7435

307 For a detailed historical review see: Geniès, E. M., Boyle, A Lapkowski, M. and Tsintavis, C. Synth. Met. 1990, 36, 139

308 Letheby, H. J. Chem. Soc. 1862, 15, 161

309 Mohilner, D. M., Adams, R. H. and Argersinger Jr, W. J. J. Am. Chem. Soc. 1962, 84, 3618

310 Diaz, A. F. and Logan, J. A. J. Electroanal. Chem. 1980, 111, 111

311 Wang, B., Tang, J. and Wang, F. Synth. Met. 1986, 13, 329

312 Chiang, J.-C. and MacDiarmid, A. G. Synth. Met. 1986, 13, 193

313 Wei, Y., Focke, W. W., Wnek, G. E., Ray, A., MacDiarmid, A. G. J. Phys. Chem. 1989, 93, 495

314 Wang, L.. Jing, X. and Wang, F. Synth. Met. 1991, 41-43, 739

315 Zotti, G., Comisso, N., D'Aprano, G. and Leclerc, M. Adv. Mater. 1992, 4, 749

316 Scherr, E. M., MacDiarmid, A. G., Manohar, S. K., Masters, J. G., Sun, Y., Tang, X., Druy, M. A., Glatkowski, P. J., Cajipe, V. B., Fischer, J. E., Cromack, K. R., Jozefowitcz, M. E., Ginder, J. M., McCall, R. P. and Epstein, A. J. Synth. Met. 1991, 41-43, 735

317 Epstein, A. J.. Ginder, J. M., Zuo, F., Bigelow, R. W., Tanner D. B., Richter, A. F., Huang, W.-S. and MacDiarmid, A. G. Synth. Met. 1987, 18, 303

318 Kitani, A., Kaya, M., Yano, J., Yoshikawa, K. and Sasaki, K Synth. Met. 1987, 18, 341

319 Vachon, D., Angus Jr, R. O., Lu, F. L., Nowak, M., Schaffer, H., Wudl, F. and Heeger, A. J. Synth. Met. 1987, 18, 297

320 Pandey, S. S., Annapoorni, S. and Malhotra, B. D. Macromolecules 1993, 26, 3190

321 Green, A. G. and Woodhead, A. E. J. Chem. Soc. Trans. 1910 , $\mathbf{9 7 , 2 3 8 8}$

322 MacDiarmid, A. G., Chiang, J. C., Richter, A. F. and Epstein, A. J. Synth. Met. 1987, 18, 285

323 MacDiarmid, A. G. 'Conjugated Polymers and Related Materials' (Proc. 81st Nobel Symposium), Oxford University Press, 1993, p. 73 (Chapter 6)

324 Angelopoulos, M., Ray, A., MacDiarmid, A. G. and Epstein, A. J. Synth. Met. 1987, 21, 21

325 Leclerc, M., Guay, J. and Dao, L. H. Macromolecules 1989, 22, 649

326 Macinnes, D. and Funt, B. L. Synth. Met. 1988, 25, 235

327 Yue, J. and Epstein, A. J. J. Am. Chem. Soc. 1990, 112, 2800

328 Cao, Y., Smith, P. and Heeger, A. J. Synth. Met. 1992, 48, 91

329 Klavetter, F. L. and Cao, Y. Synth. Met. 1993, 55-57, 989

330 Havinga, E. E., Bouman, M. M., Meijer, E. W., Pomp, A. and Simenon, M. M. J. Synth. Met. 1994, 66, 93 
331 Wudl, F., Kobayashi, M. and Heeger, A. J. J. Org. Chem. 1984, 49, 3382

332 Pomerantz, M., Chaloner-Gill, B., Harding, L. O., Tseng, J. J. and Pomerantz, W. J. Synth. Met. 1993, 55-57, 960

333 Brédas, J.-L., Heeger, A. J. and Wudl, F. J. Chem. Phys. 1986. 85,4673

334 Kürti, J., Surján, P. R. and Kertesz, M. J. Am. Chem. Soc. 1991, 113, 9865

335 Lambert, T. L. and Ferraris, J. P. J. Chem. Soc. Chem. Commun. 1991,752

336 Tanaka, S. and Yamashita, Y. Synth. Met. 1993, 55-57, 1251

337 Havinga, E. E., ten Hoeve, W. and Wynberg, H. Synth. Met. 1993, 55-57, 299

338 Jenekhe, S. A. Nature 1986, 322, 345

339 Jenekhe, S. A. Macromolecules 1990, 23, 2848

340 Chen, W.-C. and Jenekhe, S. A. Macromolecules 1995, 28, 454

341 Chen, W.-C. and Jenekhe, S. A. Macromolecules 1995, 28, 465

342 Patil, A. O. and Wudl, F. Macromolecules 1988, 21, 542

343 Meyer. W. H. Adv. Mater. 1993, 5, 254

344 Lazzaroni, R., Riga, J., Verbist, J. J., Cristiaens, L. and Renson, M. J. Chem. Soc, Chem. Commun. 1985, 999

345 Danieli, R., Taliani, C., Zamboni, R., Giro, G., Biserni, M., Mastragostino, M. and Testoni, A. Synth. Met. 1986, 13, 325

346 Jow, T. R., Jen, K. Y., Elsenbaumer, R. L., Shacklette, L. W., Angelopoulos, M. and Cava, M. P. Synth. Met. 1986, 14, 53

347 Kanbara, T. and Yamamoto, T. Macromolecules 1993, 26, 3464

348 Kanbara, T., Saito, N., Yamamoto, T. and Kubota, K. Macromolecules 1991, 24, 5883

349 Tour, J. M. and Lamba, J. J. S. J. Am. Chem. Soc. 1993, 115, 4935

350 Tsuchida, E., Nishide, H., Yamamoto, K. and Yoshida, S. Macromolecules 1987, 20, 2315

351 Tsuchida, E., Yamamoto, K., Nishide, H. and Yoshida, S. Macromolecules 1987, 20, 2030

352 Handlovitz, C. E. Macromol, Synth. 1968-1969, 3, 131

353 Shacklette, L. W., Elsenbaumer, R. L.. Chance, R. R. Eckhardt, H., Frommer, J. E. and Baughman, R. H. J. Chem Phys, 1981, 75, 1919

354 Kossmehl, G. A. 'Handbook of Conducting Polymers' (Ed. T. Skotheim), Vol. 1, Marcel Dekker, New York, 1986, pp. 393396

355 Kallitsis, J. K., Martinez, F. and Naarmann, H. Synth. Met 1993, 55-57, 773

356 Yamamoto, T., Ito, T. and Kubota, K. Chem. Lett. 1988, 153

357 Yamamoto, T., Zhou, Z.-H., Kanbara, T. and Maruyama, T. Chem. Lett. 1990, 223

358 Maruyama, T., Zhou, Z.-H., Kubota, K. and Yamamoto, T. Chem. Lett. 1992, 643

359 Maruyama. T., Kubota, K. and Yamamoto, T. Macromolecules 1993, 26, 4055

360 Yamamoto, T., Maruyama, T. and Kubota, K. J. Am. Chem Soc. 1994, 116, 4832

361 Kanbara, T., Kushida, N., Saito, N., Kuwajima, L., Kubota, K and Yamamoto, T. Chem. Lett. 1992, 583

362 Satoh, M., Kaneto, K. and Yoshino, K. J. Chem. Soc., Chem. Commun. 1984, 1627

363 Bolognesi, A., Catellani, M., Destri, S. and Porzio, W. Synth. Met. 1987, 18, 129

364 Inganäs, O., Liedberg, B., Chang-Ru, W. and Wynberg, H Synth. Met. 1985, 11, 239

365 Montheard, J. P., Pascal, T., Seytre, G., Steffan-Boiteux, G. and Douillard, A. Synth. Met. 1984, 9, 389

366 Monthéard, J. P., Pascal, T., Seytre, G. and Steffan-Boiteux, G. Makromol. Chem., Rapid Commun. 1985, 6, 679

367 Pelter, A., Rowlands. M. and Jenkins, H. Tetrahedron Lett. 1987, 28, 5213

368 Pelter, A., Maud. J. M., Jenkins, I., Sadeka, C. and Coles, G Tetrahedron Lett. 1989, 30, 3461

369 Bao, Z., Chan, W. and Yu, L. Chem. Mater. 1993, 5, 2

370 Martina, S. and Schlüter, A.-D. Macromolecules 1992, 25, 3607

371 Hoshino, Y., Miyama, N. and Suzuki, A. Bull. Chem. Soc. Jpn. 1988, 61, 3008

372 Czerwiski, W.. Ncker, N. and Fink, J. Synth. Met. 1988, 25, 71

373 Yamamoto, T., Miyazaki, Y., Fukuda, T., Zhou, Z., Maruyama, T., Kanbara, T. and Osakada, K. Synth. Met. 1993, 55-57, 1214

374 Yamamoto, T., Zhou, Z.-H., Maruyama, T. and Kanbara, T. Synth. Met. 1993, 55-57, 1209

375 Polis, D. W., Young, C. L., McLean, M. R. and Dalton, L. R. Macromolecules 1990, 23, 3231
376 McCullough, R. D. and Jayaraman, M. J. Chem. Soc., Chem. Commun. 1995, 135

377 Schulte, K. E., Reisch, J. and Hörner, L. Chem. Ber. 1962, 95. 1943

378 Reisch, J. and Schulte, K. E. Angew. Chem. 1961, 7, 241

379 Wynberg, H. and Metselaar, J. Synth. Commun. 1984, 14, 1

380 Stetter, H. and Schreckenberg, S. Chem. Ber. 1974, 107, 2453

381 Scheeren, J. W., Oomes, P. H. J. and Nivard, R. J. F. Synthesis 1973,149

382 Young. D. M. and Allen, C. F. H. Org. Synth. Coll. Vol. II, 25

383 Bracke, W. J. Polym. Sci., Part A-I 1972, 10, 975

384 Stetter, H. and Kuhlmann, H. Org. React. 1991, 40, 407

385 Pouwer, K. L. Vries, T. R., Havinga, E. E., Meijer, E. W. and Wynberg, H. J. Chem. Soc., Chem. Commun. 1988, 1432

386 Naitoh, S. Synth. Met. 1987, 18, 237

387 Joshi, M. V., Hemler, C., Cava, M. P., Cain, J. L., Bakker, M. G., McKinley, A. J. and Metzger, R. M. J. Chem. Soc. Perkin Trans 2 1993, 1081

388 Niziurski-Mann, R. E., Scordilis-Kelley, C., Liu, T.-L., Cava. M. P. and Carlin, R. T. J. Am. Chem. Soc. 1993, 115, 887

389 Sorensen, A. R., Overgaard, L. and Johannsen, 1. Synth. Met. 1993, 55-57, 1626

390 Danieli, R., Ostoja, P., Tiecco, M., Zamboni, R. and Taliani, C. J. Chem. Soc., Chem. Commun. 1986, 1473

391 Reynolds, J. R., Ruiz, J. P., Child, A. D., Nayak, K. and Marynick, D. S. Macromolecules 1991, 24, 678

392 Ruiz, J. P., Dharia, J. R., Reynolds, J. R. and Buckley, L. J. Macromolecules 1992, 25, 849

393 Reynolds, J. R., Katritzky, A. R., Soloducho, J., Belyakov, S., Sotzing, G. A. and Pyo, M. Macromolecules 1994, 27, 7225

394 Yamamoto, T., Miyazaki, Y., Fukuda, T., Zhou, Z., Maruyama, T., Kanbara, T. and Osakada, K. Synth. Met. 1993, 55-57, 1214

395 Garnier, F., Horowitz, G., Peng, X. and Fischou, D. Adv. Mater. 1990, 2, 592

396 Xu, B., Fischou, D., Horowitz, G. and Garnier, F. Adv. Mater. $1991,3,150$

397 Garnier, F. Science 1994, 5179, 1684

398 Zechmeister, L. and Sease, J. W. J. Am. Chem. Soc. 1947, 69, 273

399 Kumada, M., Tamao, K. and Sumitani, K. Org. Synth. 1978, 58, 127

400 For a review see: Nakayma, J., Konishi, T. and Hoshino, M. Heterocycles 1988, 27, 1731

401 van Pham, C., Burkhardt, A., Shabana, R., Cunningham, D. D., Mark Jr, H. B. and Zimmer, H. Phosphorus, Sulfur, and Silicon $1989,46,153$

402 Waragai, K. and Hotta, S. Synth. Met. 1991, 41-43, 519

403 Tour, J. M. and Wu, R. Macromolecules 1992, 25, 1901

404 Bäuerle, P., Pfau, F., Schlupp, H., Würtner, F., Gaudl, K.-U., Balparda Caro, M. and Fischer, P. J. Chem. Soc., Perkin Trans. 21993,489

405 Zotti, G., Schiavon, G., Berlin, A. and Pagani, G. Chem. Mater. $1993,5,430$

406 Barbarella, G., Zambianchi, M., Bongini, A. and Antolini, L. Adv. Mater. 1994, 6, 561

407 Garnier, F., Horowitz, G. and Fischou, D. Synth. Met. 1989, 28, C705

408 Yasser, A., Delabouglise, D., Hmyene, M., Nessak, B., Horowitz, G. and Garnier, F. Adv. Mater. 1992, 4, 490

409 Faïd, K. and Leclerc, M. J. Chem. Soc. Chem. Commun. 1993, 962

410 ten Hoeve, W., Wynberg, H., Havinga, E. E. and Meijer, E. W. J. Am. Chem. Soc. 1991, 113, 5887

411 Luo, T. H. and LeGoff, E. J. Chin. Chem. Soc. 1992, 39, 325

412 Maud, J. M., Haudry, P., Llewellyn, G. Vlahov, A., Hepburn, A. R., Marshall, J. M. and Goldie, D. M. Synth. Met. 1993, 5557,851

413 Alemán, C., Brillas, E., Davies, A. G., Fajarf, L., Giró, D., Juliá, L., Péres, J. J. and Rius, J. J. Org. Chem. 1993, 58, 3091

414 Van Bolhuis, F., Wynberg, H., Havinga, E. E., Meijer, E. W. and Staring, E. G. Synth. Met. 1989, 30, 381

415 Hotta, S. and Waragai, K. J. Mater. Chem. 1991, 1, 835

416 Barbarella, G., Zambianchi, M., Bongini, A. and Antolini, L. Adv. Mater. 1992, 4, 282

417 Barbarella, G., Bongini, A. and Zambianchi, M. Adv. Mater. $1991,3,494$

418 Havinga, E. E., Rotte, I., Meijer, E. W, ten Hoeve, W. and Wynberg, H. Synth. Met. 1991, 41-43, 473

419 Cao, Y., Guo, D., Pang, M. and Qian, R. Synth. Met. 1987, 18, 189 
420 Bäuerle, P. Adv. Mater. 1992, 4, 102

421 Hill, M. G., Mann, K. R., Miller, L. L. and Penneau, J.-F. J. Am. Chem. Soc. 1992, 114, 2728

422 Bäuerle, P., Segelbacher, U., Gaudl, K.-U., Huttenlocher, D. and Mehring, M. Angew. Chem.. Int. Ed. Engl. 1993, 32, 76

423 Zotti, G., Schiavon, G., Berlin, A. and Pagani, G. Chem. Mater. $1993,5,620$

424 Hill, M. G., Penneau, J.-F., Zinger, B., Mann, K. R. and Miller, L. L. Chem. Mater. 1992, 4, 1106

425 Zinger, B., Mann, K. R., Hill, M. G. and Miller, L. L. Chem. Mater. 1992, 4, 1113

426 Fichou, D., Xu, B., Horowitz, G. and Garnier, F. Synth. Met. 1991, 41-43, 463

427 Guay, J., Diaz, A., Wu, R., Tour, J. M. and Dao, L. H. Chem. Mater. 1992, 4, 254

428 Nakahara, H., Nakayama, J., Hoshino, M. and Fukuda, K. Thin Solid Films 1988, 160, 87

429 Thienpont, H., Rikken, G. L. J. A., Meijer, E. W., ten Hoeve, W. and Wynberg, H. Phys. Rev. Lett. 1990, 65, 2141

430 Effenberger, F., Wurthner, F. and Steybe, F. J. Org. Chem 1995, 60, 2082

431 Bäuerle, P., Fischer, T., Bidlingmeier, B., Stabel, A. and Rabe. J. P. Angew. Chem. 1995, 34, 303

432 Kauffmann, T. and Lexy, H. Chem. Ber. 1981, 114, 3674

433 Martina, S., Enkelmann, V., Schlüter, A.-D. and Wegner, G. Synthesis 1991, 613

434 Martina, S., Enkelmann, V., Schlüter, A.-D. and Wegner, G Synth. Met. 1991, 41-43, 403

435 Wegner, G. and Schlüter, A.-D. Acta Polym. 1993, 44, 59

436 Groenendaal, L., Peerlings, H. W. I., Vekemans, J. A. J. M. and Meijer, E. W. Synth. Met. 1995, 69, 467

437 van Haare, J. A. E. H., Groenendaal, L., Peerlings, H. W. I., Havinga, E. E., Vekemans, J. A. J. M., Janssen, R. A. J. and Meijer, E. W. Chem. Mater. 1995, 7, 1984
438 Street, G. B., Lindsey, S. E., Nazzal, A. I. and Wynne, K. J. Mol. Cryst. Liq. Cryst. 1985, 118, 137

439 Martina, S., Enkelmann, V., Schlüter, A.-D., Wegner, G., Zotti, G. and Zerbi G. Synth. Met. 1993, 55-57, 1096

440 Zerbi, G., Veronelli, M., Martina, S., Schlüter, A.-D. and Wegner, G. Adv. Mater. 1994, 6, 385

441 Zerbi, G., Veronelli, M., Martina, S. and Wegner, G. J. Chem. Phys. 1994, 100, 978

442 van Haare, J. A. E. H., Groenendaal, L., Havinga, E. E. Janssen, R. A. J. and Meijer, E. W. Angew. Chem. 1996, 35, 638

443 Yoffe, I. S. and Soloveychik, V. Y. Zh. Obshch. Khim. 1939, 9, 129

444 Honzl, J. and Tlustakova, M. J. Polym. Sci.: Part C 1968, 22, 451

445 Liebermann, H. Ann. 1914, 404, 272

446 Lu, F.-L., Wudl, F., Nowak, M. and Heeger, A. J. J. Am. Chem. Soc. 1986, 108, 8311

447 Strohriegl, P. and Jesberger, G. Makromol. Chem. 1992, 193, 909

448 Havinga, E. E. and Van Horssen, L. Synth. Met. 1987, 17, 623

449 Baker, K. N., Fratini, A. V., Resch, T., Knachel, H. C., Adams, W. W., Socci, E. P. and Farmer, B. L. Polymer 1993, 34, 1571

450 Gregorius, H., Heitz, W. and Müllen, K. Adv. Mater. 1993, 5, 279

451 Pellegrin, E., Fritzsche, H., Nücker, N., Fink, J., Drechsler, S. L., Málek, J., Meerholz, K., Heinze, J. and Roth, S. Synth. Met. 1991, 41-43, 1207

452 Schenk, R., Huber, W., Schade, P. and Müllen, K. Chem. Ber $1988,121,2201$

453 Schenk, R., Gregorius, H., Meerholz, K., Heinze, J. and Müllen, K. J. Am. Chem. Soc. 1991, 113, 2635

454 Schenk, R., Gregorius, H. and Müllen, K. Adv. Mater. 1991, 3, 492 